\section{OAK RIDGE NATIONAL. LABORATORY}

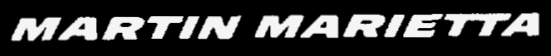

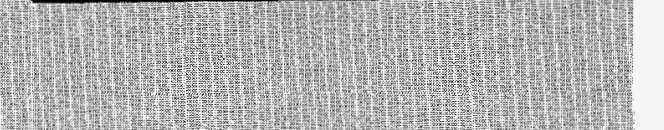

(1)

1)

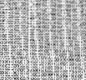

Whet

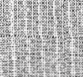

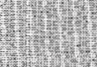

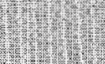

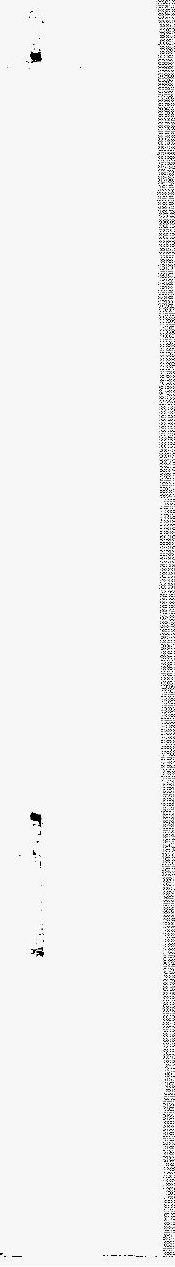

MANAGED BY

MARTIN MARIETTA ENERGY SYSTEMS, WIC.

FOR THE UNITE STATES

DEPARTMENT OF ENERGY

\section{Fixed Capital Investments} for the Uranium Soils Integrated Demonstration Soil Treatment Technologies

\author{
Douglas M. Douthat \\ Robert N. Stewart \\ Anthony Q. Armstrong
}


This report has been reproduced directly from the best available copy.

Available to DOE and DOE contractors from the Office of Scientific and Technical Information, P.O. Box 62, Oak Ridge, TN 37831; prices available from (615) 576-8401, FTS 626-8401.

Available to the public from the National Technical Information Service, U.S. Department of Commerce, 5285 Port Royal Rd., Springfield, VA 22161.

This report was prepared as an account of work sponsored by an agency of the United States Government. Neither the United States Government nor any agency thereof, nor any of their employees, makes any warranty, express or implied, or assumes any legal liability or responsibility for the accuracy, compteteness, or usefuiness of any intormation, apparatus, product, or process disclosed, or represents that its use would not infringe privately owned rights. Reference herein to any specific commercial product, process, or service by trade narne, trademark, manufacturer, or otherwise, does not necessarily consttute or imply its endorsement, recommendation, or favoring by the United States Government or any agency thereof. The views and opinions of authors expressed herein do not necessarily state or reflect those of the United States Government or any agency thereof. 


\section{DISCLAIMER}

Portions of this document may be illegible electronic image products. Images are produced from the best available original document. 


\title{
Fixed Capital Investments for the Uranium Soils Integrated Demonstration Soil Treatment Technologies
}

\author{
Douglas M. Douthat ${ }^{2}$ \\ Robert N. Stewart ${ }^{1}$ \\ Anthony Q. Armstrong ${ }^{2}$
}

Date Issued-May 1995

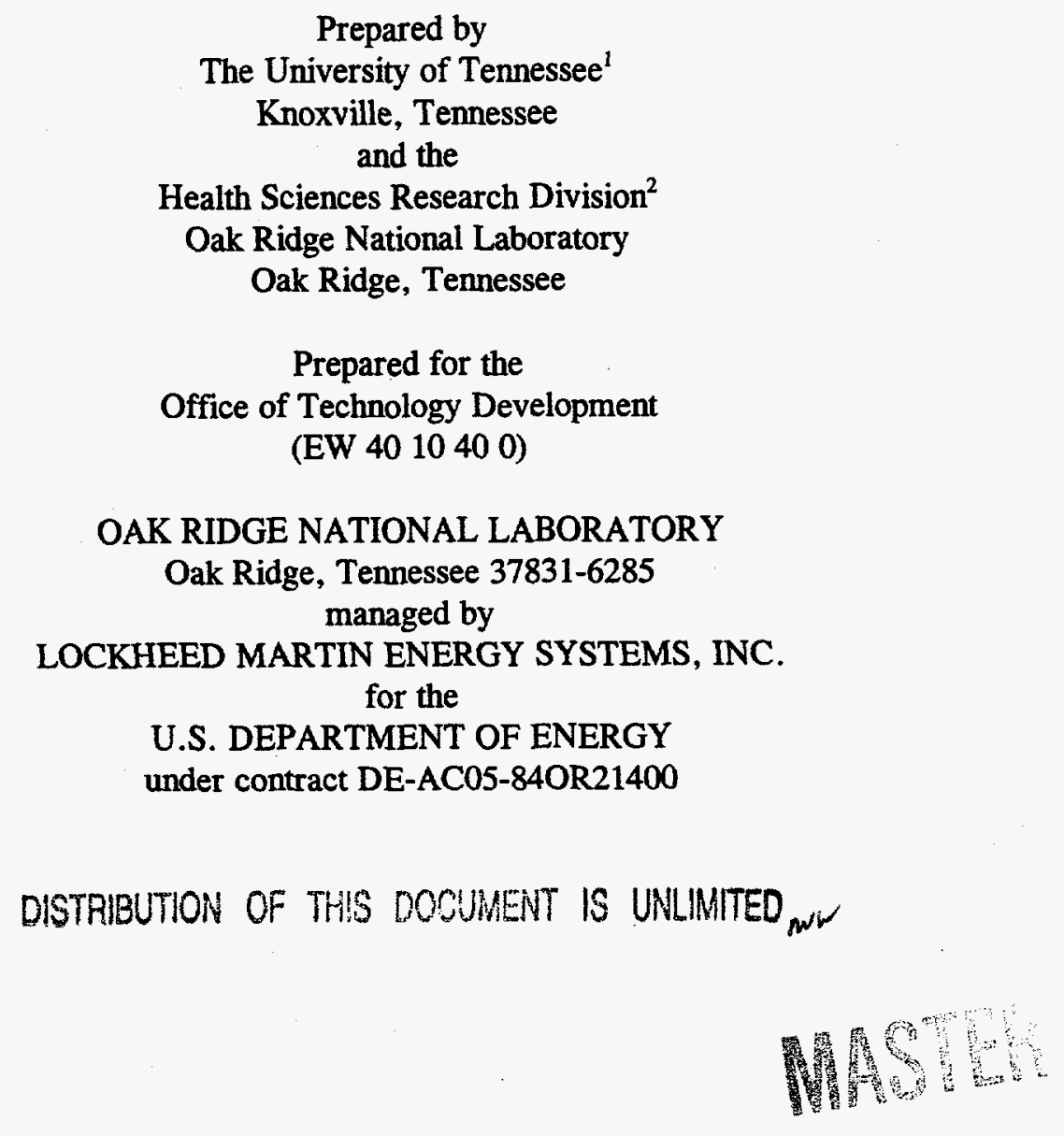


THIS PAGE INTENTIONALLY LEFT BLANK 


\section{CONTENTS}

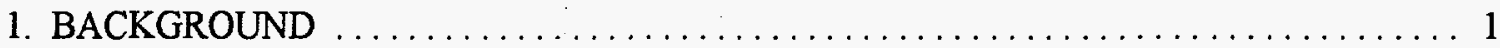

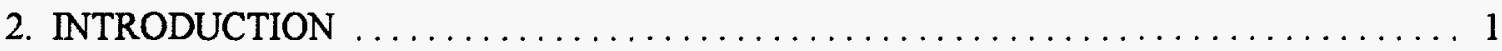

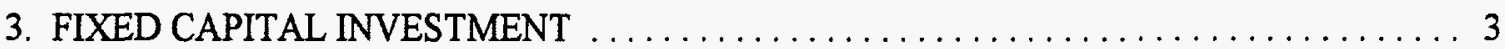

4. FCI CALCULATIONS FOR THE TREATMENT TECHNOLOGIES $\ldots \ldots \ldots \ldots \ldots \ldots 7$

4.1 SOIL PREPARATION BUILDING $\ldots \ldots \ldots \ldots \ldots \ldots \ldots \ldots \ldots \ldots \ldots$

4.2 SODIUM CARBONATE SOIL WASHING SYSTEM $\ldots \ldots \ldots \ldots \ldots \ldots \ldots \ldots$

4.3 SULFURIC ACID SOIL WASHING SYSTEM $\ldots \ldots \ldots \ldots \ldots \ldots \ldots \ldots \ldots \ldots$

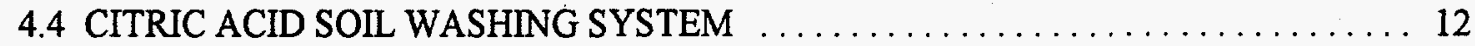

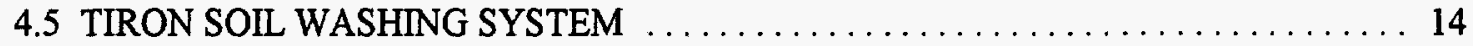

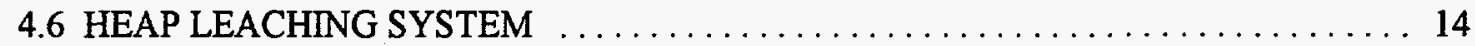

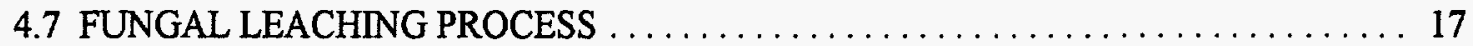

4.8 AQUEOUS BIPHASIC EXTRACTION PROCESS $\ldots \ldots \ldots \ldots \ldots \ldots \ldots \ldots \ldots$

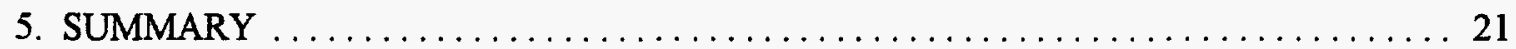

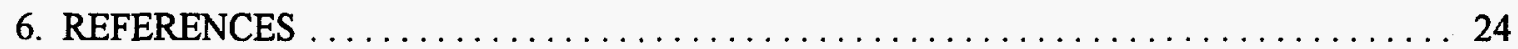

APPENDIX A. Engineering Flow Diagrams for Soil Treatment Technologies $\ldots \ldots \ldots \ldots$ A-1

APPENDIX B. Equipment Cost Estimates for Soil Treatment Technologies $\ldots \ldots \ldots \ldots$. B-1 


\section{TABLES}

Table 1. Fixed capital investment template $\ldots \ldots \ldots \ldots \ldots \ldots \ldots \ldots \ldots \ldots \ldots \ldots \ldots$

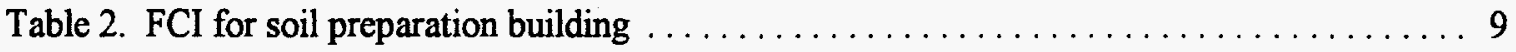

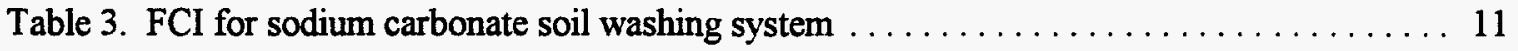

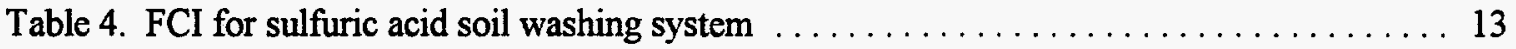

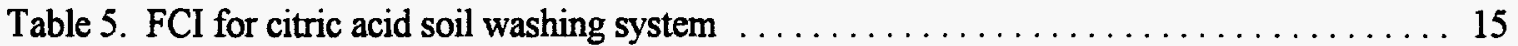

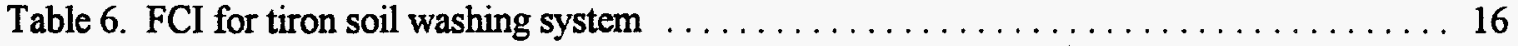

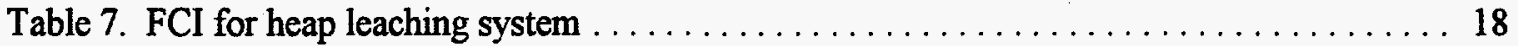

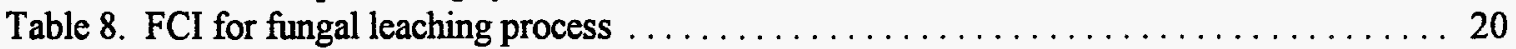

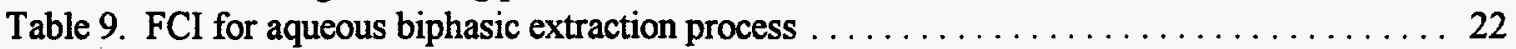

Table 10. Summary of equipment costs and FCI calculations $\ldots \ldots \ldots \ldots \ldots \ldots \ldots \ldots$ 


\section{ACKNOWLEDGMENTS}

This work was sponsored by the U.S. Department of Energy, Office of Technology Development, under the Uranium Soils Integrated Demonstration Program. The authors would like to recognize the support and guidance of Kim Nuhfer (Uranium Soils Integrated Demonstration Program coordinator) and Mike Malone (DOE-HQ program manager). In addition, the authors thank John Suitlas and Al Finke of Halliburton NUS for explanations and advice regarding the engineering designs and cost estimates for the soil treatment technologies. 


\section{BACKGROUND}

The development of a nuclear industry in the United States required mining, milling, and fabricating a large variety of uranium products. One of these products was purified uranium metal which was used in the Savannah River and Hanford Site reactors. Most of this feed material was produced at the United States Department of Energy (DOE) facility formerly called the Feed Materials Production Center at Fernald, Ohio.

Currently, this facility is called the Fernald Environmental Management Project (FEMP) and is operated by the Fernald Environmental Restoration Management Corporation (FERMCO). The facility consists of 1,050 acres in a rural area that is 18 miles northwest of Cincinnati, Ohio. The manufacturing processes were housed in a 136-acre fenced area and included uranium and thorium metal production and uranium hexafluoride reduction. Production peaked in 1960 with approximately 10,000 tons of uranium processed and began to decline in 1964 to a low of 1,230 tons in 1975. In the mid-1980s, production increased slightly but was terminated in 1989 due to the lack of demand for uranium products.

During operation of this facility, soils became contaminated with uranium from a variety of sources. The sources included deposition of airborne uranium particulates that came from facility stacks as well as leaks and spills of uranium-containing solvents and process effluents generated during nonaqueous extraction/treatment processes. The exact quantity of soil contaminated with uranium is unknown. Some estimates of soil containing unacceptable levels of uranium are as high as 2 million cubic yards. To avoid disposal of these soils in low-level radioactive waste burial sites, increasing emphasis has been placed on the remediating soils contaminated with uranium and other radionuclides.

To address remediation and management of uranium-contaminated soils at sites owned by DOE, the DOE Office of Technology Development (OTD) formed the Uranium Soils Integrated Demonstration (USID) Program to evaluate and compare the versatility, efficiency, and economics of various technologies that may be combined into systems designed to characterize and remediate uraniumcontaminated soils. The USID was initiated in 1991 and the FEMP was selected as the host site. The USID Program has five major tasks in developing and demonstrating these technologies. Each must be able to 1) characterize the uranium in soil, 2) decontaminate or remove uranium from soil, 3) treat or dispose of resulting waste streams, 4) meet necessary state and federal regulations, and 5) meet performance assessment objectives. The role of the performance assessment objectives is to provide the information necessary to conduct evaluations of the technologies. These performance assessments provide the basis for selecting the optimum system for remediation of large areas contaminated with uranium. One of the performance assessment tasks is to address the economics of full-scale implementation of soil treatment technologies developed by the USID Program. The cost of treating contaminated soil is one of the criteria used in the decision-making process for selecting remedial alternatives.

\section{INTRODUCTION}

During the past 2 years, the USID Program has directed various studies throughout the DOE national laboratories, universities, and private industry to determine the best methods to remove uranium from uranium-contaminated soils. The majority of these studies have been conducted in the laboratory at the bench-scale level, and results from these bench-scale studies have been extensively presented and published (Soil Decontamination Task Group 1993, Post and Wacks 1994). The studies have focused on the following seven soil treatment technologies: sodium carbonate soil washing system, sulfuric acid 
soil washing system, citric acid soil washing system, tiron soil washing system, heap leaching system, fungal leaching process, and aqueous biphasic extraction.

As the development of these technologies progresses from the bench-scale level to pilot plant testing, the feasibility of operating a full-scale treatment facility using the technologies studied by the USID Program will be evaluated. During the summer of 1994, Halliburton NUS developed engineering flow diagrams for full-scale treatment facilities based on each of the seven technologies. The USID Performance Assessment Group members at the Oak Ridge National Laboratory (ORNL) are responsible for developing cost estimates for the proposed treatment technologies.

Due to the stage of research and the timeframe involved to develop the flow diagrams and cost estimates for the treatment technology options, a number of assumptions and simplifications had to be made. Given the stage of the research work, much of the data used to develop the flow diagrams were preliminary and subject to revision. Therefore, the engineering diagrams and the resulting cost estimates contain a large amount of uncertainty, and they should be viewed as preliminary results only. As further research at the bench-scale and pilot plant levels are completed, the engineering designs will be refined and updated to produce a facility with optimum operating conditions. Once the engineering designs have been revised, the cost estimates will also be refined and updated, thereby eliminating some of the uncertainty.

The objective of this document is to describe the work conducted by the ORNL personnel responsible for developing cost estimates based on the full-scale implementation of the soil treatment technology alternatives being demonstrated by the USID Program. These cost estimates are based on the "best engineering design" for each treatment technology, determined by Halliburton NUS personnel after discussions with the principal investigators conducting the bench-scale studies.

The cost estimates for the treatment technology options will be conducted in three steps. The first step is to estimate the fixed capital investment (FCI), which represents the initial capital expenditure required to design and construct the full-scale treatment facility to operational readiness. The FCI is a one-time project investment cost that occurs at the beginning of the project. The second step is to develop estimates of the operational costs for each of the full-scale facility designs. Operational costs include costs for raw materials involved in processing, operating labor, supervisory labor, utilities, plant maintenance and repairs, and miscellaneous costs such as operating supplies, taxes, and insurance. Unlike FCI costs, operating costs are recurring throughout the life of the project. The third step is to estimate the life-cycle costs for each treatment technology option. The life-cycle costing approach involves projecting the current and future cash flows for soil remediation by each treatment technology over the project life, based on the estimated quantity of contaminated soil at the Fernald site. Nonrecurring costs occurring in the first year include the FCI and start-up expenses. Thereafter, operational costs for a full-scale facility based on each treatment technology are projected into future cash flows using an assumed inflation rate. Total costs to build and operate the full-scale treatment facility will then be summed over the life of the project and divided by the amount of soil to be processed to determine which treatment technology is the most cost effective based on their respective values for the treatment cost per ton of soil treated.

This document addresses the FCI for each of the treatment technologies being demonstrated by the USID Program. Future documentation will address the operational costs and the life-cycle costs for the treatment technology options. In addition, this report provides an explanation and description of the FCI, 
as well as a list and an explanation of cost ranges for the components used in deriving the FCI for each treatment technology alternative. The FCI for a soil preparation building, required regardless of the soil treatment technology being considered, is also provided. Appendix A contains the engineering flow diagrams of the soil treatment technologies which were developed by personnel at Halliburton NUS. Appendix B provides a detailed cost breakdown of the chemical processing equipment required for fullscale implementation of each soil treatment technology alternative.

\section{FIXED CAPITAL INVESTMENT}

The FCI is the capital needed to supply the necessary manufacturing and plant facilities for an industrial operation or project. For the USID project, the FCI represents the initial capital expenditure required to construct a full-scale treatment facility based on each of the proposed treatment technologies being demonstrated. The fixed capital investment estimates in this report are defined as study estimates. A study estimate is based on the knowledge of major items of equipment, with an accuracy of over plus or minus $30 \%$. A preliminary estimate is based on sufficient data to permit the estimate to be budgeted, with an accuracy of within plus or minus $20 \%$ (Peters and Timmerhaus 1991). Because specifications and design requirements for the equipment as well as the process were preliminary, there is a large probability that the actual cost will be more than the estimated cost where information is incomplete or during inflationary periods. For such estimates, the positive spread is likely to be wider than the negative (Peters and Timmerhaus 1991). Therefore, the plus or minus $30 \%$ accuracy rate for a study estimate may in fact be $+40 \%$ to $-20 \%$.

A common method for estimating the $\mathrm{FCI}$ is to define it as a function of the purchased equipment costs with each component of the FCI estimated as a percentage of the equipment cost. The method of estimating the FCI by percentage of purchased equipment cost is commonly used for study and preliminary cost estimates. Table 1 presents a checklist of the items used to estimate the FCI for chemical processing plants, along with the range for each item as a percentage of the purchased equipment cost. The cost range for the FCI items shown in Table 1 are based on input from several studies developed by chemical processing cost estimators plus additional data and interpretations from other sources with experience in modern industrial design and construction (Peters and Timmerhaus 1991). The FCI is the sum of the direct and indirect plant costs, contractor's fee, and contingency.

The cost estimator was provided with an equipment parts list for each treatment technology being demonstrated by the USID Program. Once an estimate of the total equipment cost was determined for each treatment technology, percentages of this value were used to calculate the $\mathrm{FCI}$, with the exception of building costs. The percentages of total equipment costs used for FCI calculations were based on many factors, including the type of process involved, design complexity, required materials of construction, as well as discussions with Halliburton NUS representatives experienced in estimating costs for chemical processing equipment. Building costs were determined based on unit costs and estimates of the square footage of building space required for a full-scale treatment facility for each treatment technology alternative. Unit costs for the treatment technologies' building and foundation were provided by cost estimation personnel at Halliburton NUS. Along with surveying and associated closing costs, land costs are normally included in the FCI. However, for this report they were reported as zero for the treatment technology cost estimates, because the facility was assumed to be located on already purchased land at the Fernald site. 
Table 1. Fixed capital investment template

\begin{tabular}{|c|c|c|c|}
\hline Item & Symbol & Description & Range \\
\hline 1 & E & Equipment Costs & E \\
\hline 2 & L & Cost of Installation Labor & $.25 \mathrm{E}-.55 \mathrm{E}$ \\
\hline 3 & IC & Instrumentation \& Controls & $.06 \mathrm{E}-.30 \mathrm{E}$ \\
\hline 4 & I & Insulation Costs (equip. \& piping) & $.05 \mathrm{E}-.09 \mathrm{E}$ \\
\hline 5 & $\mathbf{P}$ & Piping & $.16 \mathrm{E}-.31 \mathrm{E}$ \\
\hline 6 & $Q$ & Labor for Installation of Piping & $.40 \mathrm{P}-.50 \mathrm{P}$ \\
\hline 7 & $\mathrm{~F}$ & Electrical Installations & $.10 \mathrm{E}-.15 \mathrm{E}$ \\
\hline 8 & $\mathrm{~B}$ & Building including Services & $\begin{array}{c}.05 \mathrm{E}-.68 \mathrm{E} \\
\text { or unit costs, if available }\end{array}$ \\
\hline 9 & $\mathrm{Y}$ & Yard Improvements & $.10 \mathrm{E}-.20 \mathrm{E}$ \\
\hline \multirow[t]{2}{*}{10} & S & Service Facilities & $.30 \mathrm{E}-.80 \mathrm{E}$ \\
\hline & $\mathrm{D}$ & Direct Plant Cost & Sum $1-10$ \\
\hline 11 & ES & Engineering \& Supervision & $.15 \mathrm{E}-.80 \mathrm{E}$ \\
\hline \multirow[t]{2}{*}{12} & $\mathrm{C}$ & Construction Expenses & $.15 \mathrm{E}-.60 \mathrm{E}$ \\
\hline & IP & Indirect Plant Cost & $\mathbf{E S}+\mathbf{C}$ \\
\hline 13 & $\mathrm{CF}$ & Contractor's Fee & $.02(\mathrm{D}+\mathrm{IP})-.08(\mathrm{D}+\mathrm{IP})$ \\
\hline \multirow[t]{2}{*}{14} & $\mathrm{CO}$ & Contingency & $.05(\mathrm{D}+\mathrm{IP})-.20(\mathrm{D}+\mathrm{IP})$ \\
\hline & FCI & Fixed Capital Investment & $\mathrm{D}+\mathrm{IP}+\mathrm{CF}+\mathrm{CO}$ \\
\hline
\end{tabular}


Costs for several pieces of processing equipment were estimated from documents published in previous years. In these cases, cost indexes were used to project these values to present-day costs. A cost index is an index value for a given point in time showing the cost at that time relative to a certain base time. If the cost at some time in the past is known, the equivalent cost at the present time can be determined by multiplying the original cost by the ratio of the present index value to the index value applicable when the original cost was obtained. Many different types of cost indexes exist for estimating items such as processing equipment, labor, construction, materials, and other specialized fields (Peters and Timmerhaus 1991). The Marshall and Swift All-industry and Process-industry Equipment Index was used when costs were obtained from one of the sources containing equipment costs from the past.

The purchased equipment costs ( $E$, referring to Table 1 ) were obtained from one of the following sources: 1) vendors specializing in the type of chemical processing equipment required for each soil treatment technology, 2) cost estimating personnel at Halliburton NUS, 3) Richardson's Engineering Services Process Plant Construction Estimating Standards, 1994 edition, 4) Mining and Mineral Processing Equipment Costs and Preliminary Capital Cost Estimations, Volume 25, 1982, 5) Means Site Work and Landscape Cost Data, 12th annual edition, 1993, and 6) Plant Design and Economics for Chemical Engineers, Max S. Peters and Klaus D. Timmerhaus, 4th edition, 1991. The most accurate method for determining process equipment costs is to obtain firm bids from equipment fabricators or suppliers. Verbal and/or written quotes for the specialized equipment pieces were obtained in as many cases as possible. However, in some cases vendors were unable to provide price quotations because certain design requirements that could significantly affect costs were not available. In cases such as this, as well as for the more common types of processing equipment, costs were estimated from one or more of the above listed reference sources.

The installation of equipment $(L)$ involves costs for labor, foundations, supports, platforms, and other construction expenses related to the erection of purchased equipment. Although different ranges of installation costs exist depending on the type of chemical processing equipment, most fall within the $.25 \mathrm{E}$ to $.55 \mathrm{E}$ range specified in Table 1 . Instrumentation and controls (IC) costs can vary from $6 \%$ to $30 \%$ of the purchased equipment costs. For the soil treatment technology alternatives, IC costs were estimated at $13 \mathrm{E}$ because this value is normally used for solid-fluid chemical processing plants. The major portion of this category consists of instrument costs, installation labor costs, and expenses for auxiliary equipment and materials.

The estimated cost for piping (P), with a range of $16 \%$ to $31 \%$ of equipment costs, varies depending on the type of chemical processing plant under consideration (i.e., solid processing, solid-fluid processing, or fluid processing plant). This cost category typically includes valves, fittings, pipe, supports, and other items involved in the complete erection of all piping used directly in the treatment technology process. This includes the piping used for air, steam, water, and other process piping requirements, as well as for the equipment used to treat the contaminated soil. The labor for the installation of piping (Q) ranges from $40 \%$ to $50 \%$ of the total cost of piping. Insulation costs (I) for equipment and piping normally range from $5 \%$ to $9 \%$ of purchased equipment costs. Insulation costs vary depending on many factors, including the number of pieces of equipment exposed to very low or high temperatures (i.e., how much of the equipment is enclosed in the building and how much is located outside the building?) and the amount of piping that is required in each full-scale treatment facility design. Electrical installation costs $(\mathrm{F})$ range from $10 \%$ to $15 \%$ of equipment costs. This cost category consists primarily of installation labor and materials for power wiring, lighting, transformation and service, and instrument and control wiring (Peters and Timmerhaus 1991). 
The cost for buildings including services (B) consists of expenses for labor, materials, and supplies involved in the construction of all buildings associated with the treatment facility. The costs for plumbing, heating, lighting, ventilation, and similar building services are also included in this category. The range for this cost varies from $5 \%$ to $68 \%$ of the purchased equipment cost and is dependent on two factors: 1) the type of process plant (solid, solid-fluid, or fluid processing plant) and 2) whether or not the facility being considered is a new plant at a new site or a plant expansion at an existing site. For solid-fluid processing plants, building costs can range from $29 \%$ to $47 \%$ of purchased-equipment costs (Peters and Timmerhaus 1991). However, for this report the square footage of building space required for the treatment facility was estimated by Halliburton NUS personnel from the engineering flow diagrams, and costs were estimated from unit costs based on these building size requirements. This provides a more accurate estimate of the building cost rather than estimating the building costs as a percentage of the purchased equipment cost.

After determining the equipment costs for each of the treatment technology options being considered for the USID Program, it appears that basing the building costs solely as a percentage of the equipment cost is not as accurate as using unit costs to estimate building costs because of the wide variation in equipment costs for the treatment technology options. For example, Halliburton NUS personnel recommended that both the sodium carbonate and tiron soil washing facilities can be contained in a 2story building with $15,000 \mathrm{ft}^{2}$ per floor. Therefore, the building costs for each of the treatment technology cost estimates should be approximately the same because the estimates are based on square footage requirements. However, if the building costs for the two systems had been estimated based on a percentage of the equipment cost, the cost estimates would have been dramatically different, since the equipment cost used to calculate the FCI for the tiron system was estimated at approximately $\$ 14,896,000$, whereas the sodium carbonate system equipment cost was much less at $\$ 5,172,000$. Using a factor of $25 \%$ of the purchased equipment cost to calculate the building costs, the tiron system would have resulted in a $\$ 3,700,000$ building cost, while the sodium carbonate soil washing system would have resulted in a $\$ 1,300,000$ building cost.

Yard improvements $(\mathrm{Y})$ for the facility include the costs for site clearing and grading, roads and walkways, fencing, lighting, parking areas, landscaping, and other similar improvements. These costs range from approximately $10 \%$ to $20 \%$ of the purchased equipment cost. The total cost for service facilities (S) ranges from $30 \%$ to $80 \%$ of equipment costs. These costs include the utilities for supplying and distributing steam, water (i.e., treatment and distribution), power (i.e., electric substation and distribution), compressed air, and fuel to the soil treatment facility. In addition, waste disposal, fire protection, and miscellaneous service items such as communications, first aid, and safety installations require capital investments which fall under the category of service facility costs (Peters and Timmerhaus 1991). Service facilities costs are largely a function of plant physical size and will be present to some degree in most plants. However, there are many service facility cost categories, and for most solid-fluid chemical processing plants, there will not always be a need for each service-facility component. It is anticipated that the water and electricity requirements for each of the full-scale treatment facility options will be fairly high. Therefore, a middle to upper range value was used to estimate service facilities costs for the treatment technologies. The sum of the following items make up the direct plant cost (D) for the facility: 1) equipment, 2) equipment installation labor, 3) instrumentation and controls, 4) equipment and piping insulation, 5) piping, 6) piping installation labor, 7) electrical installations, 8) building including services, 9) yard improvements, and 10) service facilities. 
Engineering and supervision costs (ES), ranging from $15 \%$ to $80 \%$ of equipment costs, are indirect plant costs (IP), because they cannot be directly charged to equipment, materials, or labor. Costs for construction design and engineering, drafting, purchasing, accounting, cost engineering, travel, reproductions, and overhead constitute the capital investment for engineering and supervision (Peters and Timmerhaus 1991). A value close to the upper limit of the cost range was used for all of the treatment technologies, because engineering costs will undoubtedly be high due to the preliminary stage of development for each of the treatment technologies. Another indirect plant cost used in calculating the FCI for each treatment technology option is construction expense (C), ranging from $15 \%$ to $60 \%$ of equipment costs. This cost item includes temporary construction and operation, construction tools and rentals, construction payroll, insurance, and other construction overhead items. The sum of the engineering and supervision and construction expense items comprise the indirect plant costs for the treatment facility.

A contractor's fee (CF) and contingency (CO) are normally added to the direct and indirect plant costs in calculating the FCI. The CF ranges from $2 \%$ to $8 \%$ of the sum of the direct and indirect plant costs. Contingency is a project markup factor normally applied to cost estimates to account for any uncertainties or unforeseen occurrences, such as inflationary price trends, bad weather conditions, strikes, small design changes, estimation errors, or possible material shortages associated with a project. Contingency normally ranges from $5 \%$ to $20 \%$ of the sum of direct and indirect plant costs (Peters and Timmerhaus 1991). Because of the experimental and developmental nature of these treatment technologies, it was determined that the most conservative value ( $20 \%$ of the sum of direct and indirect plant costs) should be used to estimate the contingency for each treatment option. The FCI for each treatment technology is then calculated by summing the direct and indirect plant costs, contractor's fee, and contingency.

\section{FCI CALCULATIONS FOR THE TREATMENT TECHNOLOGIES}

As stated earlier, the FCI is the initial capital required to provide full-scale implementation of a soil treatment facility. For the FCI calculations, the direct and indirect plant costs for the treatment technology alternatives are based on technical judgement and discussions with cost estimating personnel at Halliburton NUS, as well as comparisons with capital investment requirements for similar facilities. As a joint effort between USID Performance Assessment Group members at ORNL and personnel at Halliburton NUS, equipment costs for each of the treatment technologies were created. ORNL Performance Assessment Group members were responsible for developing the FCI requirements for the treatment technologies and were aided by additional guidance and technical information from personnel at Halliburton NUS experienced in estimating costs for chemical processing equipment.

\subsection{SOIL PREPARATION BUILDING}

A soil preparation building in which soil is processed before treatment is required for all soil treatment technologies evaluated. A plan view of the proposed soil preparation building developed by Halliburton NUS and an equipment layout are shown in Appendix A. The soil preparation building is a double-bay facility with a total length of $150 \mathrm{ft}$, a total width of $120 \mathrm{ft}$ ( $60 \mathrm{ft}$ per bay), and a height of $30 \mathrm{ft}$. Dump trucks drive into the facility to unload contaminated soil in two soil receiving pits, one in each bay. The building is designed so that work will be conducted in each bay on alternating days. An overhead crane 
system will be used to transport the soil from the two $50 \mathrm{ft} \times 85 \mathrm{ft}$ storage areas (one in each bay) to the storage transfer hoppers which transport the soil to the main conveyor. The equipment in the soil preparation building is primarily composed of enclosed and ventilated conveyor systems and hoppers, a vibrating grizzly for soil separation, and a $60,000 \mathrm{cfm}$ baghouse air pollution control system. The baghouse system controls the dust from soil transport activities as well as the fumes from the trucks and bulldozers transporting the soil.

Discussions concerning the need for a high-efficiency particulate air (HEPA) filter system in addition to the baghouse air pollution control system have been initiated by interested participants of the USID program. One reviewer felt that potential exhaust problems, as well as worker health and safety requirements, associated with a full-scale soil treatment facility may prompt DOE to require a HEPA filter system for the soil preparation building. However, an engineer at Halliburton NUS believed that a sprayer system could be used on the contaminated soil coming into the soil preparation building to wet the soil and alleviate dust control problems. Based on his experience and site visits to soil washing facilities, he believed that the combination of the sprayer system and the $60,000 \mathrm{cfm}$ baghouse system included in the equipment list of the soil preparation building should be more than adequate to control potential dust emissions. The soil in the soil treatment building will be in a slurry, which should eliminate the need for dust control equipment in this facility.

The equipment costs for the soil preparation building, shown in Appendix B, Table B.1, are based primarily on vendor quotes and verbal communication with vendors. The total cost for the equipment in the soil preparation building is approximately $\$ 486,000$. The most expensive pieces of equipment are the baghouse air pollution control system and overhead crane system, estimated at $\$ 170,000$ and $\$ 120,000$, respectively. Table 2 shows an estimated FCI for the soil preparation building. Yard improvement and service facilities costs were estimated at the lower end of the range because the primary concern was for costs associated with the soil preparation building itself and not with the extra costs associated with these items. Building costs, as well as costs for the foundation, storage containment walls, and soil receiving pits are based on unit costs for the construction materials specified by the engineering flow diagram parts list. The total cost for the building, including services (labor, materials, and equipment), is $\$ 1,058,000$, approximately one-half of the direct plant cost of $\$ 2,202,000$. Engineering and supervision and contingency costs were estimated conservatively because of the developmental nature of this project, along with the requirement for new designs for this building as well as the full-scale soil treatment facility. The indirect plant costs for the soil preparation building are $\$ 413,000$. Adding the contractor's fee and contingency of $\$ 131,000$ and $\$ 523,000$, respectively, to the direct and indirect plant costs results in a FCI of approximately $\$ 3,269,000$ for the soil preparation building. In case it is determined that a HEPA filter system is required for the soil preparation building, a cost estimate for this type of equipment is $\$ 25,000$ per $1,000 \mathrm{cfm}$ requirement. For a $60,000 \mathrm{cfm}$ baghouse system, the estimated cost for the HEPA filter equipment is $\$ 1,500,000$. Therefore, adding

the HEPA filter system to the soil preparation building would increase the FCI value by $46 \%$ (from $\$ 3,269,000$ to $\$ 4,769,000$ ).

\subsection{SODIUM CARBONATE SOIL WASHING SYSTEM}

The engineering flow diagram for the sodium carbonate soil washing system is shown in Appendix A. The equipment costs for the sodium carbonate system are shown in Appendix B, Table B.2. The total equipment cost (E) is estimated at approximately $\$ 5,172,000$. The post-reactor and post-water 
Table 2. FCI for soil preparation building

\begin{tabular}{|c|c|c|c|c|}
\hline Item & Symbol & Description & Formula & Value \\
\hline 1 & $\mathrm{E}$ & Equipment Costs & $\mathrm{E}$ & $\$ 485,935$ \\
\hline 2 & $\mathrm{~L}$ & Cost of Installation Labor & $.40 \mathrm{E}$ & $\$ 194,374$ \\
\hline 3 & IC & Instrumentation \& Controls & $.13 \mathrm{E}$ & $\$ 63,172$ \\
\hline 4 & I & $\begin{array}{c}\text { Insulation Costs (equip. \& } \\
\text { piping) }\end{array}$ & $.05 \mathrm{E}$ & $\$ 24,297$ \\
\hline 5 & $\mathbf{P}$ & Piping & $.16 \mathrm{E}$ & $\$ 77,750$ \\
\hline 6 & Q & Labor for Installation of Piping & $.40 \mathrm{P}$ & $\$ 31,300$ \\
\hline 7 & $\mathrm{~F}$ & Electrical Installations & $.15 \mathrm{E}$ & $\$ 72,890$ \\
\hline 8 & B & Building including Services & --- & $\$ 1,058,367$ \\
\hline 9 & $\mathrm{Y}$ & Yard Improvements & $.10 \mathrm{E}$ & $\$ 48,594$ \\
\hline \multirow[t]{2}{*}{10} & $\mathrm{~S}$ & Service Facilities & $.30 \mathrm{E}$ & $\$ 145,781$ \\
\hline & D & Direct Plant Cost & Sum of $1-10$ & $\$ 2,202,258$ \\
\hline 11 & ES & Engineering \& Supervision & $.60 \mathrm{E}$ & $\$ 291,561$ \\
\hline \multirow[t]{2}{*}{12} & $\mathrm{C}$ & Construction Expenses & $.25 \mathrm{E}$ & $\$ 121,484$ \\
\hline & IP & Indirect Plant Cost & $\mathbf{E S}+\mathbf{C}$ & $\$ 413,045$ \\
\hline 13 & $\mathrm{CF}$ & Contractor's Fee & $.05(\mathrm{D}+\mathrm{IP})$ & $\$ 130,765$ \\
\hline \multirow[t]{2}{*}{14} & $\mathrm{CO}$ & Contingency & $.20(D+I P)$ & $\$ 523,061$ \\
\hline & FCI & Fixed Capital Investment & $\mathrm{D}+\mathrm{IP}+\mathrm{CF}+\mathrm{CO}$ & $\$ 3,269,128$ \\
\hline
\end{tabular}


rinse vacuum drum filters are by far the most costly pieces of equipment for this system, magnified by the fact that 10 units are required. The total estimated cost for the 10 vacuum drum filters is $\$ 2,700,000$, which is approximately $52 \%$ of the total equipment cost for the entire sodium carbonate system. Other costly items include six steel soil water rinsing clarifiers at a total cost of $\$ 720,000$ and two pre-reactor clarifiers at a total of $\$ 240,000$.

Results of the FCI calculation for the sodium carbonate soil washing system are shown in Table 3. Piping and instrumentation costs for all of the technologies fall within the same range, except for the heap leaching system. After a review of piping and instrumentation costs for several of the treatment technologies developed by Halliburton NUS, it was decided that the lower end of the range would be an appropriate factor to use for piping costs (.16E), as well as insulation costs for the equipment and piping $(.05 \mathrm{E})$. Another reason the lower end of the range was used for the piping and insulation costs is that a factor for instrumentation and controls, at $13 \%$ of equipment costs, is already being considered in the FCI calculations. Piping and instrumentation costs are interrelated and are normally included under the same heading for most FCI cost estimates. Yard improvements for all the technologies were estimated at the lower end of the range because the concern is primarily for the full-scale treatment facility itself and not the extra cost items (i.e., sidewalks and landscaping) normally considered in this cost category. With the exception of the fungal leaching process, the value of $55 \%$ of equipment costs for service facilities was used in the FCI calculations, because it represents an average value for a solid-fluid processing plant.

Building costs are based on the assumption of a 2-story building with $15,000 \mathrm{ft}^{2}$ per floor. All of the filters will be located in the top floor. Unit costs based on square footage requirements were used to estimate costs for the treatment building, building foundation, loading/unloading area, and parking area. The total cost for the building (labor, materials, and supplies) and its associated items is $\$ 1,272,000$. The direct cost for the sodium carbonate soil washing plant is approximately $\$ 14,741,000$. As in the case for the soil preparation building, engineering and supervision and contingency costs for all of the treatment technologies were estimated conservatively because of the experimental nature of this project. Indirect plant costs, consisting of construction expenses and engineering and supervision, for this system are approximately $\$ 4,396,000$. Adding the contractor's fee and contingency of $\$ 957,000$ and $\$ 3,828,000$, respectively, to the direct and indirect plant costs results in a FCI of approximately $\$ 23,922,000$ for the sodium carbonate soil washing system.

\subsection{SULFURIC ACID SOIL WASHING SYSTEM}

Appendix A provides the engineering flow diagram for the sulfuric acid soil washing system. The equipment costs for the sulfuric acid system are shown in Appendix B, Table B.3. Many of the pieces of equipment for the sulfuric acid system are also required for the sodium carbonate soil washing system. In fact, with the exception of a few expensive systems or specialized pieces of equipment, the equipment lists for the sodium carbonate, sulfuric, citric acid, and tiron soil washing systems require many of the same pieces of equipment. However, the requirement for these few specialized pieces of equipment is a major reason why the citric acid and tiron systems' total equipment costs and resulting FCI calculations are so much higher than those of the sodium carbonate and sulfuric acid systems. Also, the additional requirement for lime storage and production and an ion exchange system for the sulfuric acid system is the major difference between this system and the sodium carbonate system. The additional equipment requirements for the sulfuric acid system resulted in the need for a larger building size than that required 
Table 3. FCI for sodium carbonate soil washing system

\begin{tabular}{|c|c|c|c|c|}
\hline Item & Symbol & Description & Formula & Value \\
\hline 1 & $\mathrm{E}$ & Equipment Costs & $\mathrm{E}$ & $\$ 5,172,350$ \\
\hline 2 & $\mathrm{~L}$ & Cost of Installation Labor & $.40 \mathrm{E}$ & $\$ 2,068,940$ \\
\hline 3 & IC & Instrumentation \& Controls & $.13 \mathrm{E}$ & $\$ 672,406$ \\
\hline 4 & I & Insulation Costs (equip. \& piping) & $.05 \mathrm{E}$ & $\$ 258,618$ \\
\hline 5 & $\mathbf{P}$ & Piping & $.16 \mathrm{E}$ & $\$ 827,576$ \\
\hline 6 & $\mathrm{Q}$ & Labor for Installation of Piping & $.40 \mathrm{P}$ & $\$ 331,030$ \\
\hline 7 & $\mathrm{~F}$ & Electrical Installations & $.15 \mathrm{E}$ & $\$ 775,853$ \\
\hline 8 & B & Building including Services & --- & $\$ 1,272,400$ \\
\hline 9 & $\mathrm{Y}$ & Yard Improvements & $.10 \mathrm{E}$ & $\$ 517,235$ \\
\hline \multirow[t]{2}{*}{10} & $\mathrm{~S}$ & Service Facilities & $.55 \mathrm{E}$ & $\$ 2,844,793$ \\
\hline & D & Direct Plant Cost & Sum of 1-10 & $\$ 14,741,199$ \\
\hline 11 & $\mathrm{ES}$ & Engineering \& Supervision & $.60 \mathrm{E}$ & $\$ 3,103,410$ \\
\hline \multirow[t]{2}{*}{12} & $\mathrm{C}$ & Construction Expenses & $.25 \mathrm{E}$ & $\$ 1,293,088$ \\
\hline & IP & Indirect Plant Cost & $\mathbf{E S}+\mathbf{C}$ & $\$ 4,396,498$ \\
\hline 13 & $\mathrm{CF}$ & Contractor's Fee & $.05(\mathrm{D}+\mathrm{IP})$ & $\$ 956,885$ \\
\hline \multirow[t]{2}{*}{14} & $\mathrm{CO}$ & Contingency & $.20(D+I P)$ & $\$ 3,827,539$ \\
\hline & FCI & Fixed Capital Investment & $\mathrm{D}+\mathrm{IP}+\mathrm{CF}+\mathrm{CO}$ & $\$ 23,922,121$ \\
\hline
\end{tabular}


for the sodium carbonate, citric acid, and tiron soil washing systems.

The total equipment cost $(\mathrm{E})$ for the sulfuric acid system is estimated at approximately $\$ 7,630,000$. The post water rinse drum vacuum filters are the most costly pieces of equipment for this system, with a requirement for 10 units. The estimated cost for these filters is $\$ 400,000$ each, for a total of $\$ 4,000,000$. This is approximately $52 \%$ of the total equipment cost for the entire sulfuric acid soil washing system. Other costly items for this system include six rinsing clarifiers at a total cost of $\$ 720,000$, seven sulfuric acid storage tanks for a total of $\$ 280,000$, two lime storage tanks for a total of $\$ 250,000$, two pre-reactor clarifiers for $\$ 240,000$, three stainless steel ion exchangers for $\$ 198,000$, and two stainless steel pressure sand filters for a total of $\$ 190,000$.

The results of the FCI calculation for the sulfuric acid soil washing system are shown in Table 4. Building costs were based on the assumption of a 2-story building with $20,000 \mathrm{ft}^{2}$ per floor. Unit costs (\$/sq. $\mathrm{ft}$ or \$/cu. yd) were used to estimate costs for the treatment building, building foundation, loading/unloading area, and parking area. The total cost for the building and its associated items is approximately $\$ 1,479,000$. The direct cost for the sulfuric acid soil washing plant is $\$ 21,346,000$. Total indirect plant costs, consisting of construction expenses and engineering and supervision, are $\$ 6,485,000$. Adding the contractor's fee and contingency of $\$ 1,392,000$ and $\$ 5,566,000$, respectively, to the direct and indirect plant costs result in a FCI of approximately $\$ 34,789,000$ for the sulfuric acid soil washing system.

\subsection{CITRIC ACID SOIL WASHING SYSTEM}

The engineering flow diagram for the citric acid soil washing system is shown in Appendix A. The equipment list for the citric acid system is given in Appendix B, Table B.4. The total equipment cost (E) for the citric acid system is estimated at $\$ 13,799,000$. The citric acid and sulfuric acid soil washing systems are similar in that both require lime storage and production as well as ion exchange equipment. However, the citric acid system requires some additional equipment which has a substantial impact on the total equipment cost for the system. A vendor estimated that a 600 gallons per minute (gpm) vacuum compression evaporation/crystallization system would cost approximately $\$ 8$ million. This one piece of equipment represents approximately $58 \%$ of the cost for the entire citric acid soil washing system. The vendor stated that a 20 -gpm unit was the largest system they had designed and built, at a cost of approximately $\$ 700,000$. Other examples of size and cost estimates for a vacuum compression evaporator/crystallizer include: 1) $\$ 375,000$ for a 5 -gpm unit, 2) $\$ 450,000$ for a 10 -gpm unit, and 3) $\$ 900,000$ for a 35 -gpm unit. In addition, an additional pressure sand filter at $\$ 95,000$ and an ion exchanger at $\$ 66,000$ are required for the citric acid system versus the sulfuric acid system.

As in the sodium carbonate and sulfuric acid systems, 10 post water rinse drum vacuum filters are required for the citric acid system. The total cost for the filters, $\$ 2,700,000$, represents approximately $20 \%$ of the total equipment cost. Therefore, the vacuum compression evaporator/crystallizer and vacuum drum filters represent $78 \%$ of the total equipment cost for the citric acid system. Other costly items for this system include six soil concurrent rinsing clarifiers at a total cost of $\$ 720,000$, three pressure sand filters for a total of $\$ 285,000$, four ion exchangers at $\$ 264,000$, two lime storage silos for $\$ 250,000$, and two post-reactor clarifiers for a total of $\$ 240,000$. 
Table 4. FCI for sulfuric acid soil washing system

\begin{tabular}{|c|c|c|c|c|}
\hline Item & Symbol & Description & Formula & Value \\
\hline 1 & $\mathrm{E}$ & Equipment Costs & $\mathrm{E}$ & $\$ 7,629,650$ \\
\hline 2 & $\mathrm{~L}$ & Cost of Installation Labor & $.40 \mathrm{E}$ & $\$ 3,051,860$ \\
\hline 3 & IC & Instrumentation \& Controls & $.13 \mathrm{E}$ & $\$ 991,855$ \\
\hline 4 & I & Insulation Costs (equip. \& piping) & $.05 \mathrm{E}$ & $\$ 381,483$ \\
\hline 5 & $\mathbf{P}$ & Piping & $.16 \mathrm{E}$ & $\$ 1,220,744$ \\
\hline 6 & $Q$ & Labor for Installation of Piping & $.40 \mathrm{P}$ & $\$ 488,298$ \\
\hline 7 & $\mathrm{~F}$ & Electrical Installations & $.15 \mathrm{E}$ & $\$ 1,144,448$ \\
\hline 8 & B & Building including Services & ---- & $\$ 1,478,500$ \\
\hline 9 & $\mathrm{Y}$ & Yard Improvements & $.10 \mathrm{E}$ & $\$ 762,965$ \\
\hline \multirow[t]{2}{*}{10} & $S$ & Service Facilities & $.55 \mathrm{E}$ & $\$ 4,196,308$ \\
\hline & D & Direct Plant Cost & Sum of 1-10 & $\$ 21,346,109$ \\
\hline 11 & ES & Engineering \& Supervision & $.60 \mathrm{E}$ & $\$ 4,577,790$ \\
\hline \multirow[t]{2}{*}{12} & $\mathrm{C}$ & Construction Expenses & $.25 \mathrm{E}$ & $\$ 1,907,413$ \\
\hline & IP & Indirect Plant Cost & $\mathrm{ES}+\mathbf{C}$ & $\$ 6,485,203$ \\
\hline 13 & $\mathrm{CF}$ & Contractor's Fee & $.05(\mathrm{D}+\mathrm{IP})$ & $\$ 1,391,566$ \\
\hline \multirow[t]{2}{*}{14} & $\mathrm{CO}$ & Contingency & $.20(\mathrm{D}+\mathrm{IP})$ & $\$ 5,566,262$ \\
\hline & FCI & Fixed Capital Investment & $\mathrm{D}+\mathrm{IP}+\mathrm{CF}+\mathrm{CO}$ & $\$ 34,789,139$ \\
\hline
\end{tabular}


The FCI for the citric acid soil washing system is shown in Table 5. Building costs for this system, estimated at approximately $\$ 1,272,000$, are the same as for the sodium carbonate system because both require a twa-story building with $15,000 \mathrm{ft}^{2}$ per floor. The direct plant cost for the citric acid system is $\$ 37,206,000$. Total indirect plant costs are $\$ 11,729,000$. Adding the contractor's fee and contingency of $\$ 2,447,000$ and $\$ 9,787,000$, respectively, to the direct and indirect plant costs result in a FCI value of approximately $\$ 61,169,000$ for the citric acid soil washing system.

\subsection{TIRON SOIL WASHING SYSTEM}

Appendix A provides the engineering flow diagram for the tiron soil washing system. The equipment costs for the tiron system are shown in Appendix B, Table B.5. The total equipment cost (E) for this system is estimated at $\$ 14,896,000$. Except for a few alterations, the tiron system appears to be similar to the citric acid and sulfuric acid systems in terms of process equipment requirements. Although the tiron system requires ion exchangers, it does not require lime storage and production equipment as the citric acid and sulfuric acid systems do. Compared to the citric acid system, the tiron system requires two additional steel water rinse sand filters and two steel ion exchange units. In addition, just as the vacuum compression evaporator/crystallizer is the most costly equipment item for the citric acid system, the requirement for a biological treatment plant at an estimated cost of $\$ 8,870,000$ is clearly the largest capital expenditure for the tiron system. This represents approximately $60 \%$ of the total equipment cost for the entire tiron soil washing system. Designers of the tiron system engineering flow diagram at Halliburton NUS stated that the 200 gpm biological treatment plant should be sized and costed as a 1600 gpm sewage treatment plant. Unit costs (\$/daily flow rate) were then used to estimate the total cost to build a biological treatment plant, including overhead and profit. As in the sodium carbonate, sulfuric acid, and citric acid systems, 10 vacuum drum filters and 6 soil concurrent rinsing clarifiers at a total cost of $\$ 2,700,000$ and $\$ 720,000$, respectively, are also required for the tiron system. Other large equipment expenditures include two 40,000-gallon reactors and four 125-horsepower mixers/agitators for a total of $\$ 520,000$, two 40 -ft diameter stainless steel clarifiers for a total of $\$ 240,000$, and five pressure sand filters at a total cost of $\$ 385,000$.

The results of the FCI calculation for the tiron soil washing system are shown in Table 6. Building size requirements for the tiron system are the same as those of the sodium carbonate and citric acid systems. Therefore, the building costs for all three systems are the same, estimated at approximately $\$ 1,272,000$. The direct plant cost for the tiron system is $\$ 40,062,000$. Total indirect plant costs, consisting of construction expenses and engineering and supervision, are $\$ 12,662,000$. Adding the contractor's fee and contingency of $\$ 2,636,000$ and $\$ 10,545,000$, respectively, to the direct and indirect plant costs results in an FCI value of approximately $\$ 65,904,000$ for the tiron soil washing system.

\subsection{HEAP LEACHING SYSTEM}

Due to health and safety requirements as well as regulatory requirements, the removal of uranium from the Fernald soil by the heap leaching system requires the process facilities to be enclosed in a building. The building is a double bay, 60,000 square foot facility with a total length of 500 feet, a total width of 120 feet ( 60 feet per bay), and a height of 40 feet. The soil is transported from the soil preparation building to the heap leaching building by a system of hoppers, overhead conveyors, and cranes which are interconnected to a main conveyor and track loading hopper. The contaminated soil 
Table 5. FCI for citric acid soil washing system

\begin{tabular}{|c|c|c|c|c|}
\hline Item & Symbol & Description & Formula & Value \\
\hline 1 & $\mathrm{E}$ & Equipment Costs & $\mathrm{E}$ & $\$ 13,799,250$ \\
\hline 2 & $\mathrm{~L}$ & Cost of Installation Labor & $.40 \mathrm{E}$ & $\$ 5,519,700$ \\
\hline 3 & IC & Instrumentation \& Controls & $.13 E$ & $\$ 1,793,903$ \\
\hline 4 & $I$ & Insulation Costs (equip. \& piping) & $.05 \mathrm{E}$ & $\$ 689,963$ \\
\hline 5 & $P$ & Piping & $.16 \mathrm{E}$ & $\$ 2,207,880$ \\
\hline 6 & $\mathrm{Q}$ & Labor for Installation of Piping & $.40 \mathrm{P}$ & $\$ 883,152$ \\
\hline 7 & F & Electrical Installations & $.15 E$ & $\$ 2,069,888$ \\
\hline 8 & B & Building including Services & --- & $\$ 1,272,400$ \\
\hline 9 & $\mathrm{Y}$ & Yard Improvements & $.10 \mathrm{E}$ & $\$ 1,379,925$ \\
\hline \multirow[t]{2}{*}{10} & $S$ & Service Facilities & $.55 \mathrm{E}$ & $\$ 7,589,588$ \\
\hline & D & Direct Plant Cost & Sum of 1-10 & $\$ 37,205,647$ \\
\hline 11 & $\mathrm{ES}$ & Engineering \& Supervision & $: 60 \mathrm{E}$ & $\$ 8,279,550$ \\
\hline \multirow[t]{2}{*}{12} & $\mathrm{C}$ & Construction Expenses & $.25 \mathrm{E}$ & $\$ 3,449,813$ \\
\hline & IP & Indirect Plant Cost & $\mathrm{ES}+\mathrm{C}$ & $\$ 11,729,363$ \\
\hline 13 & $\mathrm{CF}$ & Contractor's Fee & $.05(D+I P)$ & $\$ 2,446,750$ \\
\hline \multirow[t]{2}{*}{14} & $\mathrm{CO}$ & Contingency & $.20(\mathrm{D}+\mathrm{IP})$ & $\$ 9,787,002$ \\
\hline & FCI & Fixed Capital Investment & $\mathrm{D}+\mathrm{IP}+\mathrm{CF}+\mathbf{C O}$ & $\$ 61,168,762$ \\
\hline
\end{tabular}


Table 6. FCI for tiron soil washing system

\begin{tabular}{ccccc}
\hline Item & Symbol & Description & Formula & Value \\
\hline 1 & E & Equipment Costs & E & $\$ 14,896,050$ \\
2 & L & Cost of Installation Labor & $.40 \mathrm{E}$ & $\$ 5,958,420$ \\
3 & IC & Instrumentation \& Controls & $.13 \mathrm{E}$ & $\$ 1,936,487$ \\
4 & I & Insulation Costs (equip. \& piping) & $.05 \mathrm{E}$ & $\$ 744,803$ \\
5 & P & Piping & $.16 \mathrm{E}$ & $\$ 2,383,368$ \\
6 & Q & Labor for Installation of Piping & $.40 \mathrm{P}$ & $\$ 953,347$ \\
7 & F & Electrical Installations & $.15 \mathrm{E}$ & $\$ 2,234,408$ \\
8 & B & Building including Services &..-- & $\$ 1,272,400$ \\
9 & Y & Yard Improvements & $.10 \mathrm{E}$ & $\$ 1,489,605$ \\
10 & S & Service Facilities & $.55 \mathrm{E}$ & $\$ 8,192,828$ \\
\hline & D & Direct Plant Cost & Sum of 1-10 & $\$ 40,061,714$ \\
\hline 11 & ES & Engineering \& Supervision & $.60 \mathrm{E}$ & $\$ 8,937,630$ \\
12 & C & Construction Expenses & $.25 \mathrm{E}$ & $\$ 3,724,013$ \\
\hline 14 & IP & Indirect Plant Cost & ES+C & $\$ 12,661,643$ \\
\hline & CF & Contractor's Fee & $.05(\mathrm{D}+\mathrm{IP})$ & $\$ 2,636,168$ \\
\hline 13 & FCI & Fixed Capital Investment & $\mathbf{D + I P + C F + C O}$ & $\$ 65,904,196$ \\
\hline
\end{tabular}


is placed into one of six leach cells in the heap leaching building. In addition to the hoppers and conveyor systems, chemical processing equipment required for the heap leaching system include a series of storage silos, tanks, reactors, filter presses, clarifiers, mixers, and pumps. The heap leaching building will also contain a $100,000 \mathrm{cfm}$ baghouse air pollution control system.

The engineering flow diagram for the heap leaching system is provided in Appendix $A$. The equipment list for the heap leaching system is shown in Appendix B, Table B.6. The total equipment cost $(E)$ for this process is estimated at $\$ 2,488,000$. The four sodium carbonate/bicarbonate storage silos represent the largest capital expenditure for process equipment at a total cost of $\$ 640,000$. Other costly items include two overhead crane conveyors at a total of $\$ 240,000$, three 75 -horsepower mixers for a total of $\$ 240,000$, and three 25,000 -gallon steel reactors at a total cost of $\$ 225,000$.

The results of the FCI calculation for the heap leaching process are shown in Table 7. Building costs, as well as concrete foundation and compartment wall costs, and parking and loading/unloading area costs, were calculated using unit costs $\left(\$ / \mathrm{ft}^{2}\right.$ or $\left.\$ / \mathrm{yd}^{3}\right)$ based on size requirements and the materials of construction for each item. Other building costs include a secondary containment system for the heap leaching process, composed of a synthetic membrane liner, gravel and sand drainage bed, and leak detection piping. Unit costs for these material items were also used to determine these cost factors. The total estimated direct cost for the heap leaching building, including foundation, compartment walls, parking and loading/unloading area, is approximately $\$ 4,614,000$. This cost includes the material, equipment, and labor for fabrication of the heap leaching building. Due to extensive piping requirements

for the heap leaching process, the piping and insulation cost factors (see Table 7) were increased to reflect this change. After a review of the piping requirements in the equipment parts list for the heap leaching process and discussions with Halliburton NUS personnel, it was determined that piping costs for the heap leaching process should be estimated conservatively. Therefore, the upper limit of the ranges shown in Table 1 was used for piping and insulation costs. The direct plant cost for the heap leaching system is $\$ 11,714,000$. Total indirect plant costs are $\$ 2,115,000$. Adding the contractor's fee and contingency of $\$ 691,000$ and $\$ 2,766,000$, respectively, to the direct and indirect plant costs results in a FCI value of approximately $\$ 17,286,000$ for the heap leaching system.

\subsection{FUNGAL LEACHING PROCESS}

The fungal leaching process involves the production of a lixiviant created by fermentation of a nutrient broth, removal of the fungus from the lixiviant, and utilization of the lixiviant in conventional soil washing processes. The engineering flow diagrams and equipment parts list are divided into 2 parts: 1) the fungal lixiviant production system and 2) the fungal soil remediation recycle and treatment system. Chemical processing equipment for this system includes tanks, mixers, pumps, fermenters, a cooling tower, and a polymer feed system, as well as specialized equipment such as a sterilizer, ultrafilter, evaporator/crystallizer system, and a reverse osmosis system.

Appendix A provides the engineering flow diagram for the fungal leaching process. The equipment list for the fungal leaching process is shown in Appendix B, Table B.7. The total equipment cost (E) for this system is estimated at $\$ 20,331,000$. The wet air oxidation system, at an estimated cost of $\$ 8,000,000$, represents the largest capital expenditure for equipment and approximately $39 \%$ of the total estimated equipment cost for the entire fungal leaching process. The wet air oxidation system includes an equalization tank, high pressure feed pumps, a heat exchanger, reactor, process cooler, degasser and 
Table 7. FCI for heap leaching system

\begin{tabular}{|c|c|c|c|c|}
\hline Item & Symbol & Description & Formula & Value \\
\hline 1 & $E$ & Equipment Costs & $\mathrm{E}$ & $\$ 2,488,000$ \\
\hline 2 & $\mathrm{~L}$ & Cost of Installation Labor & $.40 \mathrm{E}$ & $\$ 995,200$ \\
\hline 3 & IC & Instrumentation \& Controls & $.13 \mathrm{E}$ & $\$ 323,440$ \\
\hline 4 & I & Insulation Costs (equip. \& piping) & $.09 \mathrm{E}$ & $\$ 223,920$ \\
\hline 5 & $\mathbf{P}$ & Piping & $.31 \mathrm{E}$ & $\$ 771,280$ \\
\hline 6 & $Q$ & Labor for Installation of Piping & $.40 \mathrm{P}$ & $\$ 308,512$ \\
\hline 7 & $\mathrm{~F}$ & Electrical Installations & $.15 \mathrm{E}$ & $\$ 373,200$ \\
\hline 8 & B & Building including Services & --- & $\$ 4,613,500$ \\
\hline 9 & $\mathrm{Y}$ & Yard Improvements & $.10 \mathrm{E}$ & $\$ 248,800$ \\
\hline \multirow[t]{2}{*}{10} & $\mathbf{S}$ & Service Facilities & $.55 \mathrm{E}$ & $\$ 1,368,400$ \\
\hline & $\mathbf{D}$ & Direct Plant Cost & Sum of 1-10 & $\$ 11,714,252$ \\
\hline 11 & $\mathrm{ES}$ & Engineering \& Supervision & $.60 \mathrm{E}$ & $\$ 1,492,800$ \\
\hline \multirow[t]{2}{*}{12} & $\mathrm{C}$ & Construction Expenses & $.25 \mathrm{E}$ & $\$ 622,000$ \\
\hline & IP & Indirect Plant Cost & $\mathbf{E S}+\mathbf{C}$ & $\$ 2,114,800$ \\
\hline 13 & $\mathrm{CF}$ & Contractor's Fee & $.05(\mathrm{D}+\mathrm{IP})$ & $\$ 691,453$ \\
\hline \multirow[t]{2}{*}{14} & $\mathrm{CO}$ & Contingency & $.20(\mathrm{D}+\mathrm{IP})$ & $\$ 2,765,810$ \\
\hline & FCI & Fixed Capital Investment & $\mathrm{D}+\mathrm{IP}+\mathrm{CF}+\mathrm{CO}$ & $\mathbf{\$ 1 7 , 2 8 6 , 3 1 5}$ \\
\hline
\end{tabular}


off gas cooler, thermal fluid heat transfer system, and an oxidized wastewater pump. Other costly items include: 1) an externally mounted, vertical tube evaporator/crystallizer system with a $300 \mathrm{gpm}$ feed rate at an estimated cost of $\$ 2,500,000 ; 2)$ a reverse osmosis system costing approximately $\$ 2,000,000 ; 3$ ) five 500-horsepower mixers for the fermenters at an estimated cost of $\$ 2,125,000 ; 4$ ) a sterilizer estimated at $\$ 1,500,000 ; 5$ ) five 41,000-gallon stainless steel vertical, cylindrical fermenters estimated at a total cost of $\$ 1,125,000 ; 6)$ a $21,000 \mathrm{cfm}$ tandem rotary screw air compression system, with motors included, estimated at $\$ 1,000,000 ; 7)$ a wet air oxidation blowdown treatment system, made up of two 50,000-gallon aeration tanks with a clarifier, digester, splitter box, and sludge return pumps, costing approximately $\$ 400,000$; and 8) a tube-type membrane ultrafilter with an estimated cost of $\$ 300,000$.

The results of the FCI calculation for the fungal leaching process are shown in Table 8. The assumption was made that the fungal leaching building would require approximately the same size building as the sulfuric acid soil washing system. Therefore, building costs are estimated at approximately $\$ 1,479,000$ for a 2-story building with $20,000 \mathrm{ft}^{2}$ per floor. Based on discussions with Halliburton NUS personnel, it is anticipated that a greater demand will be placed on supplying the power, compressed air, water, etc., for the fungal leaching process compared to the other treatment technologies. For example, five fermenters mixers, each requiring a 500-horsepower motor, are used for this process. The air compressors also require four 800-horsepower motors. Therefore, the service facilities costs for the fungal leaching process will be higher than that for the other treatment technologies. Because of these additional constraints, the cost factor for the service facilities was increased from $.55 \mathrm{E}$ to $.70 \mathrm{E}$ for the fungal leaching process. The direct plant cost for the fungal leaching system is $\$ 57,471,000$. Total indirect plant costs are $\$ 17,282,000$. Adding the contractor's fee and contingency of $\$ 3,738,000$ and $\$ 14,951,000$, respectively, results in an FCI value of approximately $\$ 93,441,000$ for the fungal leaching process.

\subsection{AQUEOUS BIPHASIC EXTRACTION PROCESS}

The aqueous biphasic extraction process involves the use of a Karr Column to selectively partition the ultra fine soil particles between two immiscible aqueous phases (Soil Decontamination Task Group 1993). In the aqueous biphasic extraction process, one liquid phase is a solution of polyethylene glycol (PEG) and the other is a sodium carbonate salt solution. The approach taken by the Principal Investigator is to partition the uranium rich solid soil particles into the salt phase leaving the top of the Karr Column. Also in this salt phase is the bulk of the dissolved uranium. The PEG underflow slurry should exit the bottom of the Karr Column containing the uranium-depleted soil.

Appendix A provides the engineering flow diagram for the aqueous biphasic extraction system. The equipment costs for this treatment technology are shown in Appendix B, Table B.8. The total equipment cost (E) for this system is estimated at approximately $\$ 4,501,100$. The Karr reciprocating plate columns are by far the most expensive pieces of process equipment required for the aqueous biphasic extraction system. Based on conversations with the principal investigator, a company provided a budget estimate of $\$ 380,000$ for each Karr Column. Preliminary sketches from the company indicate that each Karr Column should be 6 feet in diameter, with a $15-\mathrm{ft}$ plate stack height. Due to the requirement for $5 \mathrm{Karr}$ Columns, the total cost for the Karr Columns is $\$ 1,900,000$, which represents $42 \%$ of the total equipment cost for the aqueous biphasic extraction process. Two belt-type horizontal pressure filters are also required, with a budgeted cost of $\$ 400,000$ each. Other large equipment expenditures include a methanol strip column at $\$ 200,000$, a PEG thickener at $\$ 150,000$, and a drum scrubber with trommel 
Table 8. FCI for fungal leaching process

\begin{tabular}{|c|c|c|c|c|}
\hline Item & Symbol & Description & Formula & Value \\
\hline 1 & $\mathrm{E}$ & Equipment Costs & $\mathrm{E}$ & $\$ 20,331,416$ \\
\hline 2 & $\mathrm{~L}$ & Cost of Installation Labor & $.40 \mathrm{E}$ & $\$ 8,132,566$ \\
\hline 3 & IC & Instrumentation \& Controls & $.13 \mathrm{E}$ & $\$ 2,643,084$ \\
\hline 4 & $I$ & Insulation Costs (equip. \& piping) & $.05 \mathrm{E}$ & $\$ 1,016,571$ \\
\hline 5 & $\mathbf{P}$ & Piping & $.16 \mathrm{E}$ & $\$ 3,253,027$ \\
\hline 6 & Q & Labor for Installation of Piping & $.40 \mathrm{P}$ & $\$ 1,301,211$ \\
\hline 7 & F & Electrical Installations & $.15 E$ & $\$ 3,049,712$ \\
\hline 8 & B & Building including Services & -- & $\$ 1,478,500$ \\
\hline 9 & $\mathrm{Y}$ & Yard Improvements & $.10 \mathrm{E}$ & $\$ 2,033,142$ \\
\hline \multirow[t]{2}{*}{10} & $S$ & Service Facilities & $.70 \mathrm{E}$ & $\$ 14,231,991$ \\
\hline & D & Direct Plant Cost & Sum of 1-10 & $\$ 57,471,220$ \\
\hline 11 & $\mathrm{ES}$ & Engineering \& Supervision & $.60 \mathrm{E}$ & $\$ 12,198,850$ \\
\hline \multirow[t]{2}{*}{12} & $\mathrm{C}$ & Construction Expenses & $.25 \mathrm{E}$ & $\$ 5,082,854$ \\
\hline & IP & Indirect Plant Cost & $\mathrm{ES}+\mathrm{C}$ & $\$ 17,281,704$ \\
\hline 13 & $\mathrm{CF}$ & Contractor's Fee & $.05(\mathrm{D}+\mathrm{IP})$ & $\$ 3,737,646$ \\
\hline \multirow[t]{2}{*}{14} & $\mathrm{CO}$ & Contingency & $.20(\mathrm{D}+\mathrm{IP})$ & $\$ 14,950,585$ \\
\hline & FCI & Fixed Capital Investment & $\mathrm{D}+\mathrm{IP}+\mathrm{CF}+\mathrm{CO}$ & $\$ 93,441,154$ \\
\hline
\end{tabular}


at an estimated cost of $\$ 150,000$.

The results of the FCI calculation for the aqueous biphasic extraction process are shown in Table 9. Building size requirements for this system are assumed to be the same as those for the sodium carbonate, citric, and tiron systems. The building cost is estimated at approximately $\$ 1,272,000$. The direct plant cost for this process is estimated at $\$ 12,993,000$. Indirect plant costs, consisting of construction expenses and engineering and supervision, for this system are $\$ 3,826,000$. Adding a contractor's fee and contingency of $\$ 841,000$ and $\$ 3,364,000$, respectively, to the direct and indirect plant costs results in a FCI of approximately $\$ 21,024,000$ for the aqueous biphasic extraction process.

\section{SUMMARY}

To evaluate the economic feasibility of designing, constructing, and operating a full-scale soil treatment facility, engineering designs and cost estimates for the seven treatment technologies investigated by the USID Program have been prepared. Engineering designs for the following treatment technologies were developed by Halliburton NUS: sodium carbonate soil washing system, sulfuric acid soil washing system, citric acid soil washing system, tiron soil washing system, heap leaching system, fungal leaching process, and aqueous biphasic extraction process. In conjunction with the engineering design development, cost estimates for each system were developed by ORNL.

The cost estimates for these seven technologies are being completed in three steps. The first step is to calculate the FCI, which represents the one-time capital investment needed to supply the necessary full-scale manufacturing and plant facilities for each soil treatment technology alternative being demonstrated by the USID Program. The second step is to develop the operational costs associated with a full-scale treatment facility for each technology. Operating costs occur throughout the life of the project. The third step is to estimate the life-cycle costs for the treatment technology alternatives. It is the first step, FCI calculations, that has been described in this report. A soil preparation building to process and store the soil before treatment is required regardless of the treatment technology being considered. The total equipment cost and the FCI for the soil preparation building and each treatment technology are summarized in Table 10. The operating costs and life-cycle costs for each technology will be documented in future reports.

The estimated equipment cost and the FCI value for the heap leaching system are the lowest of the treatment technologies considered. Although the equipment costs for the heap leaching system are $52 \%$ less than equipment costs for the sodium carbonate soil washing system, the FCI for the heap leaching system is only $28 \%$ less than the FCI for the sodium carbonate system. This is due to the fact that building costs are projected to be much higher for the heap leaching system than the other technologies. In addition, piping and insulation requirements will be more extensive for the heap leaching system compared to the other treatment technologies. In terms of FCI requirements, the most attractive options from a cost perspective after the heap leaching system are the aqueous biphasic extraction process and the sodium carbonate system, at approximately 21 million and 24 million, respectively. The FCI for the sodium carbonate system is $31 \%$ less than its nearest competitor in terms of cost, the sulfuric acid soil washing system. For the citric acid soil washing system, the vacuum compression evaporation/crystallization system with an estimated cost of $\$ 8,000,000$ (58\% of the systems' total equipment cost) drives up the total equipment cost and the resulting $\mathrm{FCI}$ cost when compared to the sodium carbonate and sulfuric acid systems. Likewise, for the tiron soil washing system, the requirement 
Table 9. FCI for aqueous biphasic extraction process

\begin{tabular}{|c|c|c|c|c|}
\hline Item & Symbol & Description & Formula & Value \\
\hline 1 & $\mathrm{E}$ & Equipment Costs & $E$ & $\$ 4,501,100$ \\
\hline 2 & $\mathrm{~L}$ & Cost of Installation Labor & $.40 \mathrm{E}$ & $\$ 1,800,440$ \\
\hline 3 & IC & Instrumentation \& Controls & $.13 \mathrm{E}$ & $\$ 585,143$ \\
\hline 4 & I & Insulation Costs (equip. \& piping) & $.05 \mathrm{E}$ & $\$ 225,055$ \\
\hline 5 & $\mathbf{P}$ & Piping & $.16 \mathrm{E}$ & $\$ 720,176$ \\
\hline 6 & $Q$ & Labor for Installation of Piping & $.40 \mathrm{P}$ & $\$ 288,070$ \\
\hline 7 & $\mathbf{F}$ & Electrical Installations & $.15 \mathrm{E}$ & $\$ 675,165$ \\
\hline 8 & B & Building including Services & --- & $\$ 1,272,400$ \\
\hline 9 & $\mathrm{Y}$ & Yard Improvements & $.10 \mathrm{E}$ & $\$ 450,110$ \\
\hline \multirow[t]{2}{*}{10} & $\underline{S}$ & Service Facilities & $.55 \mathrm{E}$ & $\$ 2,475,605$ \\
\hline & D & Direct Plant Cost & Sum of 1-10 & $\$ 12,993,264$ \\
\hline 11 & $\mathrm{ES}$ & Engineering \& Supervision & $.60 \mathrm{E}$ & $\$ 2,700,660$ \\
\hline \multirow[t]{2}{*}{12} & $\mathrm{C}$ & Construction Expenses & $.25 \mathrm{E}$ & $\$ 1,125,275$ \\
\hline & IP & Indirect Plant Cost & $\mathbf{E S}+\mathbf{C}$ & $\$ 3,825,935$ \\
\hline 13 & CF & Contractor's Fee & $.05(\mathrm{D}+\mathrm{IP})$ & $\$ 840,960$ \\
\hline \multirow[t]{2}{*}{14} & $\mathrm{CO}$ & Contingency & $.20(\mathrm{D}+\mathrm{IP})$ & $\$ 3,363,840$ \\
\hline & FCI & Fixed Capital Investment & $\mathrm{D}+\mathrm{IP}+\mathrm{CF}+\mathrm{CO}$ & $\$ 21,023,999$ \\
\hline
\end{tabular}


Table 10. Summary of equipment costs and FCI calculations

\begin{tabular}{lcc}
\hline \multicolumn{1}{c}{ Treatment Technology } & $\begin{array}{c}\text { Total Equipment } \\
\text { Cost }\end{array}$ & Fixed Capital Investment (FCI) \\
\hline Soil Preparation Building & $\$ 485,935$ & $\$ 3,269,128$ \\
Heap Leaching System & $\$ 2,488,000$ & $\$ 17,286,315$ \\
Aqueous Biphasic Extraction & $\$ 4,501,100$ & $\$ 21,023,999$ \\
Process & & \\
Sodium Carbonate Soil Washing & $\$ 5,172,350$ & $\$ 23,922,121$ \\
System & & $\$ 34,789,139$ \\
Sulfuric Acid Soil Washing System & $\$ 7,629,650$ & $\$ 61,168,762$ \\
Citric Acid Soil Washing System & $\$ 13,799,250$ & $\$ 65,904,196$ \\
Tiron Soil Washing System & $\$ 14,896,050$ & $\$ 93,441,154$ \\
Fungal Leaching Process & $\$ 20,331,416$ & \\
\hline
\end{tabular}


for a biological treatment plant at an estimated cost of $\$ 8,870,000(60 \%$ of the systems' total equipment cost) has a major effect on the systems' total equipment cost and resulting FCI calculation. The fungal leaching process results in the highest estimated total equipment cost and FCI value. The total equipment cost for the fungal leaching process is much higher than the other technologies due to the requirement for many pieces of specialized equipment. Also, service facilities costs are projected to be higher for the fungal leaching process compared to the other treatment technologies, thereby increasing the FCI for this system.

The engineering designs and the FCI cost estimates contained in this report are based on bench-scale study results and are considered preliminary because of the research and developmental nature associated with these seven technologies. Therefore, these costs are considered study estimates with an accuracy of $+40 \%$ to $-20 \%$. With the exception of building costs, the $\mathrm{FCI}$ calculations in this report were estimated as a percentage of the process equipment cost for each technology. Building costs were based on unit costs and estimates of square footage requirements provided by Halliburton NUS personnel. As further results become available from bench-scale and pilot plant studies, these engineering designs and cost estimates will be updated to provide the optimum operating conditions to remove uranium from the soil. The operational costs and the life-cycle costs for the treatment technology options being considered by the USID program will be documented in future reports.

\section{REFERENCES}

Means Site Work and Landscape Cost Data, R.S. Means Company, Inc., 12th Annual Edition, 1993.

Mining and Mineral Processing Equipment Costs and Preliminary Capital Cost Estimations, Published by the Canadian Institute of Mining and Metallurgy, Volume 25.

Peters, M.S. and K.D. Timmerhaus. 1991. Plant Design and Economics for Chemical Engineers. New York: McGraw-Hill, Inc.

Post, R.G. and M.E. Wacks, editors. 1994. Uranium soils integrated demonstration 1993 status. "Proceedings of the Symposium on Waste Management, Tucson AZ, February 27-March 3, 1994". Vol 3, pp. 2051-2135.

Process Plant Construction Estimating Standards, Richardson's Engineering Services, Inc., 1994 Edition.

Soil Decontamination Task Group. 1993. Removal of Uranium from Uranium-Contaminated Soils, Phase 1: Bench Scale Testing. ORNL-6762. Oak Ridge National Laboratory, Oak Ridge, Tennessee. 


\section{APPENDIX A}

Engineering Flow Diagrams for Soil Treatment Technologies

DEVELOPED BY HALLIBURTON NUS 
SOIL PREPARATION BUILDING

A-2 


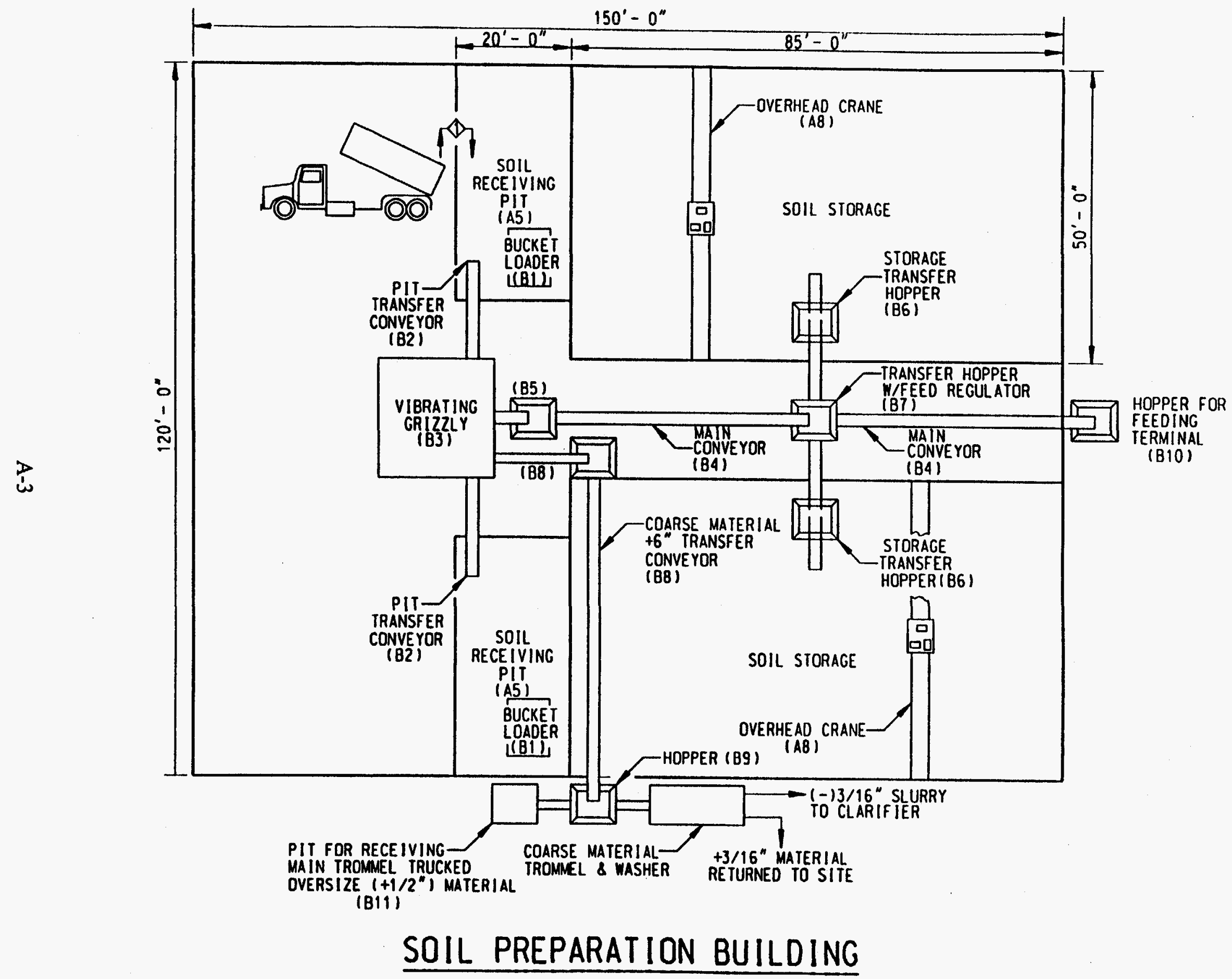


SODIUM CARBONATE SOIL WASHING SYSTEM 


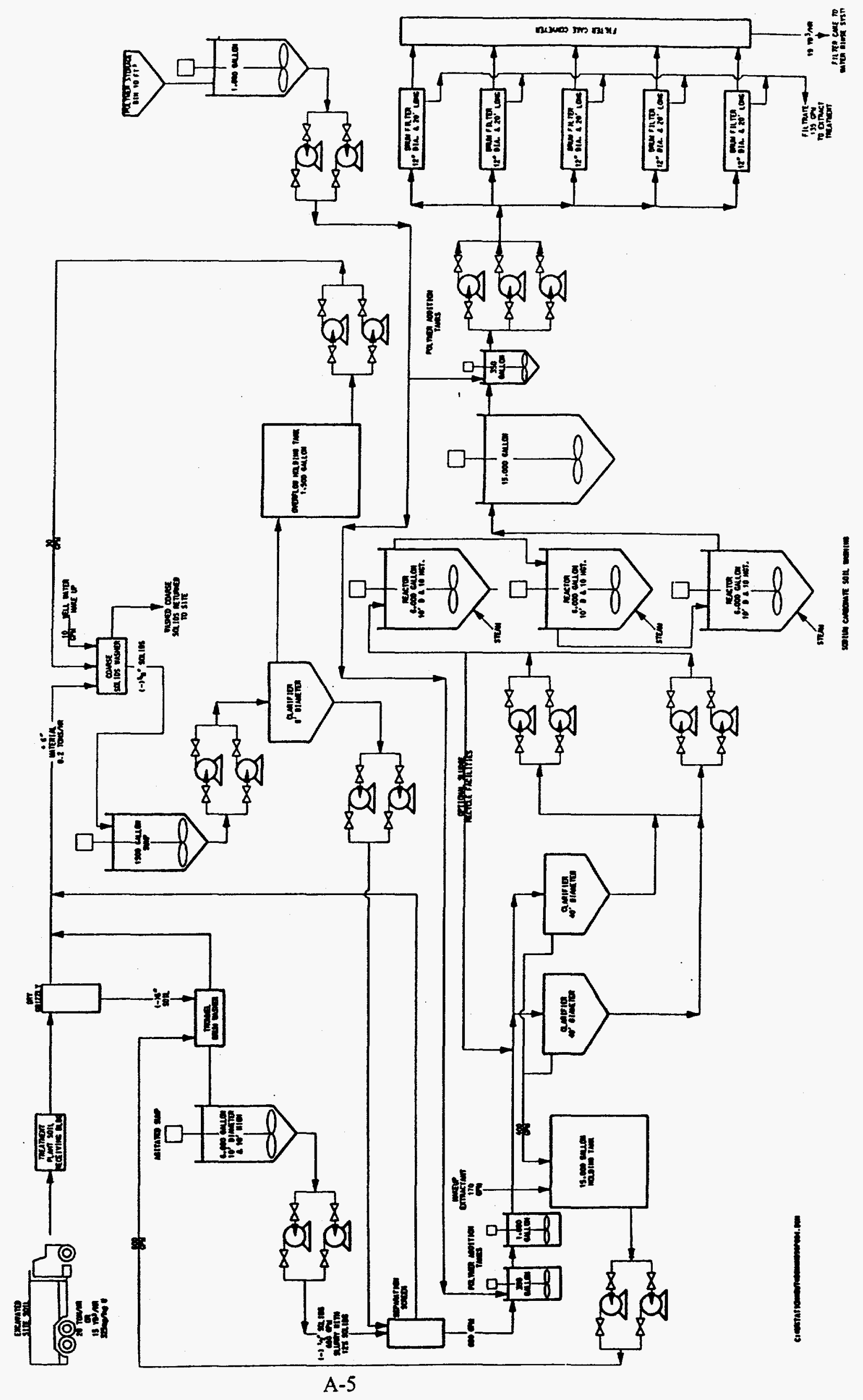




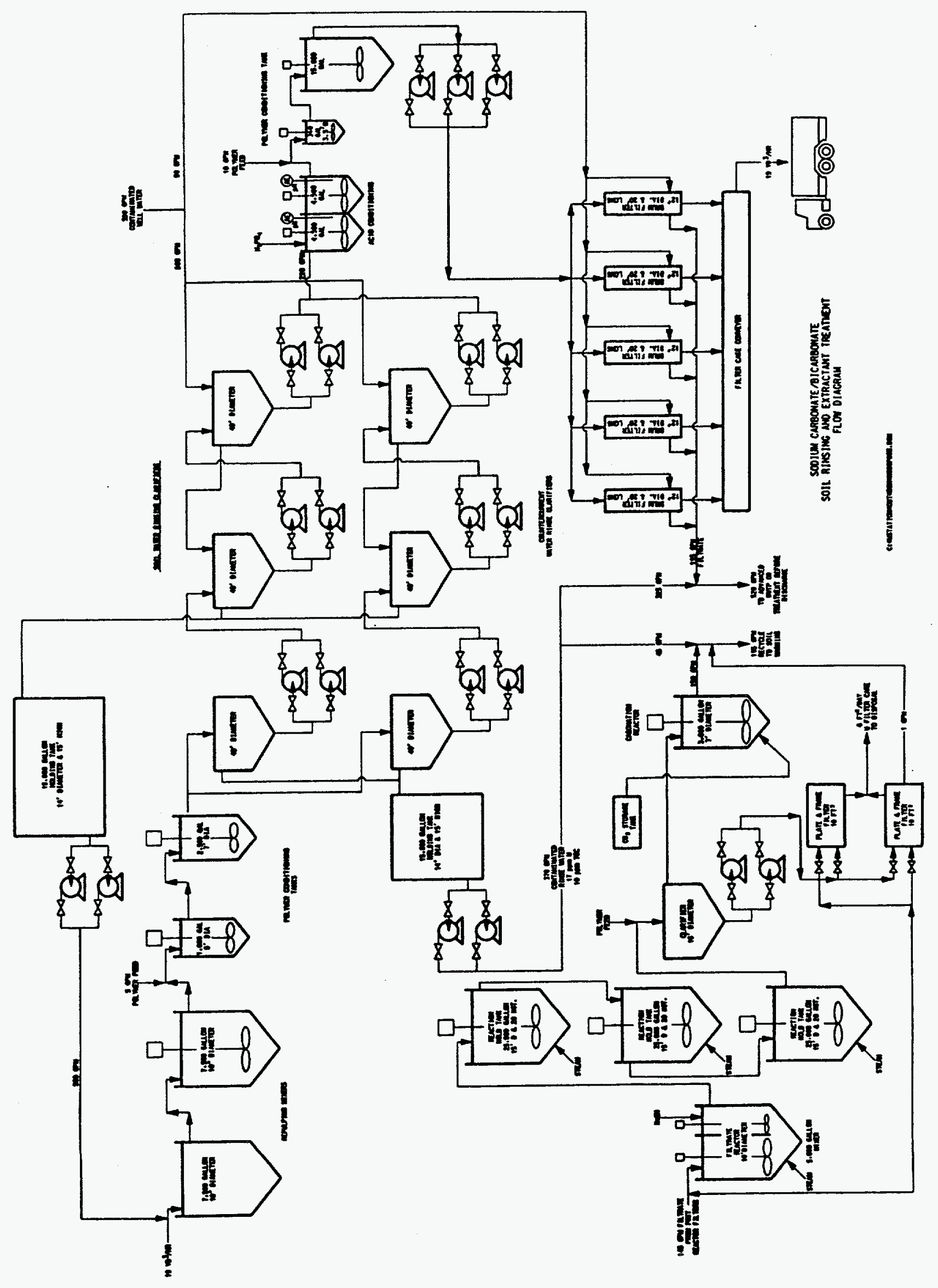


SULFURIC ACID SOIL WASHING SYSTEM 


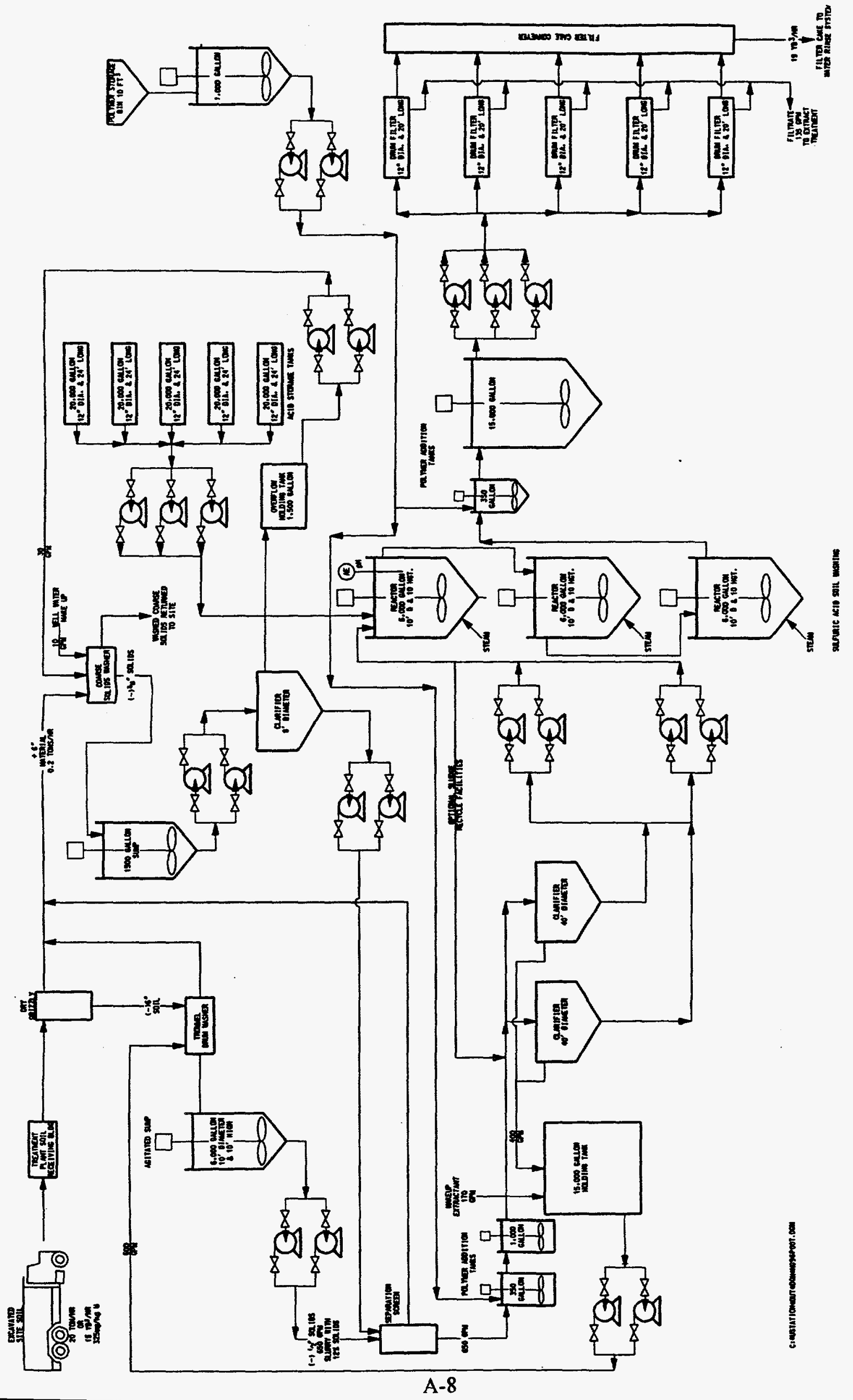




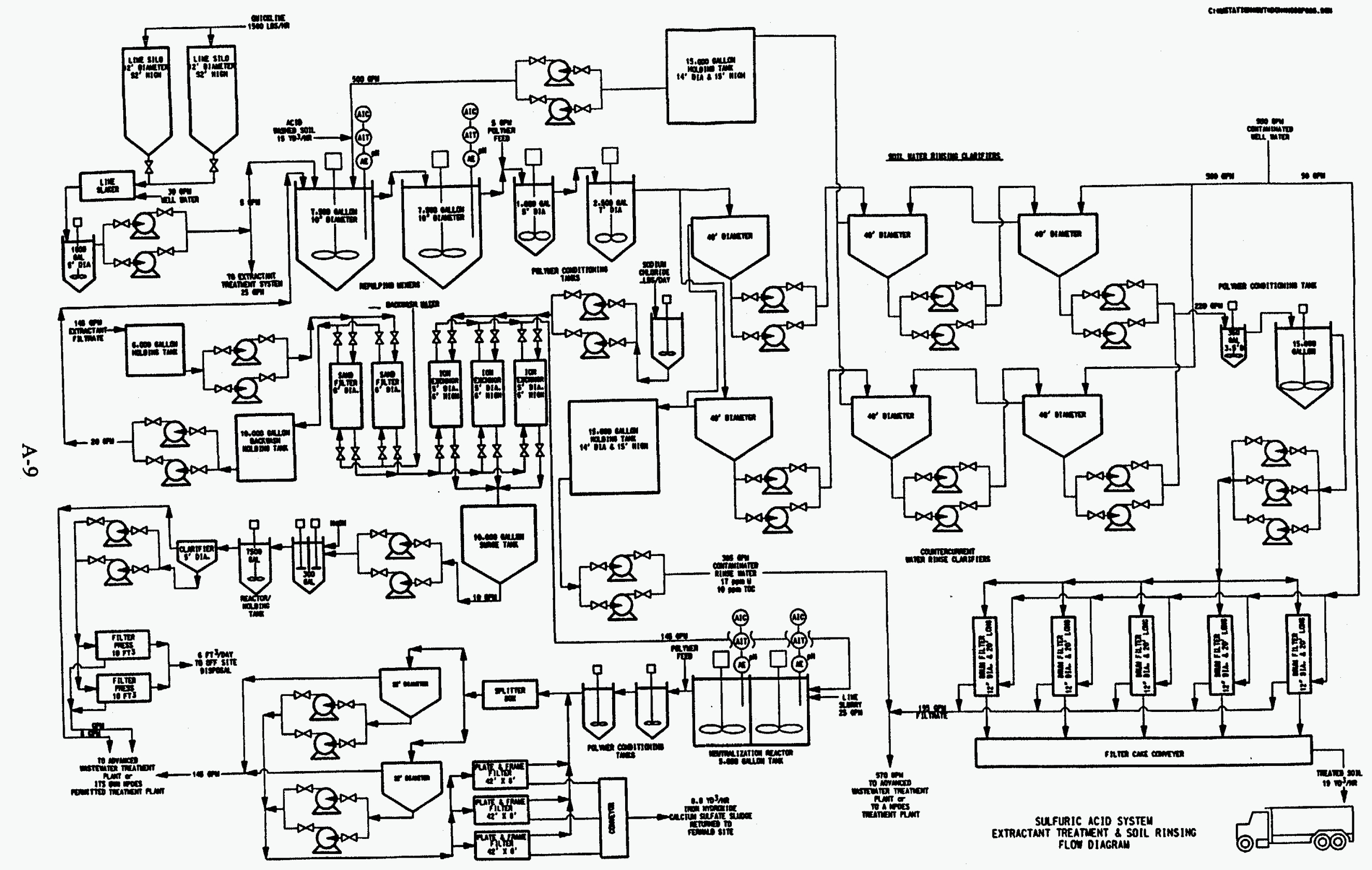




\section{CITRIC ACID SOIL WASHING SYSTEM}




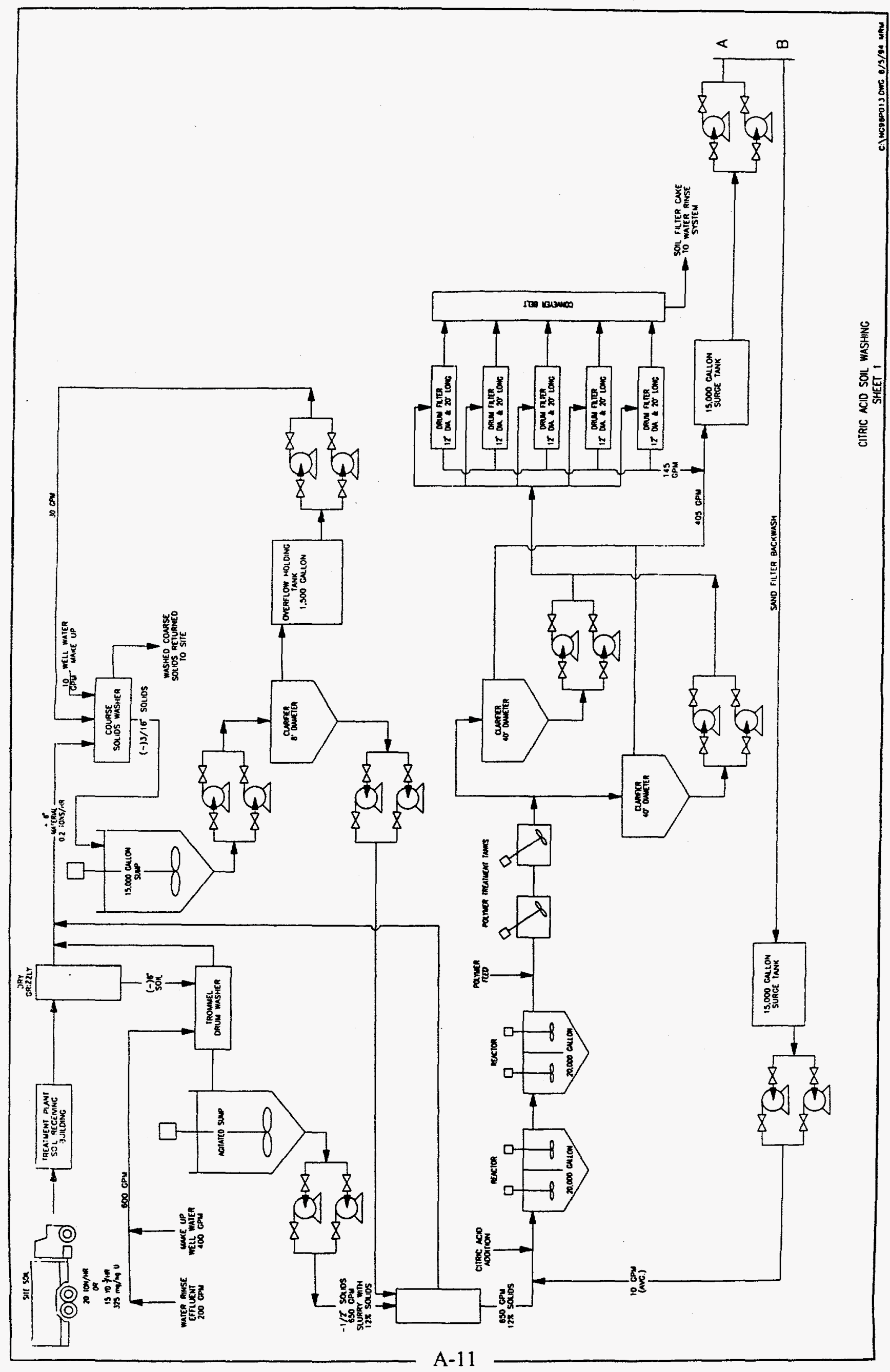




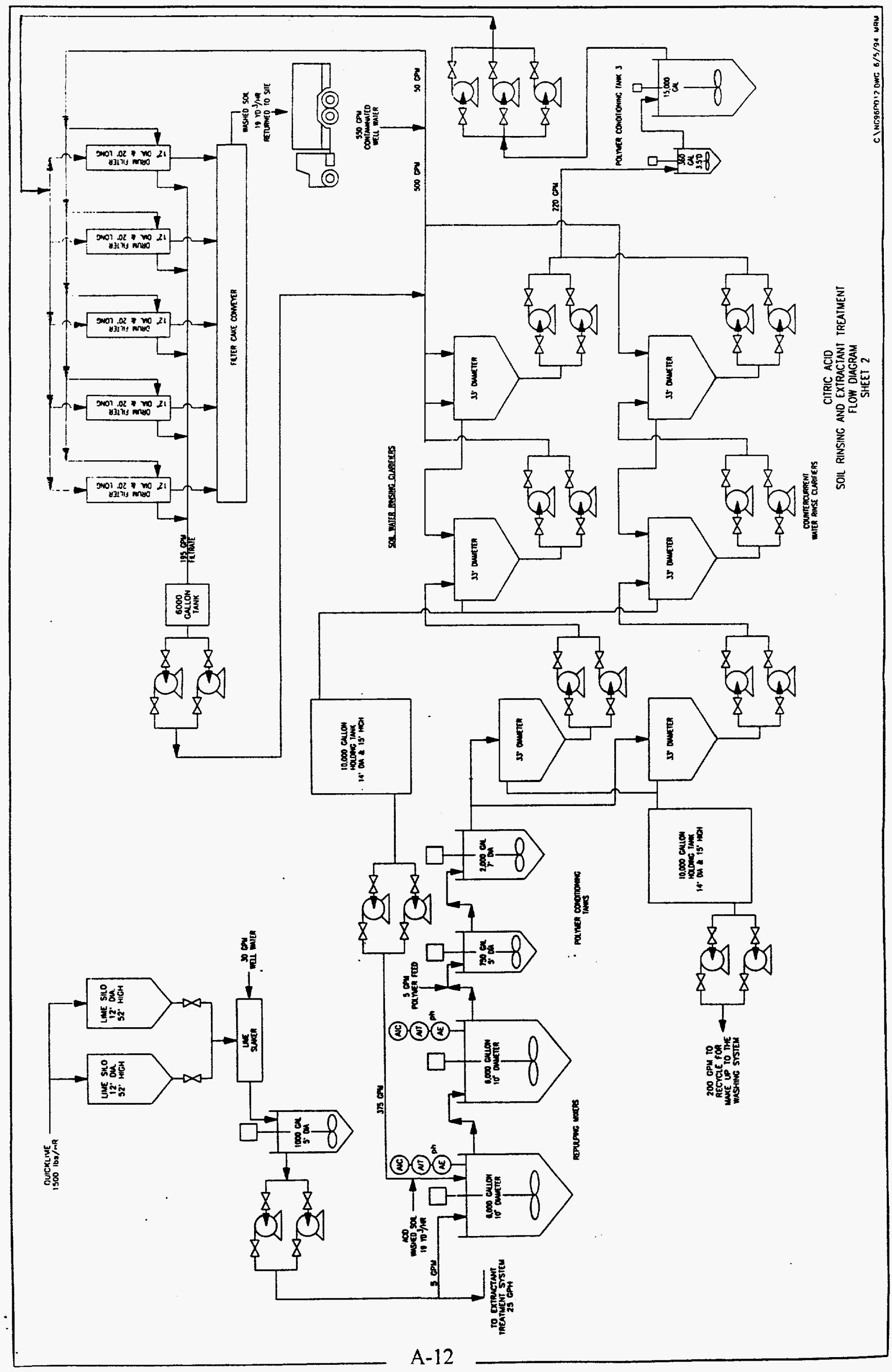




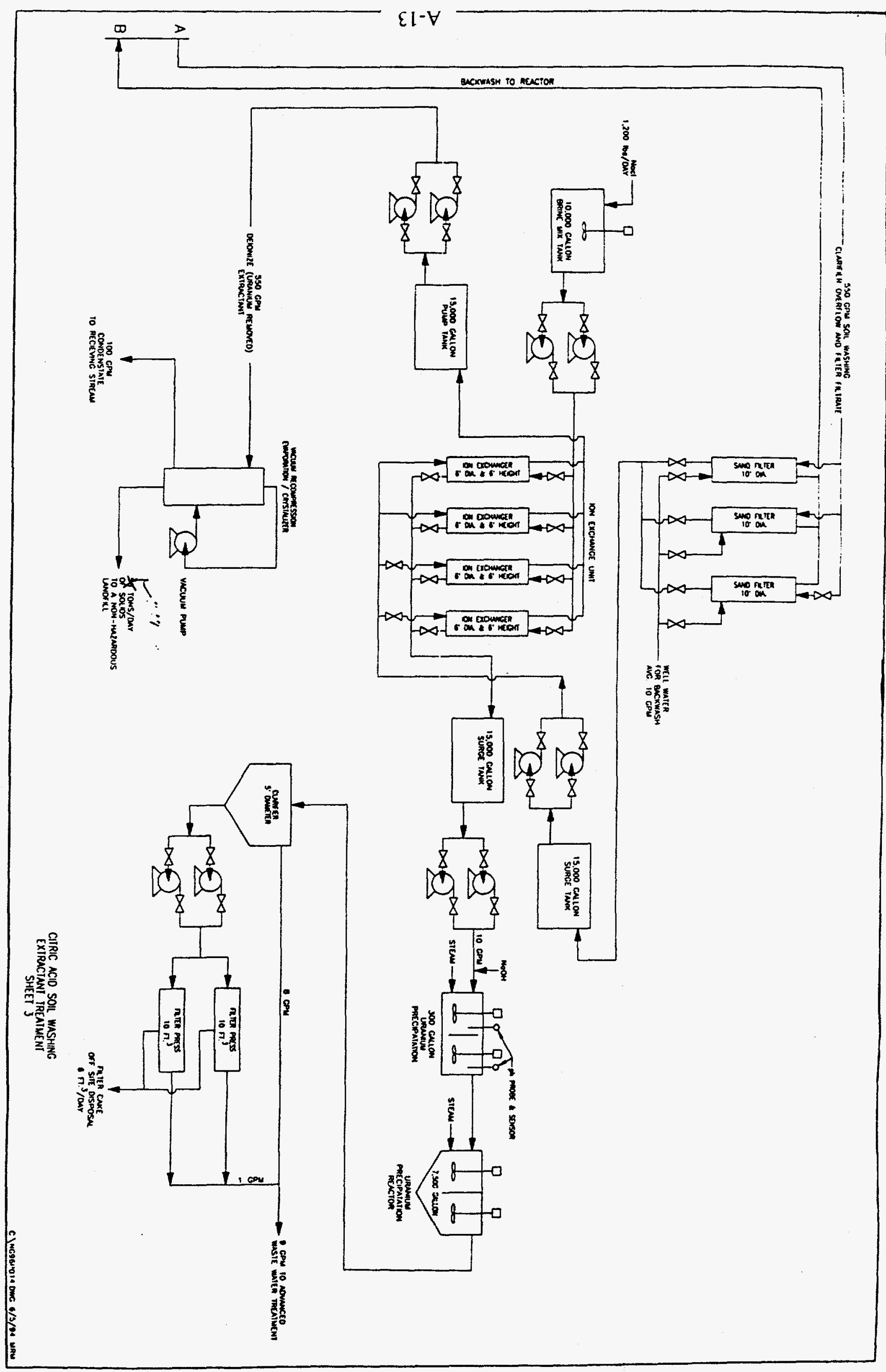




\section{TIRON SOIL WASHING SYSTEM}

A-14 


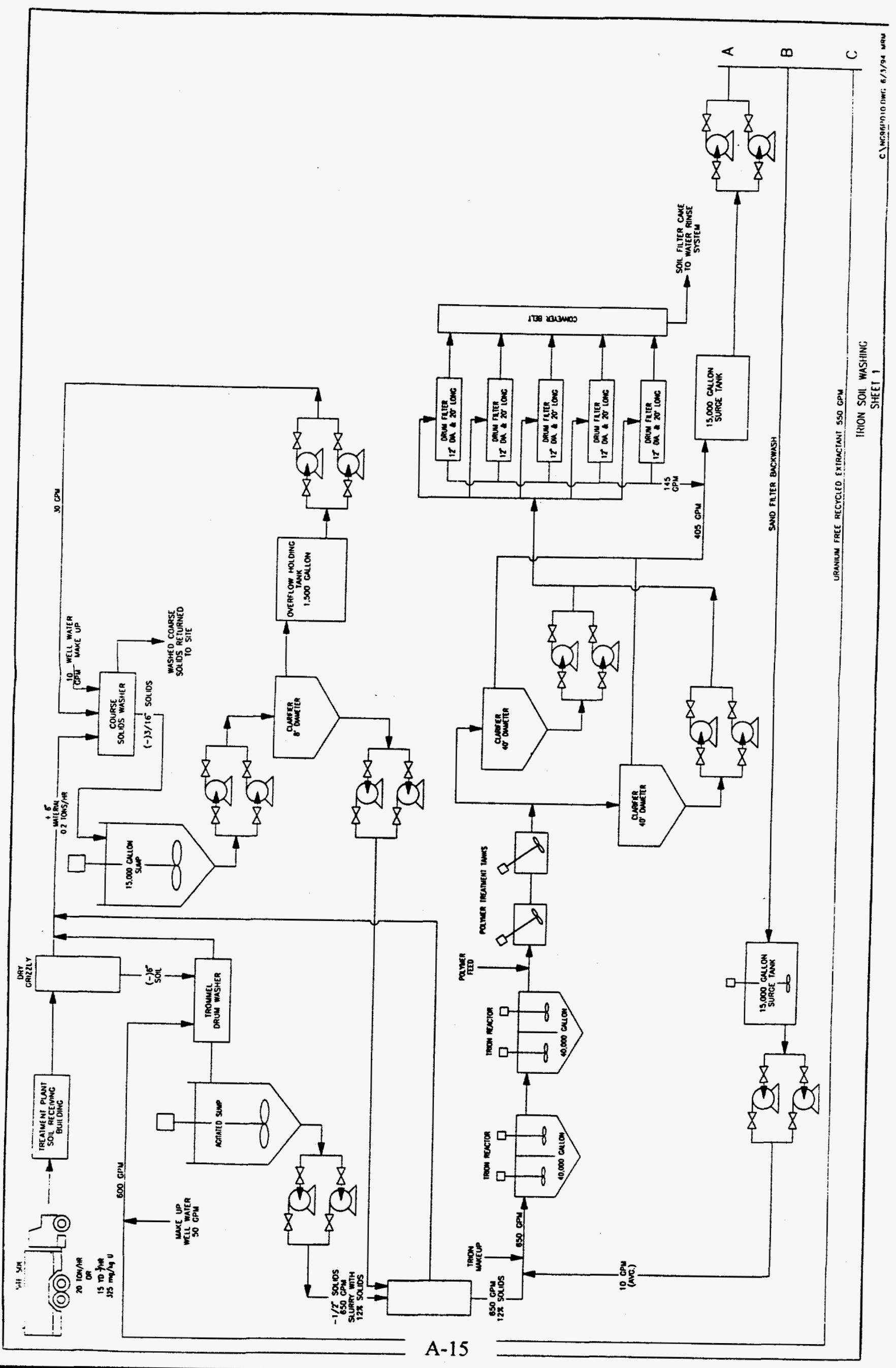




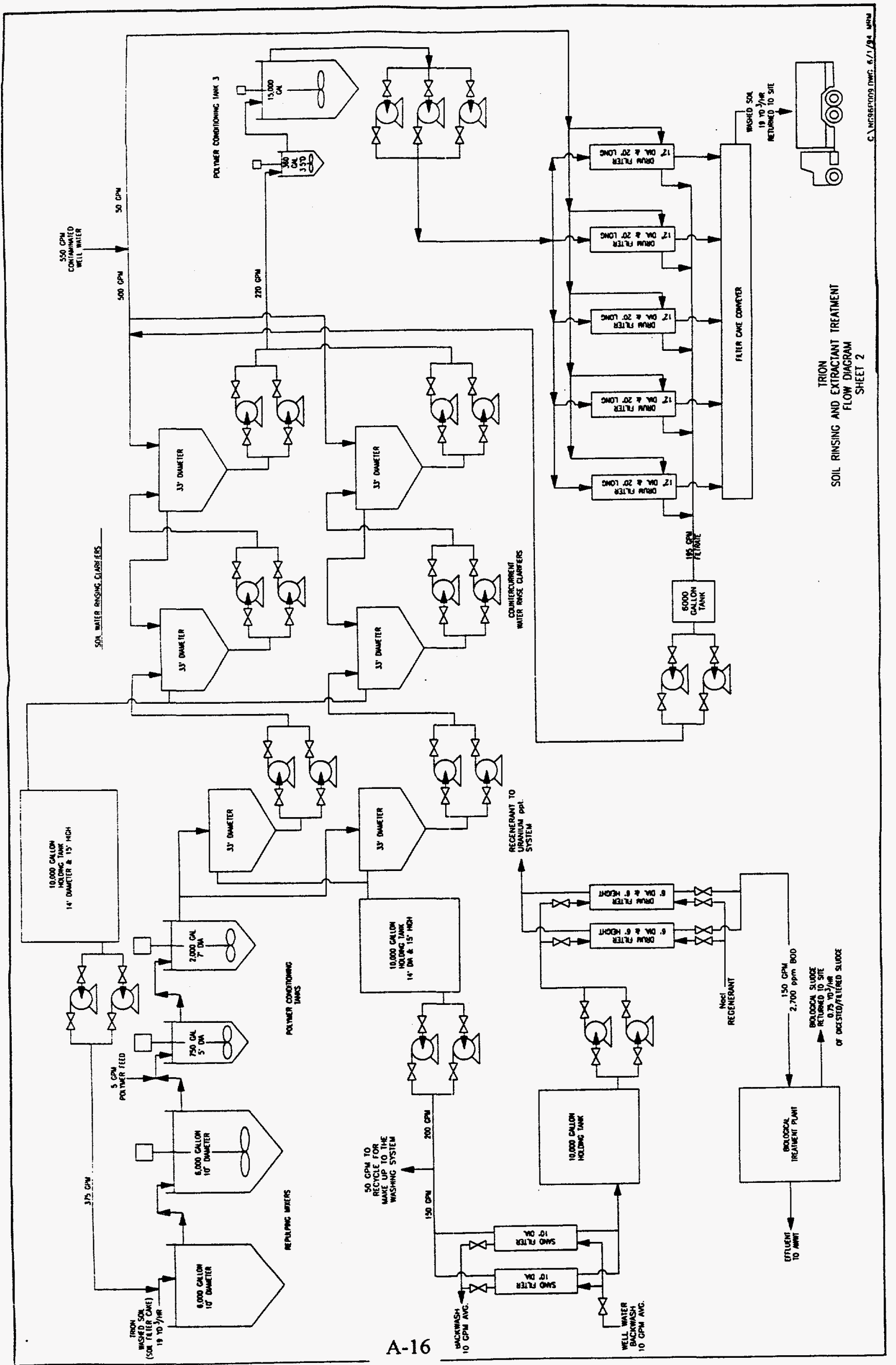




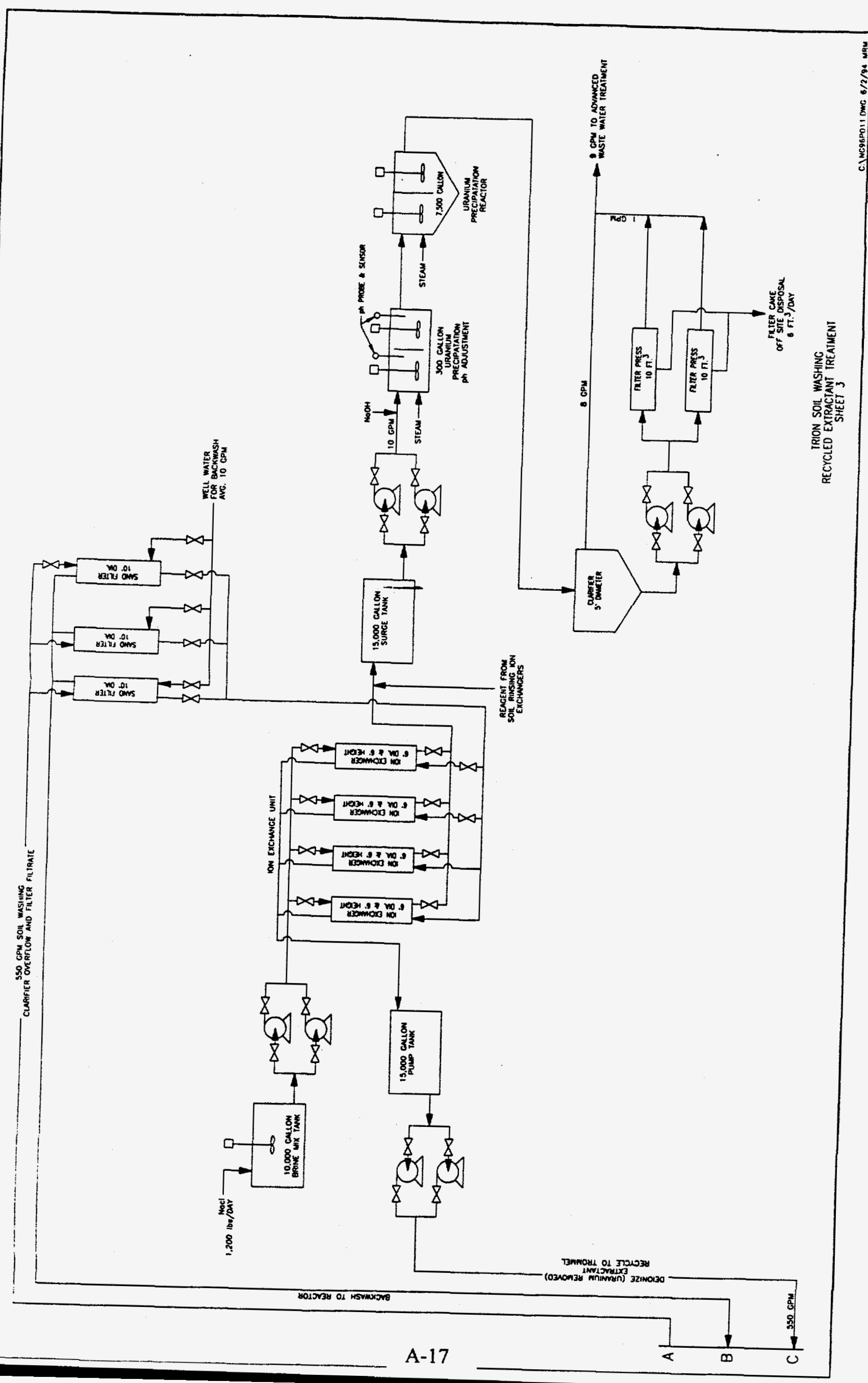




\section{HEAP LEACHING SYSTEM}

A-18 


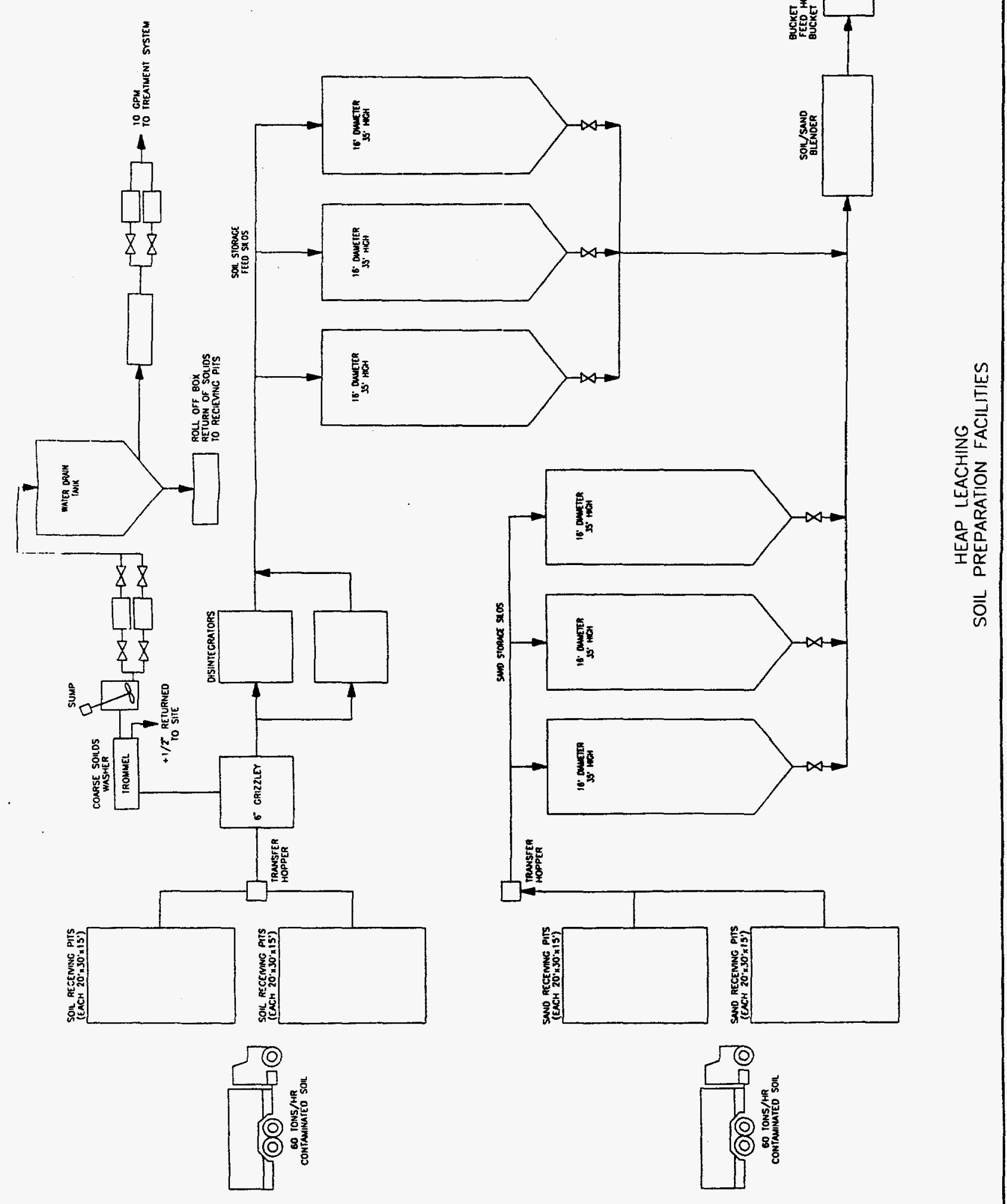




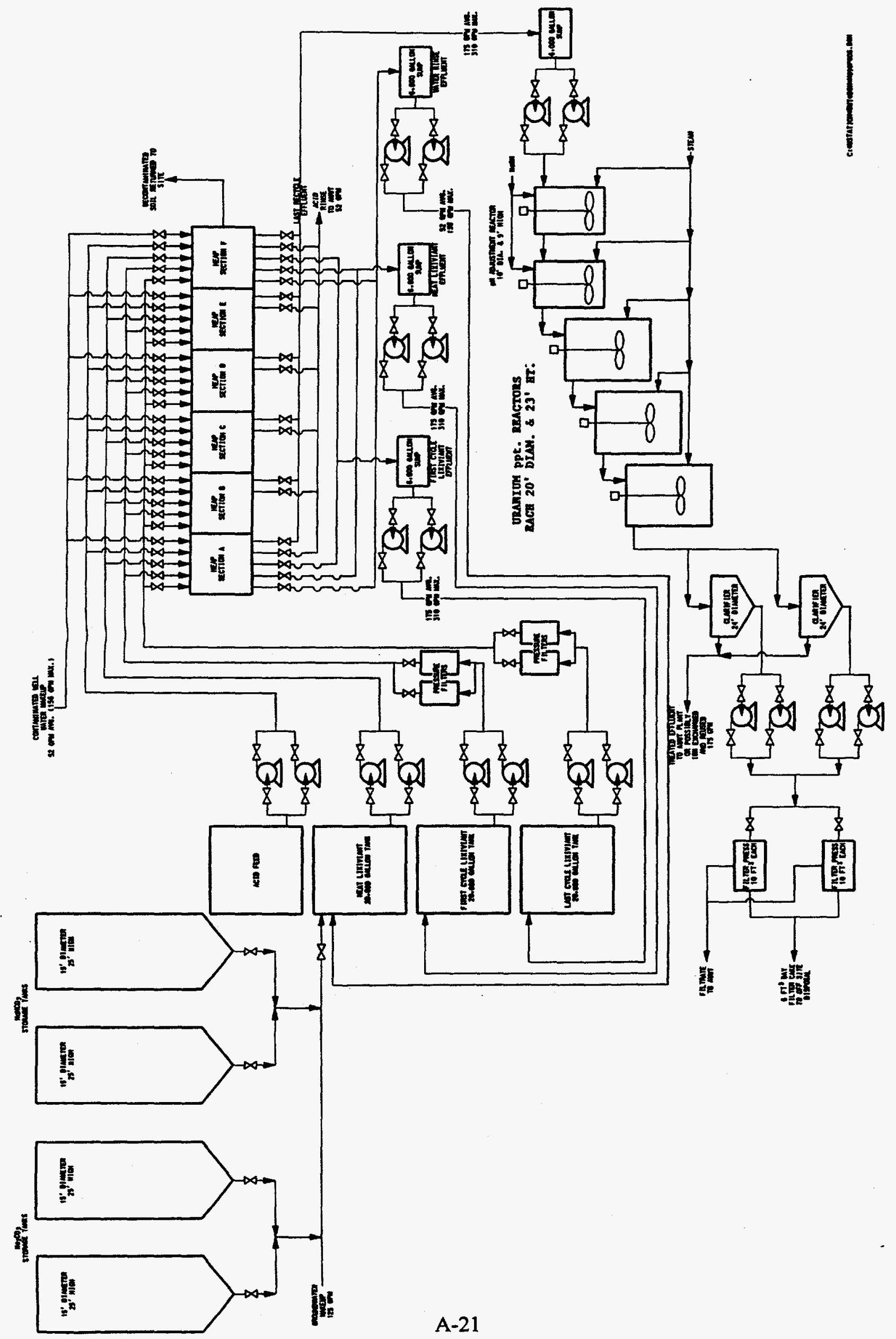




\section{FUNGAL LEACHING SYSTEM}

A-22 


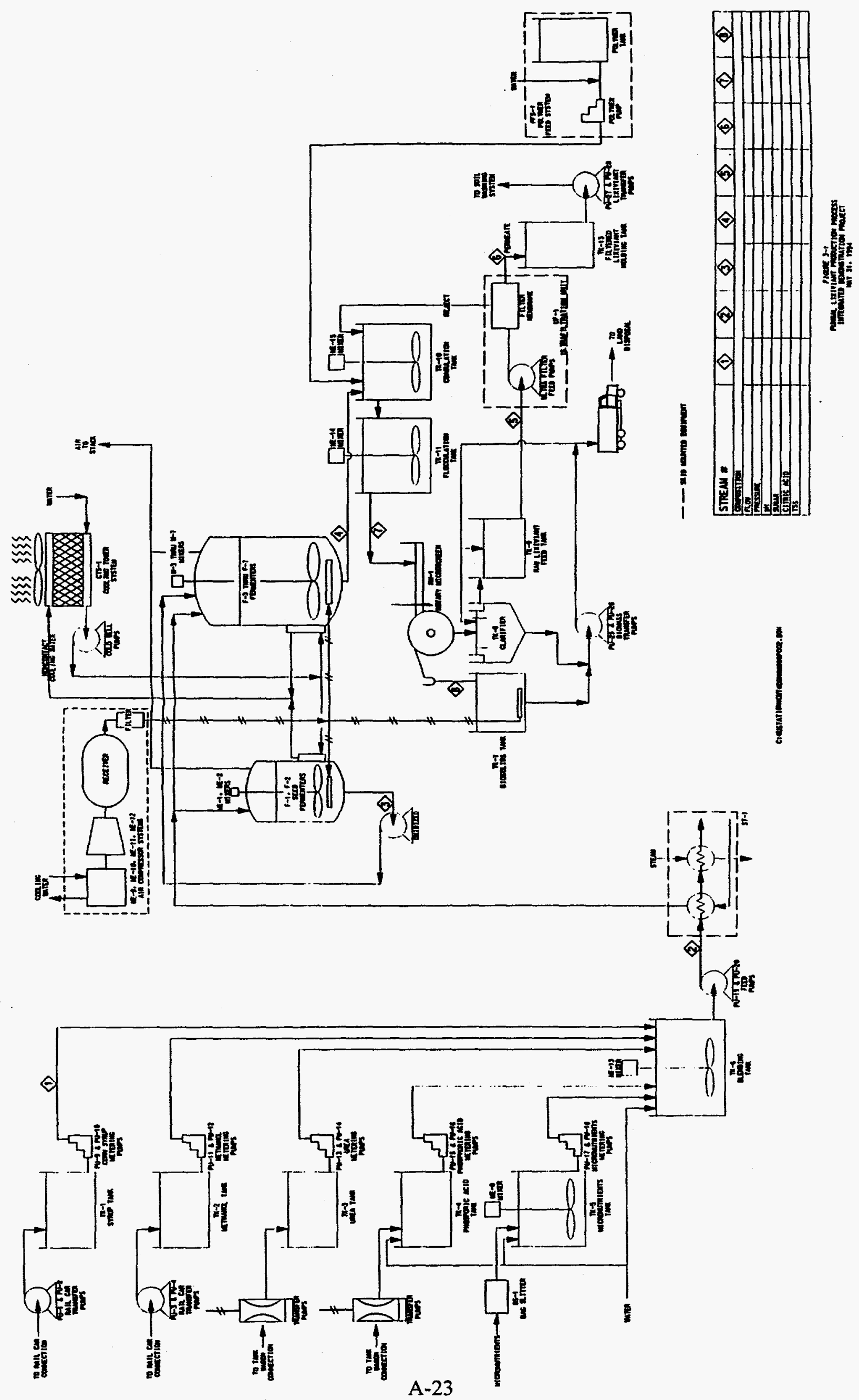




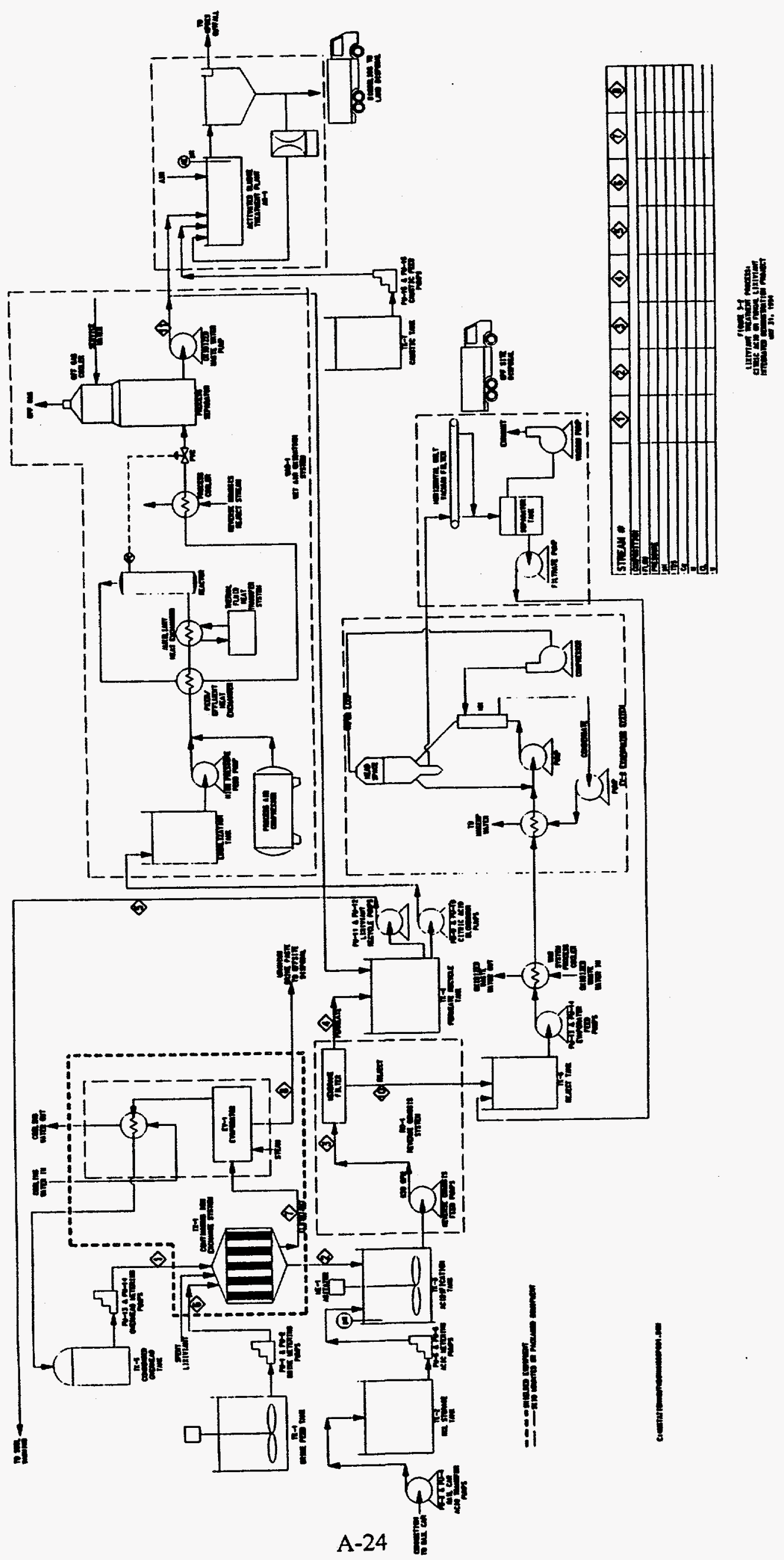




\section{AQUEOUS BIPHASIC EXTRACTION PROCESS}




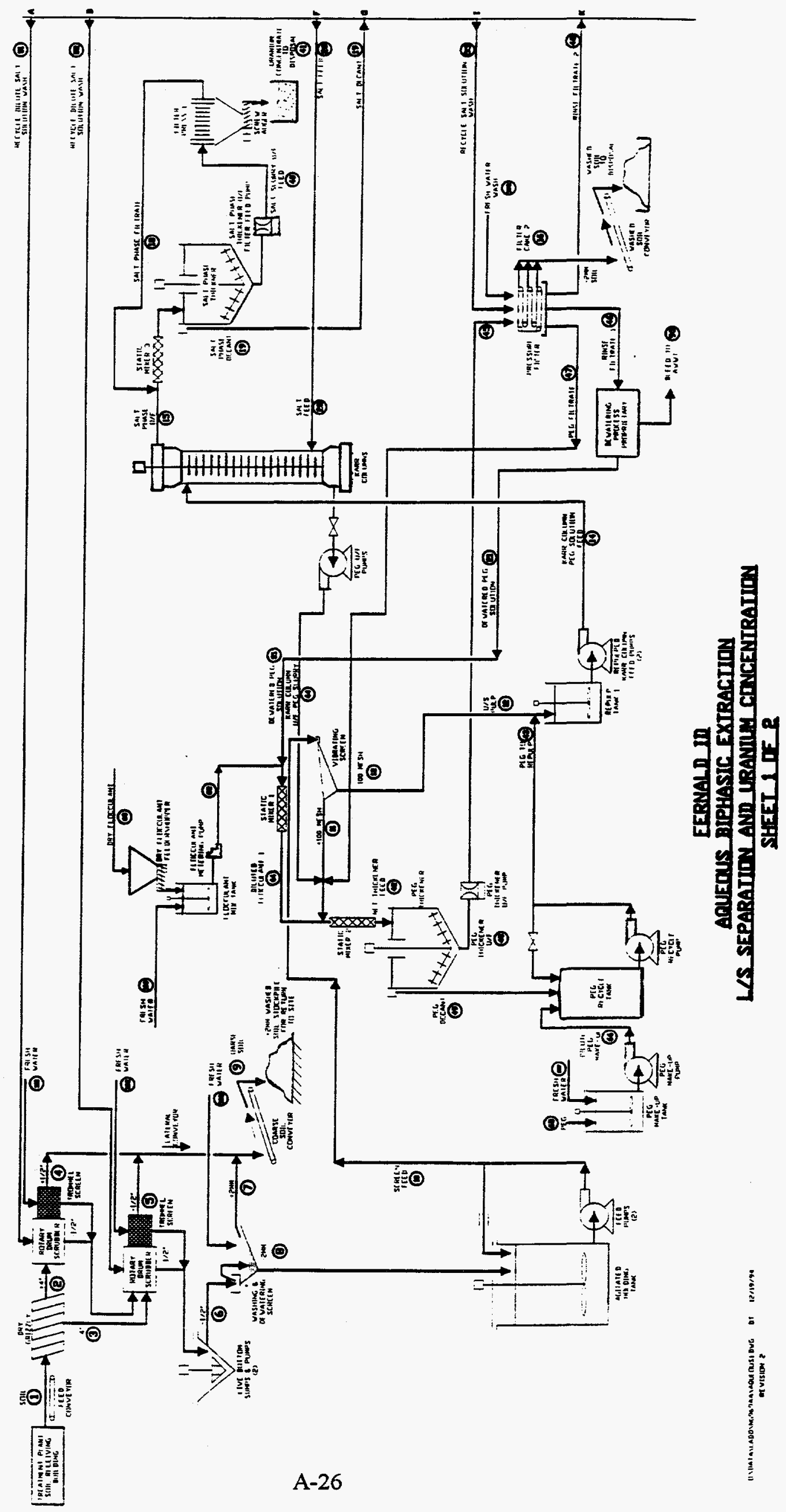




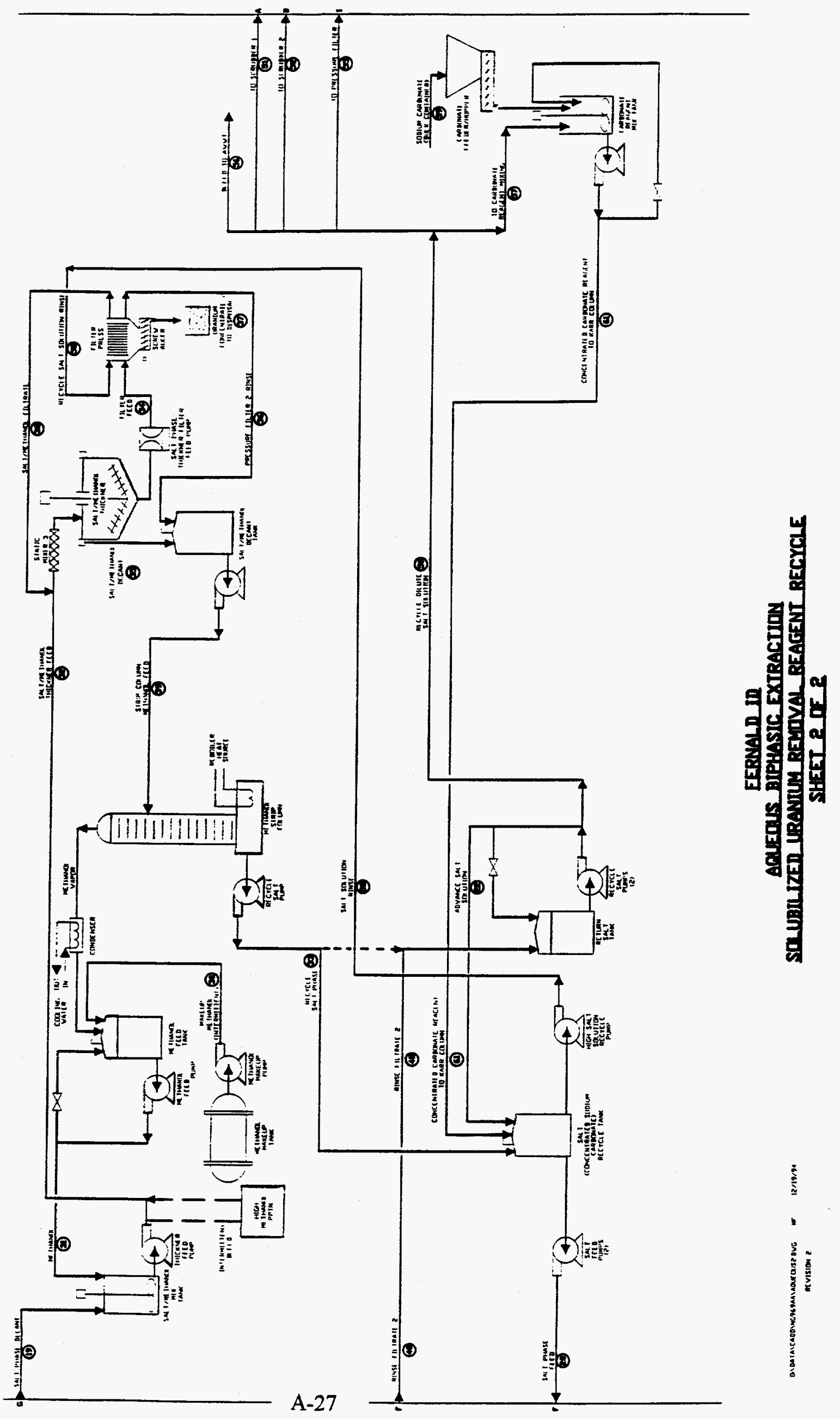




\section{APPENDIX B}

Equipment Cost Estimates for Soil Treatment Technologies 
Description of source column for the tables in Appendix B:

1) Vendor information or quote

2) Process Plant Construction Estimating Standards, Richardson's Engineering Services, Inc., 1994 Edition.

3) Mining and Mineral Processing Equipment Costs and Preliminary Capital Cost Estimations, Published by the Canadian Institute of Mining and Metallurgy, Volume 25.

4) Means Site Work and Landscape Cost Data, R.S. Means Company, Inc., 12th Annual Edition, 1993.

5) Cost estimating personnel at Halliburton NUS

6) Plant Design and Economics for Chemical Engineers, 4th Edition, Max S. Peters and Klaus D. Timmerhaus, 1991. 
Table B.1

Soil Preparation Building

\begin{tabular}{|c|c|c|c|c|c|}
\hline Item & Source & Item Description & Cost/Unit & Quantity & Total Cost \\
\hline 1 & 1 & Receiving Pit Bucket Loaders & - & 2 & - \\
2 & 1 & Pit Transfer Conveyers & - & 2 & - \\
3 & 1 & Main Conveyers & - & 2 & - \\
4 & 1 & Transfer Reversing Conveyors & - & 2 & - \\
5 & 1 & Coarse Material Conveyors & - & 2 & - \\
6 & 1 & Water Wash Trommel Feed Conveyor & - & 1 & - \\
7 & - & Total for 1 - 6 & $\$ 78,650$ & 1 & $\$ 78,650$ \\
8 & 1 & Storage Transfer Hoppers: 50 tonshr & $\$ 12,000$ & 2 & $\$ 24,000$ \\
9 & 1 & Grizzly Transfer Hopper: 80 tonshr & $\$ 12,000$ & 1 & $\$ 12,000$ \\
10 & 1 & Stored Soil Receiving Hopper: 30 tons/hr and associated feed regulator & $\$ 10,000$ & 1 & $\$ 10,000$ \\
11 & 1 & Feed Regulator for Stored Soil Receiving Hopper & $\$ 10,000$ & 1 & $\$ 10,000$ \\
12 & 1 & Coarse Material Hopper: 1 tonhr & $\$ 9,000$ & 1 & $\$ 9,000$ \\
13 & 1 & Main Trommel Feed Transfer Hopper, 30 tonshr & $\$ 10,000$ & 1 & $\$ 10,000$ \\
14 & 1 & Coarse Hopper & $\$ 9,000$ & 1 & $\$ 9,000$ \\
15 & 1 & Vibrating Grizzly: 36 x 60 (in), 6" opening,single deck, 80 tonshr, mild steel & $\$ 7,985$ & 1 & $\$ 7,985$ \\
16 & 1 & Coarse Material Trommel and Washer & $\$ 25,300$ & 1 & $\$ 25,300$ \\
17 & 5 & Overhead Crane System & $\$ 120,000$ & 1 & $\$ 120,000$ \\
18 & 1 & To, & $\$ 170,000$ & 1 & $\$ 170,000$ \\
\hline
\end{tabular}




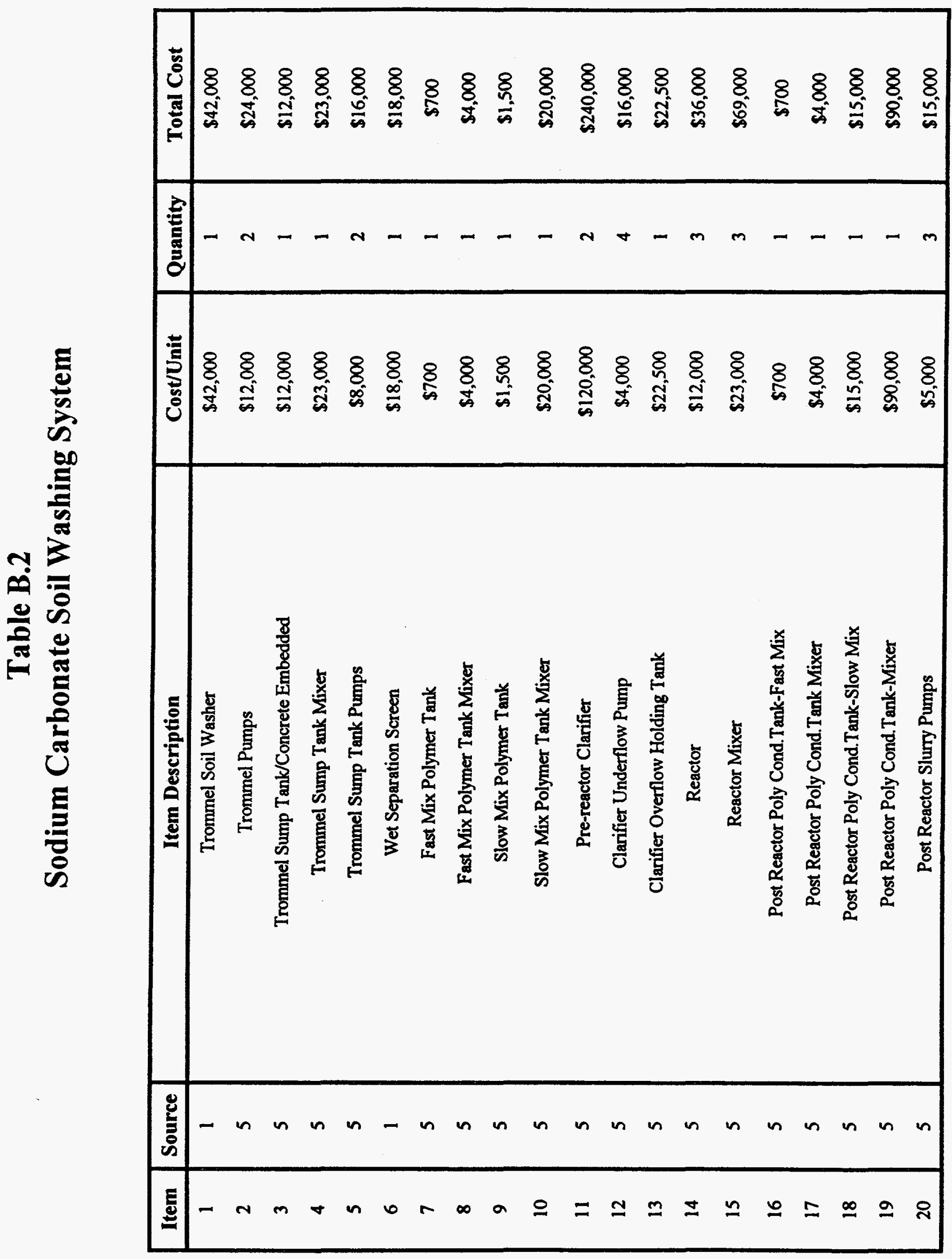




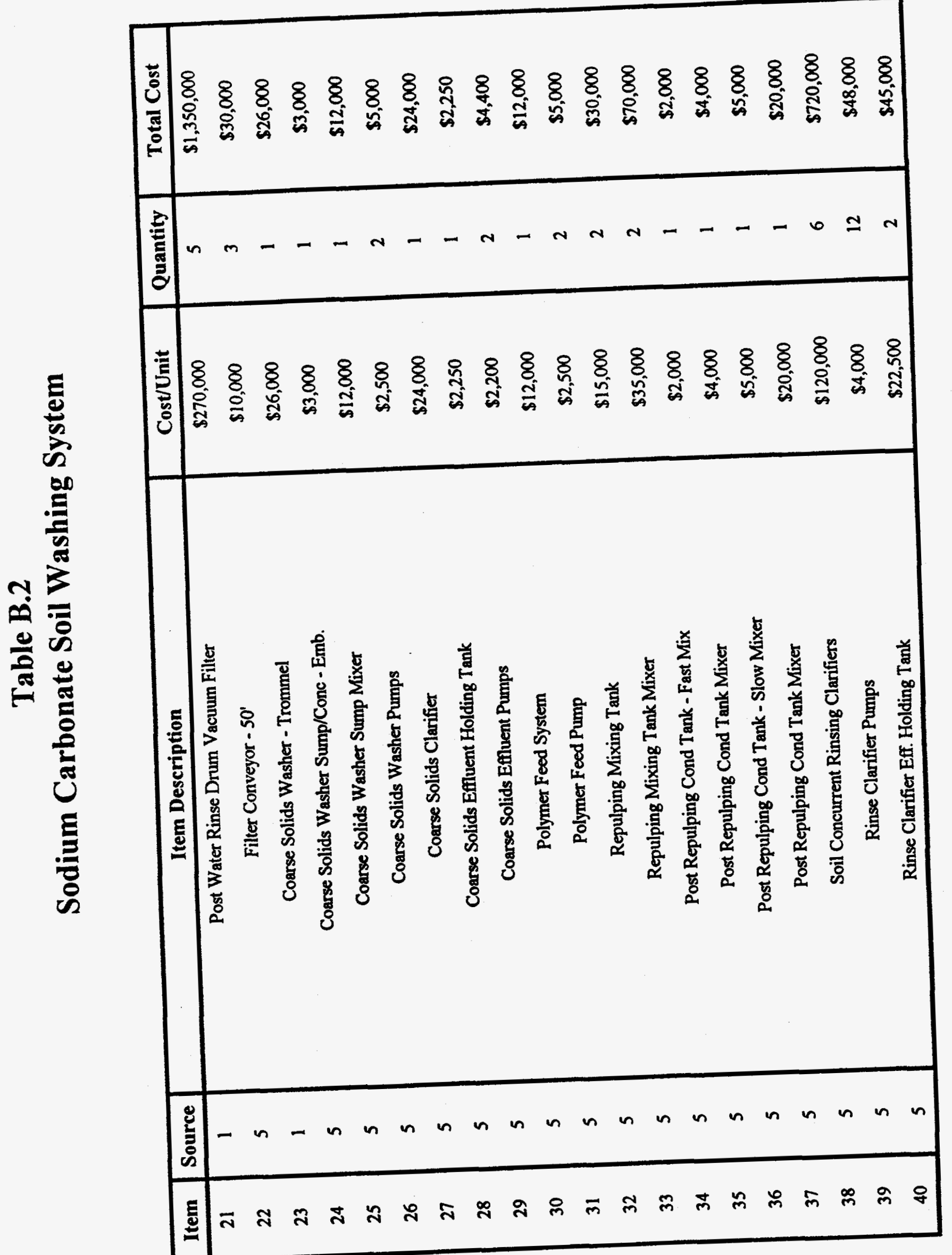


Table B.2

Sodium Carbonate Soil Washing System

\begin{tabular}{|c|c|c|c|c|c|}
\hline Item & Source & Item Description & Cost/Unit & Quantity & Total Cost \\
\hline 41 & 5 & Effluent Holding Tank Pumps & $\$ 8,000$ & 4 & $\$ 32,000$ \\
42 & 5 & Phosphoric Acid Feed System & $\$ 15,000$ & 1 & $\$ 15,000$ \\
43 & 5 & Phosphoric Acid Cond. Reactor & $\$ 8,800$ & 2 & $\$ 17,600$ \\
44 & 5 & Phosphoric Acid Cond Reactor Mixer & $\$ 35,000$ & 2 & $\$ 70,000$ \\
45 & 5 & Rinse Soil Cond Tank-Fast Mix & $\$ 700$ & 1 & $\$ 700$ \\
46 & 5 & Rinse Soil Cond Tank Mixer & $\$ 4,000$ & 1 & $\$ 4,000$ \\
47 & 5 & Rinse Soil Cond Tank-Slow Mix & $\$ 30,000$ & 1 & $\$ 330,000$ \\
48 & 5 & Rinse Soil Cond Tank Mixer & $\$ 90,000$ & 1 & $\$ 90,000$ \\
49 & 5 & Rinse Soil Cond Slurry Pumps & $\$ 5,000$ & 3 & $\$ 15,000$ \\
50 & 1 & Post Water Rinse Drum Vacuum Filter & $\$ 270,000$ & 5 & $\$ 1,350,000$ \\
51 & 5 & Filter Conveyor - 50' & $\$ 10,000$ & 3 & $\$ 30,000$ \\
52 & 5 & Extractant Filt Uranium Reactor Tank & $\$ 10,000$ & 1 & $\$ 10,000$ \\
53 & 5 & Extractant Filt Reactor Tank Mixer & $\$ 3,000$ & 1 & $\$ 3,000$ \\
54 & 5 & Filtrate Reactor Hold Tank & $\$ 50,000$ & 3 & $\$ 150,000$ \\
55 & 5 & Filtrate Reactor Hold Tank Mixer & $\$ 50,000$ & 3 & $\$ 150,000$ \\
56 & 5 & Filtrate Treatment Clarifier & $\$ 45,000$ & 1 & $\$ 45,000$ \\
57 & 5 & Filtrate Treatment Clarifier Pumps & $\$ 4,500$ & 2 & $\$ 9,000$ \\
58 & 5 & Filtrate Clarifier P \& F Filter & $\$ 30,000$ & 1 & $\$ 30,000$ \\
59 & 5 & Filtrate Trot Filter Conveyor - 20 & $\$ 5,000$ & 1 & $\$ 5,000$ \\
60 & 5 & Carbonation Reactor & $\$ 6,000$ & 1 & $\$ 6,000$ \\
\hline
\end{tabular}




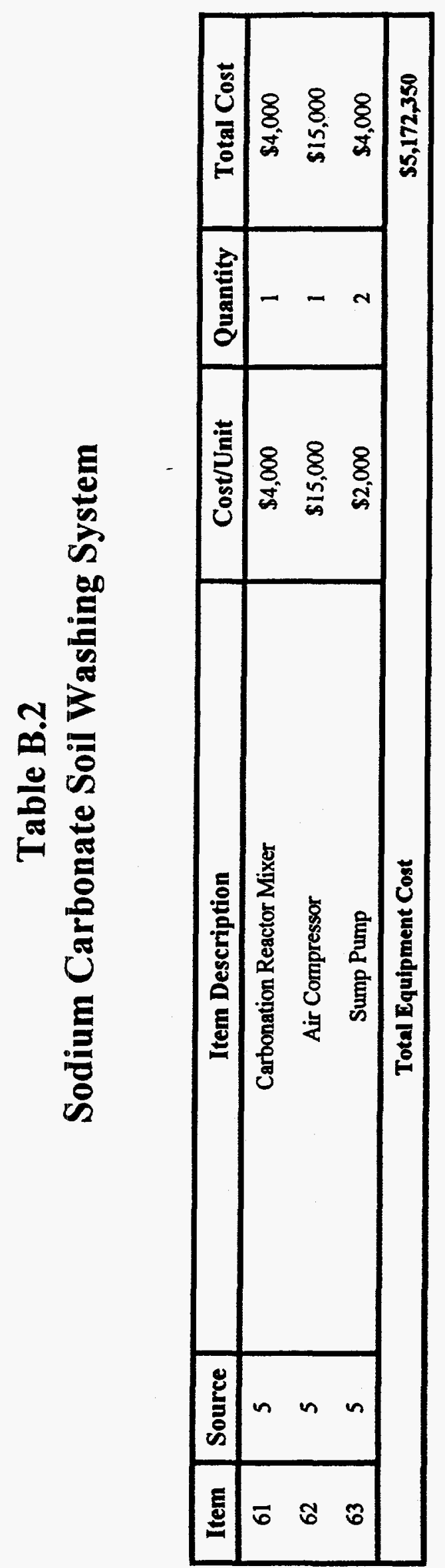


Table B.3

Sulfuric Acid Soil Washing System

\begin{tabular}{|c|c|c|c|c|c|}
\hline Item & Source & Item Description & Cost/Unit & Quantity & Total Cost \\
\hline 1 & 1 & Trommel Soil Washer & $\$ 42,000$ & 1 & $\$ 42,000$ \\
2 & 5 & Trommel Pumps & $\$ 12,000$ & 2 & $\$ 24,000$ \\
3 & 5 & Trommel Sump Tank/Concrete Embedded & $\$ 12,000$ & 1 & $\$ 12,000$ \\
4 & 5 & Trommel Sump Tank Mixer & $\$ 23,000$ & 1 & $\$ 23,000$ \\
5 & 5 & Trommel Sump Tank Pumps & $\$ 8,000$ & 2 & $\$ 16,000$ \\
6 & 1 & Wet Separation Screen & $\$ 18,000$ & 1 & $\$ 18,000$ \\
7 & 5 & Fast Mix Polymer Tank & $\$ 700$ & 1 & $\$ 700$ \\
8 & 5 & Fast Mix Polymer Tank Mixer & $\$ 4,000$ & 1 & $\$ 4,000$ \\
9 & 5 & Slow Mix Polymer Tank & $\$ 1,500$ & 1 & $\$ 1,500$ \\
10 & 5 & Slow Mix Polymer Tank Mixer & $\$ 20,000$ & 1 & $\$ 20,000$ \\
11 & 5 & Pre-Reactor Clarifier & $\$ 120,000$ & 2 & $\$ 240,000$ \\
12 & 5 & Clarifier Underflow Pump & $\$ 4,000$ & 4 & $\$ 16,000$ \\
13 & 5 & Clarifier Overflow Holding Tank & $\$ 22,500$ & 1 & $\$ 22,500$ \\
14 & 5 & Sulfuric Acid Storage Tank & $\$ 40,000$ & 7 & $\$ 280,000$ \\
15 & 5 & Sulfuric Acid Feed Pump & $\$ 6,000$ & 3 & $\$ 18,000$ \\
16 & 5 & Reactor & $\$ 12,000$ & 3 & $\$ 36,000$ \\
17 & 5 & Reactor Mixer & $\$ 23,000$ & 3 & $\$ 69,000$ \\
18 & 5 & 5 & $\$ 700$ & 1 & $\$ 700$ \\
19 & 5 & $\$ 4,000$ & 1 & $\$ 4,000$ \\
20 & 5 & Post Reactor Poly Cond.Tank - Fast Mix & $\$ 15,000$ & 1 & $\$ 15,000$ \\
\hline
\end{tabular}


Table B.3

Sulfuric Acid Soil Washing System

\begin{tabular}{|c|c|c|c|c|c|}
\hline Item & Source & Item Description & Cost/Unit & Quantity & Total Cost \\
\hline 21 & 5 & Post Reactor Poly Cond.Tank - Mixer & $\$ 90,000$ & 1 & $\$ 90,000$ \\
22 & 5 & Post Reactor Slurry Pumps & $\$ 5,000$ & 3 & $\$ 15,000$ \\
23 & 1 & Post Water Rinse Drum Vacuum Filter & $\$ 400,000$ & 5 & $\$ 2,000,000$ \\
24 & 5 & Filter Conveyor - 50 & $\$ 10,000$ & 3 & $\$ 30,000$ \\
25 & 1 & Coarse Solids Washer Trommel & $\$ 26,000$ & 1 & $\$ 26,000$ \\
26 & 5 & Coarse Solids Washer Sump/Conc Emb & $\$ 3,000$ & 1 & $\$ 3,000$ \\
27 & 5 & Coarse Solids Washer Sump Mixer & $\$ 12,000$ & 1 & $\$ 12,000$ \\
28 & 5 & Coarse Solids Washer Pumps & $\$ 2,500$ & 2 & $\$ 5,000$ \\
29 & 5 & Coarse Solids Clarifier & $\$ 24,000$ & 1 & $\$ 24,000$ \\
30 & 5 & Coarse Solids Effluent Holding Tank & $\$ 2,250$ & 1 & $\$ 2,250$ \\
31 & 5 & Coarse Solids Effluent Pumps & $\$ 2,200$ & 2 & $\$ 4,400$ \\
32 & 5 & Polymer Feed System & $\$ 12,000$ & 1 & $\$ 12,000$ \\
33 & 5 & Polymer Feed Pumps & $\$ 2,500$ & 2 & $\$ 5,000$ \\
34 & 5 & Repulping Mixing Tank & $\$ 15,000$ & 2 & $\$ 30,000$ \\
35 & 5 & Repulping Mixing Tank Mixer & $\$ 35,000$ & 2 & $\$ 70,000$ \\
36 & 5 & Lime Storage Silo & $\$ 125,000$ & 2 & $\$ 250,000$ \\
37 & 1 & Lime Slaker & $\$ 40,000$ & 1 & $\$ 40,000$ \\
38 & 5 & $\$ 1,500$ & 1 & $\$ 1,500$ \\
39 & 5 & $\$ 3,000$ & 1 & $\$ 3,000$ \\
40 & 5 & Lime Slurry Holding Tank - 10\% Slury & $\$ 2,500$ & 2 & $\$ 5,000$ \\
\hline
\end{tabular}


Table B.3

Sulfuric Acid Soil Washing System

\begin{tabular}{|c|c|c|c|c|c|}
\hline Item & Source & Item Description & Cost/Unit & Quantity & Total Cost \\
\hline 41 & 5 & Post Repulping Cond. Tank-Fast Mix & $\$ 2,000$ & 1 & $\$ 2,000$ \\
42 & 5 & Post Repulping Cond. Tank Mixer & $\$ 4,000$ & 1 & $\$ 4,000$ \\
43 & 5 & Post Repulping Cond. Tank-Slow Mix & $\$ 5,000$ & 1 & $\$ 5,000$ \\
44 & 5 & Post Repulping Cond. Tank Mixer & $\$ 20,000$ & 1 & $\$ 20,000$ \\
45 & 5 & Soil Concurrent Rinsing Clarifiers & $\$ 120,000$ & 6 & $\$ 720,000$ \\
46 & 5 & Rinse Clarifier Pumps & $\$ 4,000$ & 12 & $\$ 48,000$ \\
47 & 5 & Rinse Clarifier Eff. Holding Tank & $\$ 22,500$ & 2 & $\$ 45,000$ \\
48 & 5 & Efluent Holding Tank Pumps & $\$ 8,000$ & 4 & $\$ 32,000$ \\
49 & 5 & Phosphoric Acid Feed System & $\$ 15,000$ & 1 & $\$ 15,000$ \\
50 & 5 & Phosphoric Acid Cond. Reactor & $\$ 8,800$ & 2 & $\$ 17,600$ \\
51 & 5 & Phosphoric Acid Cond. Reactor Mixer & $\$ 35,000$ & 2 & $\$ 70,000$ \\
52 & 5 & Rinse Soil Cond. Tank-Fast Mix & $\$ 700$ & 1 & $\$ 700$ \\
53 & 5 & Rinse Soil Cond. Tank Mixer & $\$ 4,000$ & 1 & $\$ 4,000$ \\
54 & 5 & Rinse Soil Cond. Tank-Slow Mix & $\$ 30,000$ & 1 & $\$ 30,000$ \\
55 & 5 & Rinse Soil Cond. Tank Mixer & $\$ 9,000$ & 1 & $\$ 90,000$ \\
56 & 5 & Rinse Soil Cond. Slurry Pumps & $\$ 5,000$ & 3 & $\$ 15,000$ \\
57 & 1 & Post Water Rinse Filter - Vacuum Drum & $\$ 400,000$ & 5 & $\$ 2,000,000$ \\
58 & 5 & Filter Conveyor - 50 & $\$ 10,000$ & 3 & $\$ 30,000$ \\
59 & 5 & Acid Treatment System Holding Tank & $\$ 12,000$ & 1 & $\$ 12,000$ \\
60 & 5 & Acid Extractant Pumps & $\$ 7,000$ & 2 & $\$ 14,000$ \\
\hline
\end{tabular}


Table B.3

Sulfuric Acid Soil Washing System

\begin{tabular}{|c|c|c|c|c|c|}
\hline Item & Source & Item Description & Cost/Unit & Quantity & Total Cost \\
\hline 61 & 1 & Pressure Sand Filter & $\$ 95,000$ & 2 & $\$ 190,000$ \\
62 & 1 & Ion Exchange Unit & $\$ 66,000$ & 3 & $\$ 198,000$ \\
63 & 5 & Ion Exchange Sod. Chloride Mix Tank & $\$ 20,000$ & 1 & $\$ 20,000$ \\
64 & 5 & Ion Exchange Mix Tank Mixer & $\$ 22,000$ & 1 & $\$ 22,000$ \\
65 & 5 & Ion Exchange Pumps & $\$ 4,000$ & 2 & $\$ 8,000$ \\
66 & 5 & Ion Exchange Regenerant Surge Tank & $\$ 20,000$ & 1 & $\$ 20,000$ \\
67 & 5 & Uranium Prec. Reactor Tank & $\$ 800$ & 1 & $\$ 800$ \\
68 & 5 & Uranium Prec. Reactor Tank Mixer & $\$ 1,500$ & 1 & $\$ 1,500$ \\
69 & 5 & Caustic Feed System & $\$ 15,000$ & 1 & $\$ 15,000$ \\
70 & 5 & Uranium Reactor Hold Tank & $\$ 11,300$ & 1 & $\$ 11,300$ \\
71 & 5 & Uranium Reactor Hold Tank Mixer & $\$ 12,000$ & 1 & $\$ 12,000$ \\
72 & 5 & Uranium Prec. Treatment Clarifier & $\$ 15,000$ & 2 & $\$ 30,000$ \\
73 & 5 & Uranium Treatment Clarifier Pumps & $\$ 2,500$ & 2 & $\$ 5,000$ \\
74 & 5 & Filter Presses - each 10 cubic feet & $\$ 25,000$ & 2 & $\$ 50,000$ \\
75 & 5 & Neutralization Tank & $\$ 10,000$ & 1 & $\$ 10,000$ \\
76 & 5 & Neutralization Tank Mixer & $\$ 6,000$ & 1 & $\$ 6,000$ \\
77 & 5 & Fast Mix Polymer Tank & $\$ 400$ & 1 & $\$ 400$ \\
78 & 5 & Fast Mix Polymer Tank Mixer & $\$ 1,000$ & 1 & $\$ 1,000$ \\
79 & 5 & Slow Mix Polymer Tank & $\$ 800$ & 1 & $\$ 800$ \\
80 & 5 & Slow Mix Polymer Tank Mixer & $\$ 1,500$ & 1 & $\$ 1,500$ \\
\hline
\end{tabular}


Table B.3

Sulfuric Acid Soil Washing System

\begin{tabular}{|c|c|c|c|c|c|}
\hline Item & Source & Item Description & Cost/Unit & Quantity & Total Cost \\
\hline 81 & 5 & Clarifier & $\$ 66,000$ & 2 & $\$ 132,000$ \\
\hline 82 & 5 & Clarifier Underflow Pumps & $\$ 7,000$ & 4 & $\$ 28,000$ \\
\hline 83 & 1 & Plate \& Frame Filter Press & $\$ 50,000$ & 3 & $\$ 150,000$ \\
\hline 84 & 5 & Filter Cake Conveyor & $\$ 7,500$ & 1 & $\$ 7,500$ \\
\hline 85 & 5 & Air Compressor & $\$ 20,000$ & 2 & $\$ 40,000$ \\
\hline 86 & 5 & Sump Pump & $\$ 2,000$ & 2 & $\$ 4,000$ \\
\hline \multicolumn{5}{|c|}{ Total Equipment Cost } & $\$ 7,629,650$ \\
\hline
\end{tabular}


Table B.4

Citric Acid Soil Washing System

\begin{tabular}{|c|c|c|c|c|c|}
\hline Item & Source & Item Description & Cost/Unit & Quantity & Total Cost \\
\hline 1 & 1 & Trommel Soil Washer & $\$ 42,000$ & 1 & $\$ 42,000$ \\
2 & 5 & Trommel Pumps & $\$ 12,000$ & 2 & $\$ 24,000$ \\
\hline & 5 & Trommel Sump & $\$ 12,000$ & 1 & $\$ 12,000$ \\
\hline & 5 & Trommel Sump Mixer & $\$ 23,000$ & 1 & $\$ 23,000$ \\
$\mathbf{S}$ & 5 & Trommel Sump Pumps & $\$ 8,000$ & 2 & $\$ 16,000$ \\
6 & 1 & Wet Separation Screen & $\$ 18,000$ & 1 & $\$ 18,000$ \\
7 & 5 & Fast Mix Polymer Tank & $\$ 700$ & 1 & $\$ 700$ \\
8 & 5 & Fast Mix Polymer Tank Mixer & $\$ 4,000$ & 1 & $\$ 4,000$ \\
9 & 5 & Slow Mix Polymer Tank & $\$ 1,500$ & 1 & $\$ 1,500$ \\
10 & 5 & Slow Mix Polymer Tank Mixer & $\$ 20,000$ & 1 & $\$ 20,000$ \\
11 & 5 & Post-Reactor Clarifiers & $\$ 120,000$ & 2 & $\$ 240,000$ \\
12 & 5 & Clarifier Underflow Pumps & $\$ 4,000$ & 4 & $\$ 16,000$ \\
13 & 5 & Clarifier Overflow Holding Tank & $\$ 22,500$ & 1 & $\$ 22,500$ \\
14 & 5 & Reactor & $\$ 4,000$ & 2 & $\$ 80,000$ \\
15 & 5 & Reactor Mixers & $\$ 50,000$ & 4 & $\$ 200,000$ \\
16 & 1 & Post-Reactor Filters - Vacuum Drum & $\$ 270,000$ & 5 & $\$ 1,350,000$ \\
17 & 5 & Filter Conveyer - Open Belt - 50 feet & $\$ 30,000$ & 1 & $\$ 30,000$ \\
18 & 1 & Coarse Solids Washer & $\$ 26,000$ & 1 & $\$ 26,000$ \\
19 & 5 & $\$ 3,000$ & 1 & $\$ 3,000$ \\
20 & 5 & Coarse Solids Washer Sump - Steel Tank Emb. & $\$ 12,000$ & 1 & $\$ 12,000$ \\
\hline
\end{tabular}


Table B.4

Citric Acid Soil Washing System

\begin{tabular}{|c|c|c|c|c|c|}
\hline Item & Source & Item Description & Cost/Unit & Quantity & Total Cost \\
\hline 21 & 5 & Coarse Solids Washer Sump Pumps & $\$ 2,500$ & 2 & $\$ 5,000$ \\
22 & 5 & Coarse Solids Clarifier & $\$ 24,000$ & 1 & $\$ 24,000$ \\
23 & 5 & Coarse Solids Effluent Holding Tank & $\$ 2,250$ & 1 & $\$ 2,250$ \\
24 & 5 & Coarse Solids Effluent Holding Tank Pumps & $\$ 2,200$ & 2 & $\$ 4,400$ \\
25 & 5 & Polymer Mix Tank with Bin Feeder & $\$ 6,000$ & 2 & $\$ 12,000$ \\
26 & 5 & Polymer Mix Tank Pumps & $\$ 2,500$ & 2 & $\$ 5,000$ \\
27 & 5 & Repulping Mixing Tank & $\$ 15,000$ & 2 & $\$ 30,000$ \\
28 & 5 & Repulping Mixing Tank Mixer & $\$ 35,000$ & 2 & $\$ 70,000$ \\
29 & 5 & Lime Storage Silos & $\$ 125,000$ & 2 & $\$ 250,000$ \\
30 & 1 & S & $\$ 44,100$ & 1 & $\$ 44,100$ \\
31 & 5 & Lime Slaker - Max Capacity 2,500lbs/hr ave 1500 lbs/hr & $\$ 1,500$ & 1 & $\$ 1,500$ \\
32 & 5 & Slurried Lime Holding Tank - 10\% Slurry & $\$ 3,000$ & 1 & $\$ 3,000$ \\
33 & 5 & Slurried Lime Holding Tank - 10\% Slurry Mixer & $\$ 2,500$ & 2 & $\$ 5,000$ \\
34 & 5 & Slurried Lime Holding Tank - 10\% Slurry Pump & $\$ 2,000$ & 1 & $\$ 2,000$ \\
35 & 5 & Post-Repulping Polymer Cond Tank - Fast Mix & $\$ 4,000$ & 1 & $\$ 4,000$ \\
36 & 5 & Post-Repulping Polymer Cond Tank Mixer - Fast Mix & $\$ 24,000$ & 1 & $\$ 24,000$ \\
37 & 5 & Post-Repulping Polymer Cond Tank - Slow Mix & $\$ 20,000$ & 1 & $\$ 20,000$ \\
38 & 5 & Post-Repulping Polymer Cond Tank Mixer - Slow Mix & $\$ 120,000$ & 6 & $\$ 720,000$ \\
39 & 5 & Soil Concurrent Rinsing Clarifiers & $\$ 4,000$ & 12 & $\$ 48,000$ \\
40 & 5 & Rinse Clarifier Pumps & $\$ 22,500$ & 2 & $\$ 45,000$ \\
\hline
\end{tabular}


Table B.4

Citric Acid Soil Washing System

\begin{tabular}{|c|c|c|c|c|c|}
\hline Item & Source & Item Description & Cost/Unit & Quantity & Total Cost \\
\hline 41 & 5 & Efluent Holding Tank Pumps & $\$ 8,000$ & 4 & $\$ 32,000$ \\
42 & 5 & $\$ 700$ & 1 & $\$ 700$ \\
43 & 5 & Rinsed Soil Polymer Conditioning Tank - Fast Mix & $\$ 4,000$ & 1 & $\$ 4,000$ \\
44 & 5 & Rinsed Soil Polymer Conditioning Tank Mixer - Fast Mix & $\$ 30,000$ & 1 & $\$ 30,000$ \\
45 & 5 & Rinsed Soil Polymer Conditioning Tank - Slow Mix & $\$ 90,000$ & 1 & $\$ \$ 0,000$ \\
46 & 5 & Rinsed Soil Polymer Conditioning Tank Mixer - Slow Mix & $\$ 5,000$ & 3 & $\$ 15,000$ \\
47 & 1 & Rinsed Soil Poly. Cond. Tank - Slow Mix Pump & $\$ 270,000$ & 5 & $\$ 1,350,000$ \\
48 & 5 & Post-Water Rinse Filters - Vacuum Drum & $\$ 10,000$ & 3 & $\$ 30,000$ \\
49 & 5 & Filter Conveyor - Open Belt & $\$ 20,000$ & 1 & $\$ 20,000$ \\
50 & 5 & Water Rinse Holding Tank & $\$ 7,000$ & 2 & $\$ 14,000$ \\
51 & 1 & Hold Tank Pumps & $\$ 95,000$ & 3 & $\$ 285,000$ \\
52 & 1 & Sand Filters (Pressure) & $\$ 66,000$ & 4 & $\$ 264,000$ \\
53 & 5 & Ion Exchanger & $\$ 20,000$ & 1 & $\$ 20,000$ \\
54 & 5 & In Exchange Resin Sodium Chloride Mix Tank & $\$ 22,000$ & 1 & $\$ 22,000$ \\
55 & 5 & Ion Exchange Resin Sodium Chloride Tank Mixer & $\$ 4,000$ & 2 & $\$ 8,000$ \\
56 & 5 & Ion Exchange Resin Sodium Chloride Tank Pump & $\$ 20,000$ & 1 & $\$ 20,000$ \\
57 & 5 & Ion Exchange Regenerant Surge Tank & $\$ 2,500$ & 2 & $\$ 5,000$ \\
58 & 5 & Ion Exchange Regenerant Surge Tank Pump & $\$ 800$ & 1 & $\$ 800$ \\
59 & 5 & Uranium Precipitation Reactor Tank & $\$ 750$ & 2 & $\$ 1,500$ \\
60 & 5 & Uranium Precipitation Reactor Tank Mixer & $\$ 11,300$ & 1 & $\$ 11,300$ \\
\hline
\end{tabular}


Table B.4

\section{Citric Acid Soil Washing System}

\begin{tabular}{|c|c|c|c|c|c|}
\hline Item & Source & Item Description & Cost/Unit & Quantity & Total Cost \\
\hline 61 & 5 & Uranium Reaction Hold Tank Mixer & $\$ 12,000$ & 1 & $\$ 12,000$ \\
\hline 62 & 5 & Uranium Precipitator Clarifier - 10 gpm Avg. Design 20 gpm & $\$ 15,000$ & 2 & $\$ 30,000$ \\
\hline 63 & 5 & Clarifier Underflow Pumps & $\$ 2,500$ & 2 & $\$ 5,000$ \\
\hline 64 & 5 & Filter Presses - each $10 \mathrm{ft}^{3}$ & $\$ 25,000$ & 2 & $\$ 50,000$ \\
\hline 65 & 1 & Vacuum Compression Evaporator/Crystallizer - 600 gpm & $\$ 8,000,000$ & 1 & $\$ 8,000,000$ \\
\hline 66 & 5 & Air Compressor & $\$ 15,000$ & 1 & $\$ 15,000$ \\
\hline 67 & 5 & Sump Pump & $\$ 2,000$ & 2 & $\$ 4,000$ \\
\hline \multicolumn{5}{|c|}{ Total Equipment Cost } & $\$ 13,799,250$ \\
\hline
\end{tabular}

$\frac{1}{\frac{1}{\sigma}}$ 


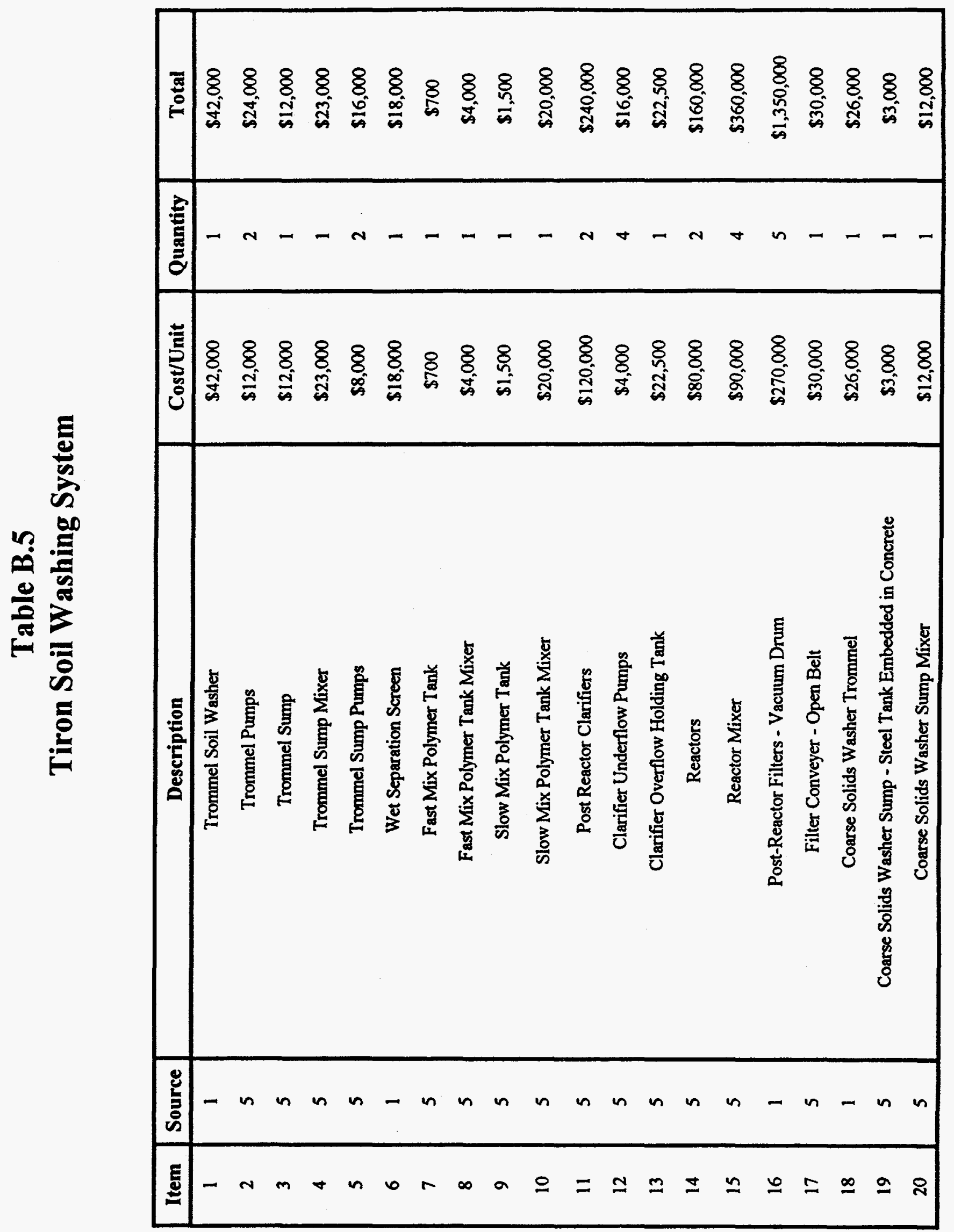




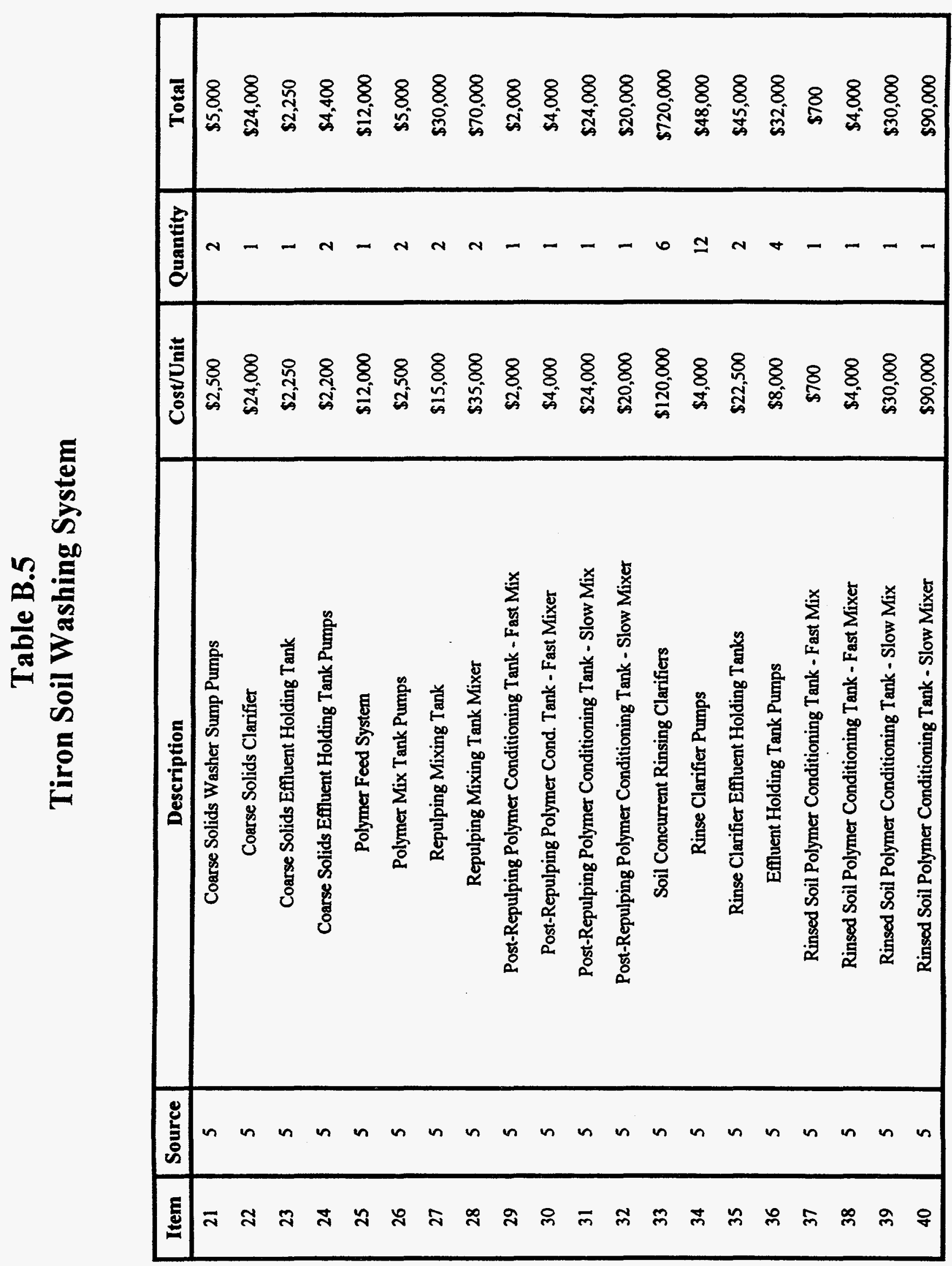




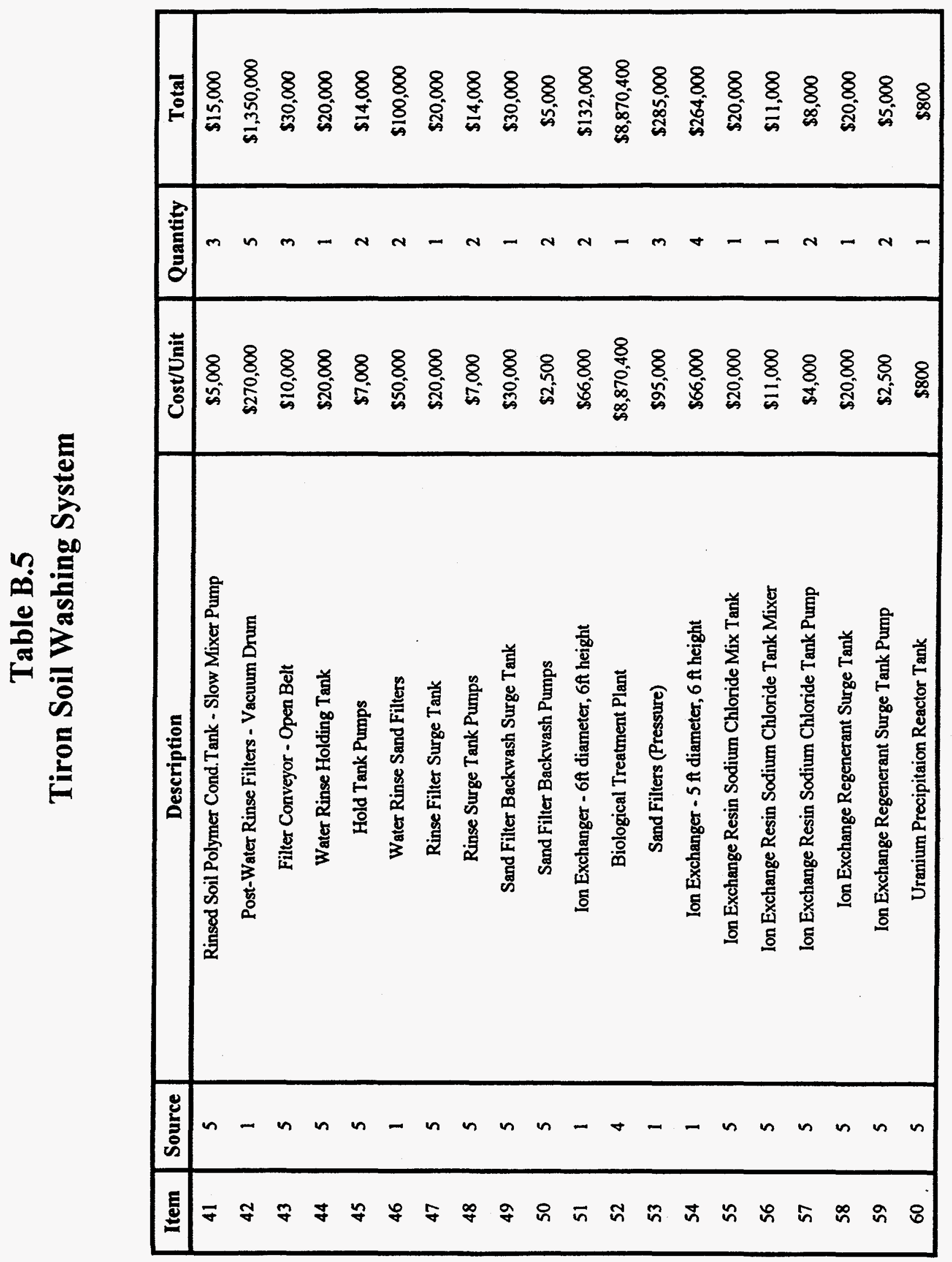




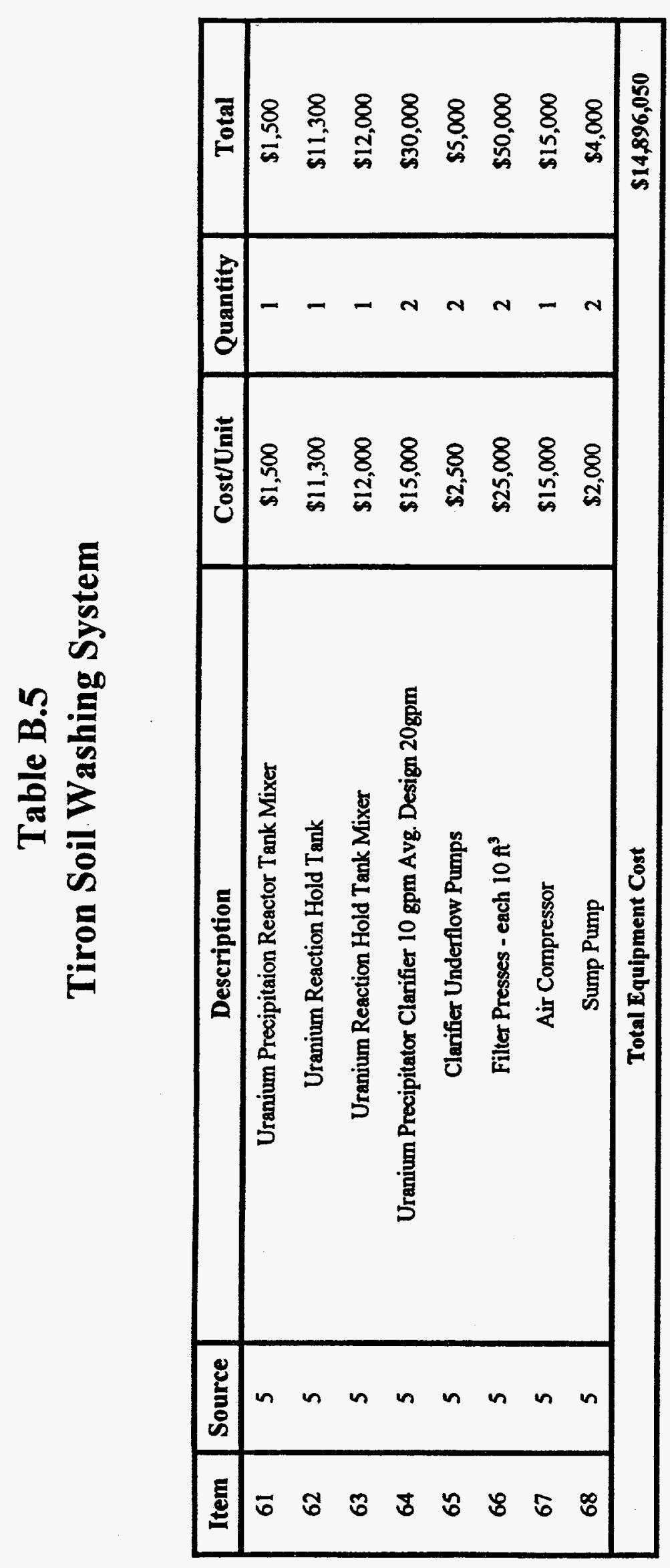


Table B.6

Heap Leaching System

\begin{tabular}{|c|c|c|c|c|c|}
\hline Item & Source & Item Description & Cost/Unit & Quantity & Total Cost \\
\hline 1 & $5 \& 1$ & Main Conveyor - 500' & $\$ 200,000$ & 1 & $\$ 200,000$ \\
\hline 2 & 5 & Overhead Crane Conveyor & $\$ 120,000$ & 2 & $\$ 240,000$ \\
\hline 3 & 1 & Hoppers & $\$ 25,000$ & 4 & $\$ 100,000$ \\
\hline 4 & 5 & Acid Feed Tank & $\$ 30,000$ & 1 & $\$ 30,000$ \\
\hline 5 & 5 & Acid Feed Pumps & $\$ 8,000$ & 2 & $\$ 16,000$ \\
\hline 6 & 5 & Sodium Carb/Carbonate Storage Silo & $\$ 160,000$ & 4 & $\$ 640,000$ \\
\hline 7 & 5 & Neat, 1st Cycle, Last Lix. Storage Tank & $\$ 40,000$ & 3 & $\$ 120,000$ \\
\hline 8 & 5 & Neat, 1st Cycle, Last Lix. Pumps & $\$ 10,000$ & 6 & $\$ 60,000$ \\
\hline 9 & 5 & Drainage Sump/Conc Emb & $\$ 12,000$ & 4 & $\$ 48,000$ \\
\hline 10 & 5 & Drainage Sump Pumps & 59,000 & 8 & $\$ 72,000$ \\
\hline 11 & 5 & PH Adjustment Tanks & $\$ 16,000$ & 2 & $\$ 32,000$ \\
\hline 12 & 5 & PH Adjustment Tank Mixer & $\$ 4,000$ & 2 & $\$ 8,000$ \\
\hline 13 & 5 & Uranium Precipitation Reactors & $\$ 75,000$ & 3 & $\$ 225,000$ \\
\hline 14 & 5 & Uranium Precipitation Reactor Mixers & $\$ 80,000$ & 3 & $\$ 240,000$ \\
\hline 15 & 5 & Clarifier & $\$ 84,000$ & 2 & $\$ 168,000$ \\
\hline 16 & 5 & Clarifier Underflow Pumps & $\$ 5,000$ & 4 & $\$ 20,000$ \\
\hline 17 & 5 & Filter Press & $\$ 25,000$ & 2 & $\$ 50,000$ \\
\hline 18 & 5 & Air Compressor & $\$ 15,000$ & 1 & $\$ 15,000$ \\
\hline 19 & 5 & Sump Pump & $\$ 2,000$ & 2 & $\$ 4,000$ \\
\hline 20 & 1 & 100,000 CFM Baghouse Collection System & $\$ 200,000$ & 1 & $\$ 200,000$ \\
\hline & & Total Equipment Cost & & & $\$ 2,488,000.00$ \\
\hline
\end{tabular}


Table B.7

\section{Fungal Leaching Process}

\begin{tabular}{|c|c|c|c|c|c|}
\hline Item & Source & Item Description & Cost/Unit & Quantity & Total Cost \\
\hline 1 & 2 & Railcar Corn Syrup Transfer Pumps & $\$ 4,934$ & 2 & $\$ 9,868$ \\
2 & 2 & Railcar Methanol Transfer Pumps & $\$ 4,821$ & 2 & $\$ 9,642$ \\
3 & 5 & Urea Transfer Pumps & $\$ 2,500$ & 2 & $\$ 5,000$ \\
4 & 5 & Phosphoric Acid Transfer Pumps & $\$ 2,500$ & 2 & $\$ 5,000$ \\
5 & 5 & Corn Syrup Metering Pumps & $\$ 2,500$ & 2 & $\$ 5,000$ \\
6 & 2 & Methanol Metering Pumps & $\$ 3,500$ & 2 & $\$ 7,000$ \\
7 & 2 & Urea Metering Pumps & $\$ 3,420$ & 2 & $\$ 6,840$ \\
8 & 2 & Phosphoric Acid Metering Pumps & $\$ 3,920$ & 2 & $\$ 7,840$ \\
9 & 2 & Micronutrient Metering Pumps & $\$ 3,420$ & 2 & $\$ 6,840$ \\
10 & 2 & Feed Pumps & $\$ 4,176$ & 2 & $\$ 8,352$ \\
11 & 2 & Cooling Water Pumps & $\$ 7,973$ & 2 & $\$ 15,946$ \\
12 & 2 & Biomass Transfer Pumps & $\$ 6,479$ & 2 & $\$ 12,958$ \\
13 & 2 & Lixiviant Transfer Pumps & $\$ 5,655$ & 2 & $\$ 11,310$ \\
14 & 5 & Corn Syrup Tank & $\$ 126,000$ & 1 & $\$ 126,000$ \\
15 & 5 & Methanol Tank & $\$ 80,000$ & 1 & $\$ 80,000$ \\
16 & 1 & Urea Tank & $\$ 7,500$ & 1 & $\$ 7,500$ \\
17 & $1 \& 3$ & Phosphoric Acid Tank & $\$ 750$ & 1 & $\$ 750$ \\
18 & $1 \& 3$ & Micronutrients Tank & $\$ 1,300$ & 1 & $\$ 1,300$ \\
19 & 5 & Blending Tank & $\$ 5,800$ & 1 & $\$ 5,800$ \\
20 & 5 & Biosolids Tank & $\$ 12,000$ & 1 & $\$ 12,000$ \\
\hline
\end{tabular}




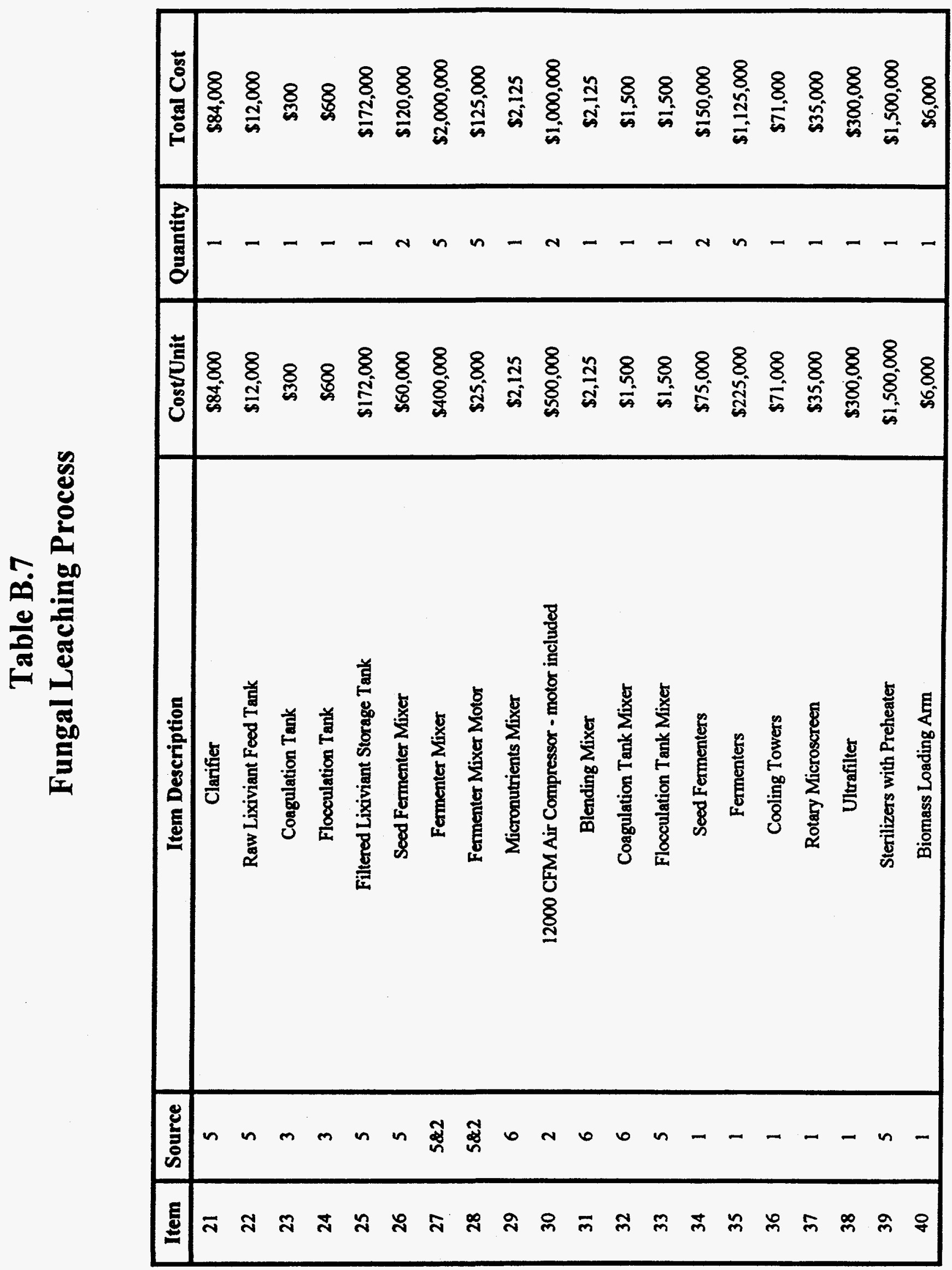


Table B.7

Fungal Leaching Process

\begin{tabular}{|c|c|c|c|c|c|}
\hline Item & Source & Item Description & Cost/Unit & Quantity & Total Cost \\
\hline 41 & 5 & Polymer Feed System & $\$ 17,000$ & 1 & $\$ 17,000$ \\
42 & $1 \& 3$ & Continuous lon Exchange System & $\$ 54,000$ & 1 & $\$ 54,000$ \\
43 & 5 & Reverse Osmosis System & $\$ 2,000,000$ & 1 & $\$ 2,000,000$ \\
44 & 5 & Evaporator & $\$ 150,000$ & 1 & $\$ 150,000$ \\
45 & 5 & Evaporator/Crystallizer System & $\$ 2,500,000$ & 1 & $\$ 2,500,000$ \\
46 & 5 & Wet Air Oxidation System & $\$ 8,000,000$ & 1 & $\$ 8,000,000$ \\
47 & 1 & Heat Exchanger & $\$ 15,000$ & 1 & $\$ 15,000$ \\
48 & 5 & WAO Blowdown Treatment System & $\$ 200,000$ & 2 & $\$ 400,000$ \\
49 & 1 & Brine Feed Tank & $\$ 3,200$ & 1 & $\$ 3,200$ \\
50 & 1 & Hydrochloric and Storage Tank & $\$ 30,000$ & 1 & $\$ 30,000$ \\
51 & 1 & Acidification Tank & $\$ 11,000$ & 1 & $\$ 11,000$ \\
52 & 1 & Permeate Recycle Tank & $\$ 10,500$ & 1 & $\$ 10,500$ \\
53 & 1 & Condensed Overhead Tank & $\$ 250$ & 1 & $\$ 250$ \\
54 & 1 & Reject Tank & $\$ 6,500$ & 1 & $\$ 6,500$ \\
55 & 5 & Caustic Tank & $\$ 12,000$ & 1 & $\$ 12,000$ \\
56 & 2 & Brine Metering Pumps & $\$ 4,000$ & 2 & $\$ 8,000$ \\
57 & 2 & Rail Car Acid Transfer Pumps & $\$ 3,018$ & 2 & $\$ 6,036$ \\
58 & 2 & Acid Metering Pumps & $\$ 4,327$ & 2 & $\$ 8,654$ \\
59 & 2 & Citric Acid Blowdown Pumps & $\$ 3,358$ & 2 & $\$ 6,716$ \\
60 & 2 & Lixiviant Recycle Pumps & $\$ 4,312$ & 2 & $\$ 8,624$ \\
\hline
\end{tabular}




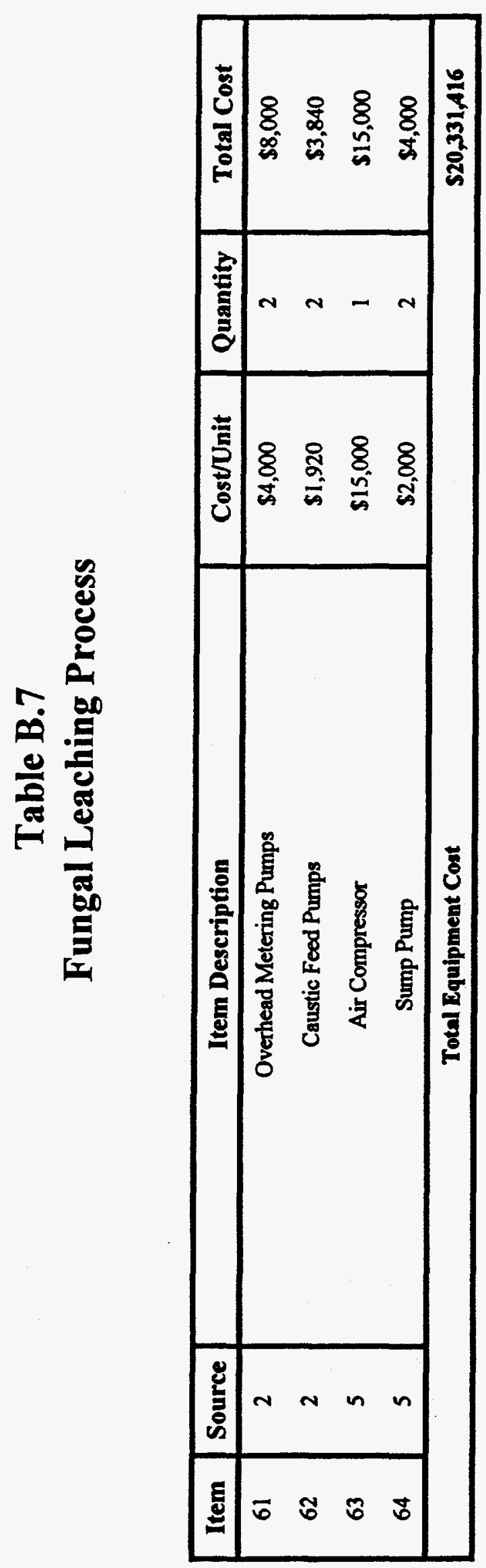

B-25 
Table B.8

Aqueous Biphasic Extraction

\begin{tabular}{|c|c|c|c|c|c|}
\hline Item & Source & Item Description & Cost/Unit & Quantity & Total Cost \\
\hline 1 & 1 & Grizzly Feed Conveyor (@ \$600/ft) & $\$ 60,000$ & 1 & $\$ 60,000$ \\
\hline 2 & 5 & Dry grizzly & $\$ 40,000$ & 1 & $\$ 40,000$ \\
\hline 3 & 5 & Drum Scrubber 1 with trommel screen & $\$ 90,000$ & 1 & $\$ 90,000$ \\
\hline 4 & 5 & Drum Scrubber 2 with trommel screen & $\$ 150,000$ & 1 & $\$ 150,000$ \\
\hline 5 & 5 & O/S Soil Transport Conveyor (@\$600/t) & $\$ 60,000$ & 1 & $\$ 60,000$ \\
\hline 6 & 5 & Washing \& Dewatering Screen $\left(6^{\prime} \times 8^{\prime}\right.$ screen deck) & $\$ 40,000$ & 1 & $\$ 40,000$ \\
\hline 7 & 5 & Slurry Pump and Sump ( 1 pump \& 1 standby, $150 \mathrm{gpm} \& 50 \mathrm{TDII}$ ) & $\$ 7,000$ & 2 & $\$ 14,000$ \\
\hline 8 & 5 & Agitated 1 lolding Tank (15,000 gallon carbon steel shell) & $\$ 30,000$ & 1 & $\$ 30,000$ \\
\hline 9 & 5 & Holding Tank Mixer ( $15 \mathrm{HP}$ motor, 72 in dia. impellor) & $\$ 14,600$ & 1 & $\$ 14,600$ \\
\hline 10 & 5 & Feed Pumps (centrifugal, 250 gpm max. output, $65 \mathrm{ft} \mathrm{TDH,} 20 \mathrm{HP}$ ) & $\$ 9,000$ & 2 & $\$ 18,000$ \\
\hline 11 & 5 & Vibrating Screen (48 in. $x 96$ in. with 3.5 HP motor) & $\$ 40,000$ & 1 & $\$ 40,000$ \\
\hline 12 & 5 & Static Mixer 1 (1.5 in. $x 18$ in., $316 \mathrm{SS}$ shell, $50 \mathrm{gpm})$ & $\$ 1,500$ & 1 & $\$ 1,500$ \\
\hline 13 & 5 & Static Mixer 2 (4 in. $\times 24$ in., $316 \mathrm{SS}, 300 \mathrm{gpm})$ & $\$ 5,000$ & 1 & $\$ 5,000$ \\
\hline 14 & 5 & Dry Flocculant I lopper/Feeder (.65 lb floc/ton soil solids, $5 \mathrm{cu}$ ft hopper) & $\$ 15,000$ & 1 & $\$ 15,000$ \\
\hline 15 & 5 & Flocculant Mix Tank (1000 gallons, 6 dia. x $6 \mathrm{fth}, 316 \mathrm{SS}$, mixer bridge) & $\$ 4,000$ & 1 & $\$ 4,000$ \\
\hline 16 & 5 & Flocculant Mix Tank Agitator ( $5 \mathrm{HP}$ motor, 30 in impellor, variable speed) & $\$ 10,000$ & 1 & $\$ 10,000$ \\
\hline 17 & 5 & Flocculant Metering Pump (dual diaphragm, 0-160 gpm, $2 \mathrm{HP}$ var. motor) & $\$ 17,500$ & 1 & $\$ 17,500$ \\
\hline 18 & 5 & PEG Thickener (250 gpm feed, $28 \mathrm{fl}$ dia., $10 \mathrm{ft}$ high, with rake, $15 \mathrm{HP}$ ) & $\$ 150,000$ & 1 & $\$ 150,000$ \\
\hline 19 & 5 & PEG Makeup Tank ( $6^{\prime}$ x $8^{\prime}$ cyl. tank, 1000 gal., $316 \mathrm{SS}$, mixer bridge) & $\$ 4,000$ & 1 & $\$ 4,000$ \\
\hline 20 & 5 & PEG Makeup Tank Agitator (5 HP var. sp. motor, 30 in dia impellor) & $\$ 10,000$ & 1 & $\$ 10,000$ \\
\hline
\end{tabular}


Table B.8

\section{Aqueous Biphasic Extraction}

\begin{tabular}{|c|c|c|c|c|c|}
\hline Item & Source & Item Description & Cost/Unit & Quantity & Total Cost \\
\hline 21 & 5 & PEG Makeup Pump (centrifugal, $200 \mathrm{gpm}, 65^{\prime}$ head, $15 \mathrm{HP}$ ) & $\$ 5,000$ & 1 & $\$ 5,000$ \\
\hline 22 & 5 & PEG Recycle Tank $(9,000$ gallons max., 4,500 gpm WV, 12'D x 12' H) & $\$ 18,000$ & 1 & $\$ 18,000$ \\
\hline 23 & 5 & PIEG Recycle Pumps (centrifugal, $225 \mathrm{gpm}, 65^{\prime}$ head, $15 \mathrm{HIP}$ ) & $\$ 5,000$ & 2 & $\$ 10,000$ \\
\hline 24 & 5 & PEG Repulp Tank (6' $\times 8^{\prime}$ cyl. tank, $1000 \mathrm{gal}$. WV, $316 \mathrm{SS}$, mixer bridge) & $\$ 4,000$ & 1 & $\$ 4,000$ \\
\hline 25 & $\mathbf{I}$ & Karr Columns $\left(6^{\prime} \mathrm{D} \times 10^{\prime} \mathrm{H}\right.$, rotating $5 \mathrm{HP}$ drive, $340 \mathrm{gpm}$ net flow) & $\$ 380,000$ & 5 & $\$ 1,900,000$ \\
\hline 26 & 5 & Karr Column PI:G U/F Pumps (centrifugal, $350 \mathrm{gpm}, 65^{\prime}$ head, $20 \mathrm{HIP}$ ) & $\$ 9,000$ & 2 & $\$ 18,000$ \\
\hline 27 & 5 & Static Mixer 3 (150 gpm max, $316 \mathrm{SS})$ & $\$ 4,500$ & 1 & $\$ 4,500$ \\
\hline 28 & 5 & Salt Phase Thickener (20' dia., 8' sidewalls, rake, $10 \mathrm{HP}$ ) & $\$ 95,000$ & 1 & $\$ 95,000$ \\
\hline 29 & 5 & PEG Thickener Underflow Pumps (dual diaphragm, 0-75 gpm, 100 psig) & $\$ 5,000$ & 2 & $\$ 10,000$ \\
\hline 30 & 5 & Salt Thickener Underflow Pumps (dual diaphragm, 0-20 gpm, $100 \mathrm{psig}$ ) & $\$ 2,500$ & 2 & $\$ 5,000$ \\
\hline 31 & 5 & Recessed Plate Concentrate Filter (plate filter press, 27.3 cu ft capacity) & $\$ 20,000$ & 1 & $\$ 20,000$ \\
\hline 32 & 5 & Horizontal Pressure lillters (LAROX PF-16, belt type, 409 sq ff FA, 25 HP) & $\$ 400,000$ & 2 & $\$ 800,000$ \\
\hline 33 & 5 & Washed Soil Conveyor (@ \$600/ft) (24 in x 100 L, 4 in sidewalls) & $\$ 60,000$ & 1 & $\$ 60,000$ \\
\hline 34 & 5 & Salt/Methanol Mix Tank ( $8^{\prime}$ x $8^{\prime}$ cyl. tank, 2000 gallon WV, 316SS) & $\$ 8,000$ & 1 & $\$ 8,000$ \\
\hline 35 & 5 & Pl:G Repulp Tank Agitator ( $10 \mathrm{HP}$ motor, 42 in dia. impellor) & $\$ 13,500$ & 1 & $\$ 13,500$ \\
\hline 36 & 5 & Salt/Meth. Thickener Feed Pumps (centrifugal, 350 gpm max., $65^{\prime}$ head) & $\$ 9,000$ & 2 & $\$ 18,000$ \\
\hline 37 & 5 & Static Mixer 4 (250 gpm max, $316 \mathrm{SS})$ & $\$ 4,500$ & 1 & $\$ 4,500$ \\
\hline 38 & 5 & SaluMethanol Thickener (20' dia, 8 ' sidewalls, rake, $10 \mathrm{HP}$ ) & $\$ 95,000$ & 1 & $\$ 95,000$ \\
\hline 39 & 5 & Salt/Methanol Thickener Underflow Pumps (dual diaphragm, 0-20 gpm) & $\$ 2,500$ & 2 & $\$ 5,000$ \\
\hline 40 & 5 & Recessed Plate Precipitate Filters (plate filter press, $54.6 \mathrm{cu}$ ft capacity) & $\$ 18,000$ & 2 & $\$ 36,000$ \\
\hline
\end{tabular}


Table B.8

\section{Aqueous Biphasic Extraction}

\begin{tabular}{|c|c|c|c|c|c|}
\hline Item & Source & Item Description & Cost/Unit & Quantity & Total Cost \\
\hline 41 & 5 & Air Compressors (150 psig, $50 \mathrm{HP}$ ) & $\$ 48,500$ & 2 & $\$ 97,000$ \\
\hline 42 & 5 & Methanol Feed Tank (cyl. 15000 gallon max, carbon steel) & $\$ 30,000$ & 1 & $\$ 30,000$ \\
\hline 43 & 5 & Methanol Precip. Feed Pumps (centrifugal, $300 \mathrm{gpm}, 65^{\prime}$ head, $15 \mathrm{HP}$ ) & $\$ 6,000$ & 2 & $\$ 12,000$ \\
\hline 44 & 5 & Methanol Makeup Pump (centrifugal, $300 \mathrm{gpm}, 65^{\prime}$ head, $15 \mathrm{HP}$ ) & $\$ 6,000$ & 1 & $\$ 6,000$ \\
\hline 45 & 5 & Mcthanol Makeup Tank (3000 gallon tank truck trailer, $316 \mathrm{SS}$ ) & $\$ 13,000$ & 1 & $\$ 13,000$ \\
\hline 46 & 5 & Salt/Methanol Decant Tank (15000 gallon, $14^{\prime} \mathrm{D} \times 16^{\prime} \mathrm{H}$, carbon steel) & $\$ 30,000$ & 1 & $\$ 30,000$ \\
\hline 47 & 5 & Methanol Strip Column Feed Pumps (centrifugal, $300 \mathrm{gpm}, 65^{\prime}$ head) & $\$ 6,000$ & 2 & $\$ 12,000$ \\
\hline 48 & 5 & Methanol Strip Column ( $10^{\prime} \mathrm{D} \times 32^{\prime} \mathrm{H}, 16$ trays, 2000 gallon reboiler) & $\$ 200,000$ & 1 & $\$ 200,000$ \\
\hline 49 & 5 & Recycle Salt Pumps (centrifugal, $300 \mathrm{gpm}, 100^{\circ}$ head, $20 \mathrm{HP}$ ) & $\$ 6,000$ & 2 & $\$ 12,000$ \\
\hline 50 & 5 & Recycie Salt Solution Pumps (centrifugal, $300 \mathrm{gpm}, 100^{\prime}$ head, $20 \mathrm{HP}$ ) & $\$ 6,000$ & 2 & $\$ 12,000$ \\
\hline 51 & 5 & High Solution Recycle Pump (centrifugal, $300 \mathrm{gpm}, 100^{\prime}$ head, 20 IIP) & $\$ 6,000$ & 1 & $\$ 6,000$ \\
\hline 52 & 5 & Karr Column Salt Solution Feed Pumps (centrifugal, 300 gpm, 100' head) & $\$ 6,000$ & 2 & $\$ 12,000$ \\
\hline 53 & 5 & Concentrated Carbonate Reagent Pump (centrifugal, $300 \mathrm{gpm}, 65^{\prime}$ head) & $\$ 6,000$ & 1 & $\$ 6,000$ \\
\hline 54 & 5 & Salt (High-Carbonate) Recycle Tank (1 2000 gallon max., 14' D x 16' H, CS) & $\$ 25,000$ & 1 & $\$ 25,000$ \\
\hline 55 & 5 & Return Salt (Low-Carbonate) Tank (12000 gallon max., 14'D x 16'H, CS) & $\$ 25,000$ & 1 & $\$ 25,000$ \\
\hline 56 & 5 & Carbonate Makeup Tank (6'D x 8'H cyl, 1000 gallon WV, $316 \mathrm{SS}$, impellor) & $\$ 4,000$ & 1 & $\$ 4,000$ \\
\hline 57 & 5 & Carbonate Reagent Tank Agitator (5 HP motor, 30 in dia. impellor) & $\$ 10,000$ & 1 & $\$ 10,000$ \\
\hline 58 & 5 & Bulk Carbonate Storage Containers ( 316 SS, 6 cu yd cap., conical dis.) & $\$ 3,500$ & 12 & $\$ 42,000$ \\
\hline 59 & 5 & Bulk Carbonate Screw Feeder (3.2-160 cu ft/hr, timer, 5 cu ft hopper) & $\$ 15,000$ & 1 & $\$ 15,000$ \\
\hline
\end{tabular}


Table B.8

\section{Aqueous Biphasic Extraction}

\begin{tabular}{|c|c|c|c|c|c|}
\hline Item & Source & Item Description & Cost/Unit & Quantity & Total Cost \\
\hline 60 & 5 & PEG Repulp Tank Agitator (7.5 HP, 30 in dia. impellor) & $\$ 11,000$ & 1 & $\$ 11,000$ \\
61 & 5 & Repulped Karr Column Feed Pumps (centrifugal, 350 gpm max, 65' head) & $\$ 9,000$ & 2 & $\$ 18,000$ \\
\hline \multicolumn{2}{|c|}{ Total Equipment Cost } & $\$ 4,501,100$ \\
\hline
\end{tabular}

